\title{
BREASTFEEDING AND POSTPARTUM DEPRESSION
}

Breastfeeding and Postpartum Depression:

Assessing the Influence of Breastfeeding Intention and Other Risk Factors

\author{
Carley J. Pope
}

\author{
A thesis submitted to the Faculty of Graduate Studies \\ In partial fulfillment of the requirements for the degree of \\ Master of Arts (Clinical Psychology) \\ Department of Psychology \\ Lakehead University \\ Thunder Bay, Ontario
}

April 2015

Supervisor: Dr. D. Mazmanian

Second Reader: Dr. M. Bédard

Internal External Examiner: Dr. K. McQueen

C Carley J. Pope 
ProQuest Number: 10611976

All rights reserved

INFORMATION TO ALL USERS

The quality of this reproduction is dependent upon the quality of the copy submitted.

In the unlikely event that the author did not send a complete manuscript and there are missing pages, these will be noted. Also, if material had to be removed, a note will indicate the deletion.

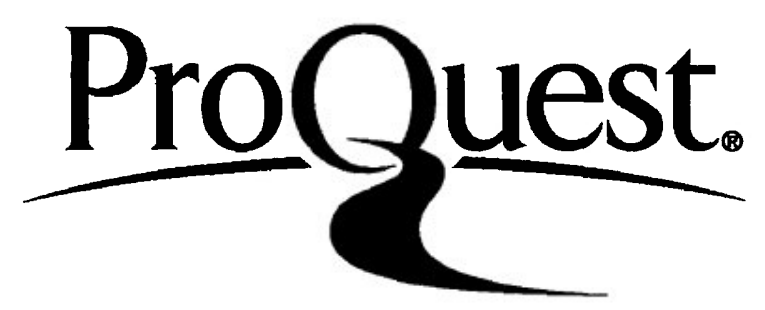

ProQuest 10611976

Published by ProQuest LLC (2017). Copyright of the Dissertation is held by the Author.

All rights reserved.

This work is protected against unauthorized copying under Title 17, United States Code Microform Edition $\odot$ ProQuest LLC.

ProQuest LLC.

789 East Eisenhower Parkway

P.O. Box 1346

Ann Arbor, Ml 48106 - 1346 


\title{
BREASTFEEDING AND POSTPARTUM DEPRESSION
}

\begin{abstract}
Risk and protective factors for postpartum depression have been extensively studied, and more recently an association between breastfeeding and maternal mood has been reported. The purpose of the present study was to clarify the association between breastfeeding and postpartum depression by assessing if women who did not breastfeed were at greater risk of postpartum depression compared to women who attempted to breastfeed, and if intent to breastfeed or other known risk factors influenced the association. The association between breastfeeding duration and postpartum depressive symptoms was also examined. Breastfeeding information, demographic information, and scores on the Edinburgh Postnatal Depression Scale were examined from the Canadian Maternity Experience Survey. This survey contains data collected from 6421 Canadian mothers between October 2006 and January 2007, and 2848 women between five and seven months postpartum were included in the current analyses. In contrast to previous research and the hypotheses of this study, logistic regression analyses revealed that breastfeeding attempt and duration were not associated with postpartum depression at five to seven months postpartum. Although a relationship between the prenatal intention to combination feed and postpartum depression was observed, these variables were no longer related once other potential risk factors were controlled for. Factors that were associated with postpartum depression included lower income, higher perceived stress, lower perceived social support, no history of depression, or no recent history of abuse. These findings suggest that the association between breastfeeding and postpartum depression reported by previous researchers may in fact be due to alternative risk factors.
\end{abstract}




\section{BREASTFEEDING AND POSTPARTUM DEPRESSION}

\section{Acknowledgements}

This work would not be possible without the support and contribution from a number of very special individuals, each of whom have altruistically contributed to my personal, academic, and professional development in their own unique way.

First and foremost I offer my sincerest gratitude to my supervisor Dr. Dwight Mazmanian whose support and guidance has made my thesis work possible and an invaluable learning experience. His motivation and enthusiasm, as well as his immense knowledge and propensity for detail, make him an excellent mentor. I consider myself very fortunate to have the opportunity to learn from him and to be challenged by him, and know that my empirical and clinical skills are being enhanced considerably as a result.

I would also like to thank my thesis committee. Dr. Michel Bédard played an instrumental role in this project and I am very grateful for his expertise, advice, and thorough attention to detail. As well, some of Dr. Karen McQueen's empirical work contributed to the conceptualization for this thesis and I am sincerely grateful for her support of this project and helpful advice.

I must also thank Dr. Verinder Sharma whose compassionate and innovative clinical and empirical work has inspired my genuine passion for clinical research and academic writing. I am incredibly fortunate to have him as an ongoing supporter and collaborator in this project and others, and I will be forever grateful to have him as a mentor and role model.

I am also grateful to Ms. Christina Sommerdyk, who opened her home to me on several occasions so I could complete this project. I am so very thankful for her ongoing support, guidance, and friendship. I consider myself very fortunate and appreciative to have her in my corner both as my dearest friend and as my colleague. 


\section{BREASTFEEDING AND POSTPARTUM DEPRESSION}

I would also like to thank Dr. Riley Hinson and Dr. Monica Stelzl for their continual support to pursue my academic goals. I hope everyone, at least once in their lifetime, gets to experience a mentor as caring, reassuring, and encouraging as they were with me.

As well, I am eternally grateful for the unwavering love, devotion, and encouragement of my husband Adam. He is my rock and my greatest supporter. I am so fortunate that he was and is so enthusiastic about coming on this amazing adventure with me.

I would like to thank the Public Health Agency of Canada and Statistics Canada for compiling the data and making it available for empirical exploration and thanks to Mika Oehling for her kind assistance with the application process. Sincere thanks to Western University Research Data Center's Academic Director, Dr. Paul Philippe-Pare, for graciously allowing me to use Western's facility to access the data. I would also like to thank the staff at the Research Data Center at Western University, Bradley Corbett, Nathalie Metzer, and Kelly Bairos, for their patience, guidance, and assistance in accessing the micro data files and for being so welcoming at each visit.

Finally, thank you to all of my colleagues in the Health, Hormones, and Behaviour lab and the faculty, staff, and students in the Clinical Psychology and Psychological Science programs and in the Department of Graduate Studies at Lakehead University for everything you are teaching me and all the support you provide. In particular, thanks to Nicole Poirier, Victoria Pitura, and Chad Keefe for accompanying and supporting me through what is proving to be the most exhilarating and rewarding experience of my life. 


\section{Table of Contents}

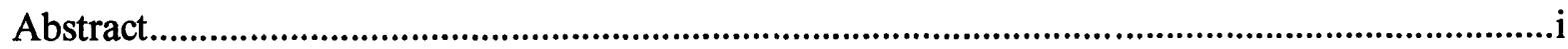

Acknowledgements.................................................................................................................

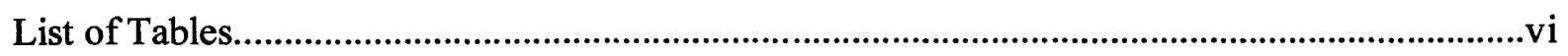

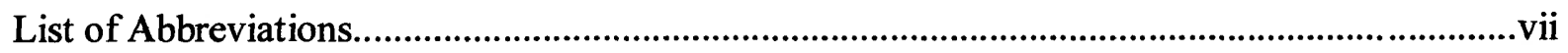

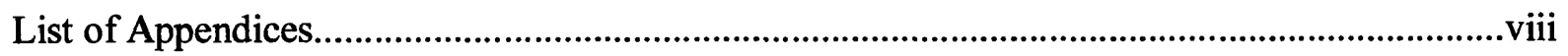

Introduction...........................................................................

Epidemiology of Postpartum Depression.........................................................................

Consequences of Postpartum Depression.................................................................

Risk Factors for Postpartum Depression.......................................

Protective Factors against Postpartum Depression................................5

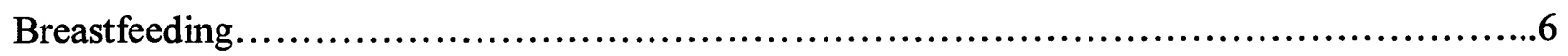

Breastfeeding and Postpartum Depression............................................

Breastfeeding Intention and Initiation.......................................... 8

Breastfeeding and Maternal Mood.............................................

Breastfeeding Duration......................................................11

Breastfeeding Dose-Response Effect....................................... 12

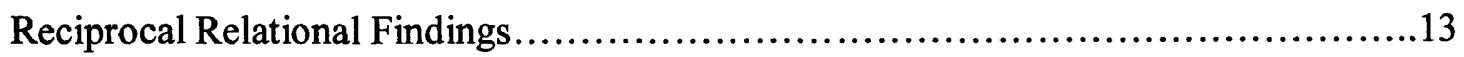

No Association or Non-Significant Trends..................................... 14

Mechanism of Action........................................................ 14

Conflicting Research Findings..................................................

Current Investigation................................................................ 18

Specific Aims........................................................... 19 


\section{BREASTFEEDING AND POSTPARTUM DEPRESSION}

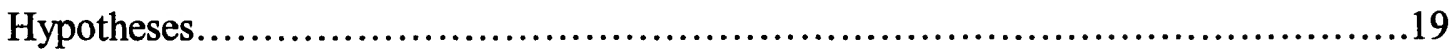

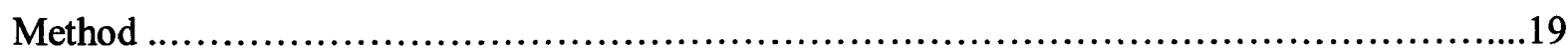

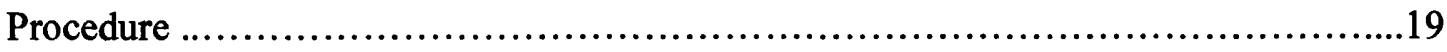

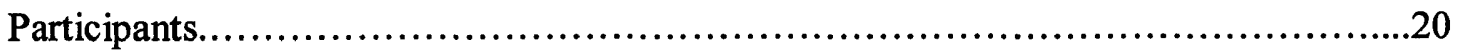

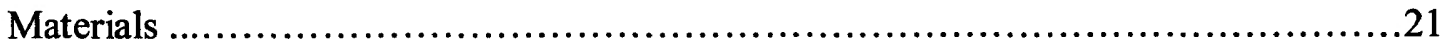

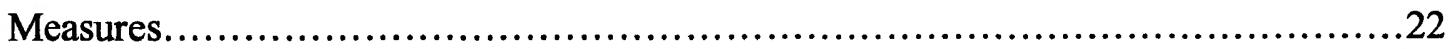

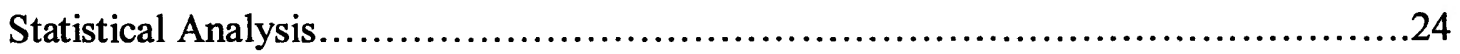

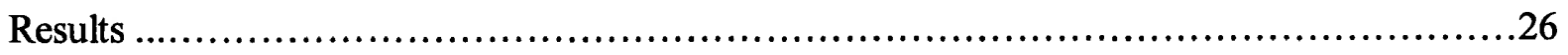

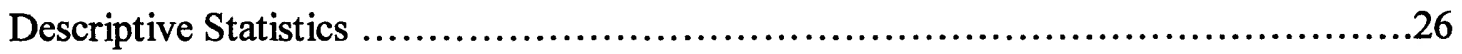

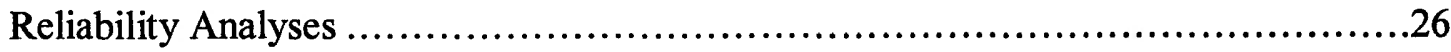

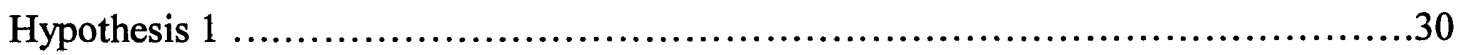

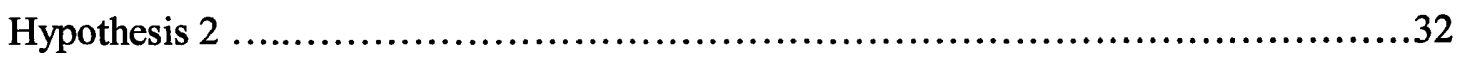

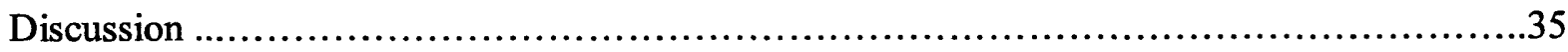

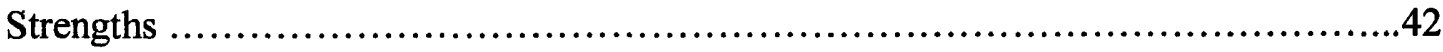

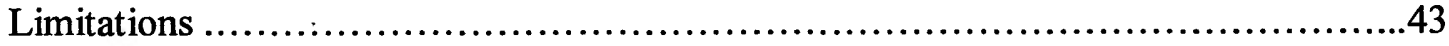

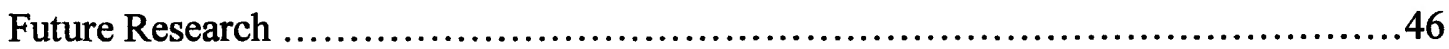

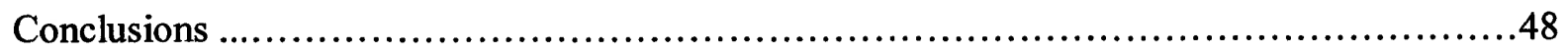

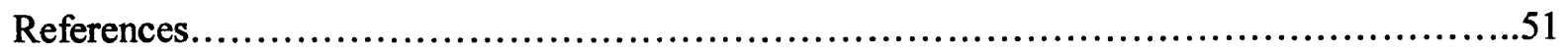

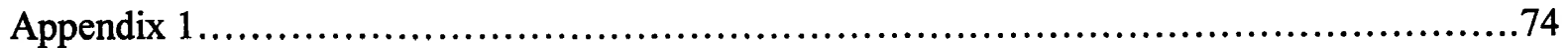

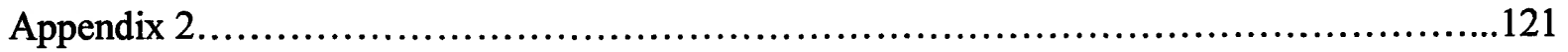




\section{BREASTFEEDING AND POSTPARTUM DEPRESSION}

\section{List of Tables}

Table 1

Descriptive Statistics of Women in the Sample

Table 2

Descriptive Statistics of Depression and Breastfeeding Variables.

Table 3

Edinburgh Postnatal Depression Scale (EPDS) Inter-Item Correlation Matrix.

Table 4

Edinburgh Postnatal Depression Scale (EPDS) Corrected Item Total

Correlation.

Table 5 Binary Logistic Regression Analysis of Breastfeeding Intent, Attempt, and Postpartum Depression Risk Factors with Depression Scores...........31

Table 6 Correlations for Breastfeeding Duration with Edinburgh Postnatal Depression Scale (EPDS) scores.....................................33

Table 7 Binary Logistic Regression Analysis of Breastfeeding Duration and Edinburgh Postnatal Depression Scale (EPDS) Scores 
BREASTFEEDING AND POSTPARTUM DEPRESSION

\section{List of Abbreviations}

$\begin{array}{ll}\text { APA } & \text { American Psychiatric Association } \\ \text { CMES } & \text { Canadian Maternity Experience Survey } \\ \text { DSM-5 } & \text { Diagnostic and Statistical Manual for Mental Disorders - Fifth Edition } \\ \text { EPDS } & \text { Edinburgh Postnatal Depression Scale } \\ \text { HSS } & \text { Hormonal Sensitivity Syndrome } \\ \text { ICD } & \text { International Classification of Diseases } \\ \text { IOR } & \text { Inverted Odds Ratio } \\ \text { LICO } & \text { Low Income Cut-Off } \\ \text { OR } & \text { Odds Ratio } \\ \text { RDC } & \text { Research Data Centre } \\ \text { SES } & \text { socioeconomic status }\end{array}$




\section{BREASTFEEDING AND POSTPARTUM DEPRESSION}

\section{List of Appendices}

Appendix 1

Canadian Maternity Experience Survey

.74

Appendix 2

Variable Recoding of Canadian Maternity Experience Survey .121 


\section{BREASTFEEDING AND POSTPARTUM DEPRESSION}

\section{Breastfeeding and Postpartum Depression:}

\section{Assessing the Influence of Breastfeeding Intention and Other Risk Factors}

\section{Epidemiology of Postpartum Depression}

Postpartum depression is a serious mental health condition that affects $13 \%$ to $19 \%$ of women who have recently given birth (O'Hara \& McCabe, 2013). Postpartum depression is characterized as a persistent low mood in new mothers, which is often accompanied by feelings of sadness, worthlessness, and/or hopelessness. Postpartum depression differs from the "baby blues" as the "baby blues" is a briefer period of mild emotional disturbance (including dysphoria, tearfulness, mood lability, insomnia, irritability, and anxiety) which is experienced by $80 \%$ of women within the first few days following childbirth and usually remits within 10 days (Heron, Haque, Oyebode, Craddock, \& Jones, 2009).

Currently, the Diagnostic and Statistical Manual for Mental Disorders - Fifth Edition (DSM-5) classifies depression with peripartum onset as beginning during pregnancy or within the first four weeks postpartum (American Psychiatric Association [APA], 2013). The International Classification of Diseases (ICD) classifies postpartum depression as occurring within the first six weeks postpartum (World Health Organization, n.d.). In contrast to the current recommendations, some researchers recommend that this time frame be extended in future revisions of these guides to account for episode onset within the first six months postpartum (Sharma \& Mazmanian, 2014). Further, in spite of the current DSM-5 guidelines, many researchers use a time frame that ranges up to one year postpartum for onset of postpartum depression (O’Hara \& McCabe, 2013).

While the clinical profile of postpartum depression is similar to depression occurring at other times in a woman's life, it may differ in some respects due to the profound physiological 
changes occurring during pregnancy and the postpartum period (Bloch et al., 2000; O'Hara \& McCabe, 2013). In fact, it is estimated that as many as $40-80 \%$ of postpartum women experience mild symptoms of mood disturbance within the first few days following childbirth (Buttner, O’Hara, \& Wisner, 2012). Moreover, many postpartum women experience symptoms following pregnancy that are characteristic of depression, such as disturbances in appetite, energy, and sleep (O'Hara, Schlechte, Lewis, \& Wright, 1991). These factors make it difficult to differentiate clinically significant depressive disorder from common symptoms experienced as a result of childbirth and caring for a new infant.

While postpartum depression can be brief and remit unexpectedly, it has been reported that that approximately $30 \%$ of women in community samples who experience postpartum depression continue to be depressed up to two years postpartum (Horowitz \& Goodman, 2004) and $50 \%$ of women from clinical samples continue to have major depression throughout, and in some cases beyond, the first year postpartum (Vliegen, Casalin, \& Luyten, 2014). Furthermore, the illness course can vary and chronic depression for these women may consist of stable mild depression, stable major depression, or recurrent episodes of major depression without full remission between episodes (Vliegen, Casalin, \& Luyten, 2014).

\section{Consequences of Postpartum Depression}

Compared to depression occurring at other time points in a woman's life, there is some evidence to suggest that women experiencing postpartum depression are at an increased risk for comorbid obsessive compulsive disorder (Abramowitz et al., 2000; Russell, Fawcett, \& Mazmanian, 2013) and anxiety (Hendrick, Altshuler, Strouse, \& Grosser, 2000; O’Brien, Buikstra, \& Hegney, 2008), as well as suicidal ideation and thoughts of harm to the self or the infant (Jennings, Ross, Popper, \& Elmore, 1999; Pope, Xie, Sharma, \& Campbell, 2013; Wisner 
et al., 2013). Further, suicide is a leading cause of death for mothers during the postpartum period, and women experiencing a depressive episode are at particular risk (Lindahl, Pearson, \& Colpe, 2005). In addition to being associated with comorbid disorders, postpartum depression is associated with numerous consequences (Pope, Sharma, \& Mazmanian, 2014a). Negative longterm consequences to the infant's social, emotional, cognitive, and physical development have been reported (Field, 2010). Children of mothers with a history of unipolar disorder are at increased risk of developing psychosocial and emotional or behavioural disturbances (Korhonen, Luoma, Salmelin, \& Tamminen, 2012), as well as intellectual disabilities (Morgan et al., 2012). Additionally, postpartum depression is associated with disturbance in mother-infant interactions and bonding as well as deficient parenting and parental safety practices (Field, 2010; Moehler, Brunner, Wiebel, Reck, \& Resch, 2006). Infanticide is another possible serious and tragic consequence when postpartum depression is accompanied by psychosis. However, women experiencing nonpsychotic postpartum depression are unlikely to commit infanticide (Spinelli, 2004). Postpartum psychosis is far less common than postpartum depression but can result in serious and devastating consequences for the mother and the infant as well as the rest of the family (Ganjekar, Desai, \& Chandra, 2013). Often postpartum psychosis leads to hospitalization and considerable functional impairment (Robertson, Jones, Haque, Holder, \& Craddock, 2005). There is however, some debate concerning the degree to which psychosis is related to the unipolar variation of postpartum depression (Spinelli, 2004). Emerging evidence suggests that postpartum psychosis is more likely a variant of bipolar disorder (Brockington, 2004).

\section{Risk Factors for Postpartum Depression}

While younger age (Chaudron et al., 2001; Mayberry, Horowitz, \& Declercq, 2007), minority status (Horowitz, Murphy, Gregory, \& Wojcik, 2011; Howell, Mora, Horowitz, \& 
Leventhal, 2005), and lower levels of education (Horowitz et al., 2011; Meltzer-Brody, Boschloo, Jones, Sullivan, \& Penninx, 2013; Mayberry et al., 2007) have been identified by some investigators as potential predictive factors for developing postpartum depression, it appears that low socioeconomic status (SES) may account for the associations found between these variables and postpartum depression (Hamdan \& Tamim, 2012; O'Hara \& McCabe, 2013). However, financial poverty in and of itself is not adequate to explain the development of postpartum depression, as many women of low SES do not develop depressive symptoms (Segre, O'Hara, Arndt, \& Stuart, 2007). Moreover, moderate or high SES does not necessarily protect women from postpartum depression (Ross et al., 2006). Interestingly, returning to work in the early postpartum has also been found to be related to increased risk for postpartum depressive symptoms (Hamdan \& Tamim, 2012), though this may also be a result of SES circumstances.

Additional predictors of postpartum depression include immigration status (Davey, Tough, Adair, \& Benzies, 2011), living in a large urban area (Vigod et al., 2013), stressful life events (Davey, Tough, Adair, \& Benzies, 2011), poor marital relationships (Bilszta et al., 2008), being single/divorced/separated (Nishioka et al., 2011), and poor social support (Nielsen Forman, Videbech, Hedegaard, Dalby Salvig, \& Secher, 2000). Women are also at increased risk if they are primiparous (Di Florio et al., 2014), if they did not want the pregnancy (Csatordai et al., 2007), or if the infant has a difficult temperament (Britton, 2011). Other factors include neuroticism (Meltzer-Brody et al., 2013), and history of depression or anxiety prior to pregnancy, and depression during pregnancy (Davey et al., 2011; Elisei, Lucarini, Murgia, Ferranti, \& Attademo, 2013; Hamdan \& Tamim, 2012; Jardri et al., 2006; Pippins et al., 2006). As well as a history of recent abuse (Jesse, Walcott-McQuigg, Mariella, \& Swanson, 2005; Meltzer-Brody et al., 2013), history of alcohol, substance abuse (see Chapman \& Wu, 2013 for a 
review) or smoking (Dagher \& Shenassa, 2012) also increases risk. Moreover, a mood episode following a first childbirth increases the probability that the mother will experience a mood episode following subsequent deliveries (Freeman et al., 2002). In addition to predictors for developing postpartum depression, a few studies have also evaluated factors that predict a more chronic or persistent course of postpartum depression. These include poor quality relationships with spouse, stressful life circumstances, and a history of depression, sexual abuse, or maternal neglect as a child. As well, difficulty with role transition into motherhood may also result in a more chronic illness course (Vliegen, Casalin, \& Luyten, 2014).

\section{Protective Factors against Postpartum Depression}

Some researchers have examined not only what puts women at risk for postpartum depression but also what factors may protect women from developing the postpartum illness. Miranda and colleagues (2012) found that healthier affective relationships with the postpartum women's own mothers resulted in women being less likely to develop postpartum depression, even when at high risk for developing the disorder. Moreover, increased perceived social support during the third trimester (Castle, Slade, Barranco-Wadlow, \& Rogers, 2008) as well as in the first month following pregnancy (Pearlstein, Howard, Salisbury, \& Zlotnick, 2009) is also inversely related to the development of depressive symptoms postpartum. Furthermore, Jesse and colleagues (2005) found that greater levels of social support and increased self-esteem were protective against postpartum depression for African American women at high risk for postpartum depression. As well, receiving educational information on "postnatal concerns" and "negative feelings" appear to offer some protective benefits against postpartum depressive symptoms in primiparous and multiparous women, respectively (Youash et al., 2013). Finally, research is emerging which suggests that breastfeeding may offer protective benefits against 
postpartum depression (Figueiredo, Canário, \& Field, 2013); however, the exact nature of the association between breastfeeding and postpartum depression remains unclear.

\section{Breastfeeding}

Breastfeeding has gained a notable amount of international attention due to increasing evidence that it is related to numerous infant and maternal health benefits. In fact, Health Canada (2013) recommends exclusive breastfeeding for at least the first six months postpartum and then continuing, in conjunction with complementary foods, for at least two years postpartum. Benefits for the infant include protection against infection, especially gastrointestinal and respiratory infection (Duijts, Ramadhani, \& Moll, 2009). Breastfeeding is also associated with a lower incidence of postneonatal death (Chen \& Rogan, 2004). In addition to the numerous shortterm advantages, breastfeeding is also suggested to be associated with various long term advantages for the infant such as lower cholesterol and blood-pressure, as well as a reduced risk for the development of type-2 diabetes and obesity later in life (Robinson \& Fall, 2012).

These infant health benefits are attributed to important nutrition and immunological support provided by breast milk (Riskin et al., 2012). For example, one particular antibody found in breast milk, secretory immunoglobulin A, offers particular immune system protection and cannot be reproduced in infant formula (Niers, Stasse-Wolthuis, Rombouts, \& Rijkers, 2007). Moreover, the physical health benefits of breastfeeding are not limited to the infant; they also extend to the mother. Such benefits include a reduced risk for breast cancer (do Carmo França-Botelho, Ferreira, França, França, \& Honório-França, 2012), ovarian cancer (Luan et al., 2013), and osteoporosis later in life (Tsvetov, Levy, Benbassat, Shraga-Slutzky, \& Hirsch, 2013). 


\section{BREASTFEEDING AND POSTPARTUM DEPRESSION}

In addition to the various infant and maternal physical health benefits found to be related to breastfeeding, there are numerous reports of breastfeeding being associated with improved infant and maternal mental health and well-being. In particular, breastfeeding is associated with the improved cognitive and motor development of breastfed children (Bernard et al., 2013), though the exact role of breastfeeding is unclear (Walfisch, Sermer, Cressman, \& Koren, 2013). In terms of maternal benefits, research shows that breastfeeding is associated with an increased amount of maternal sleep compared to mothers who formula feed their infants (Doan, Gardiner, Gay, \& Lee, 2007). As well, breastfeeding is also implicated in improvements in maternal mood, including in women with postpartum depressive symptoms (Figueiredo, Canário, \& Field, 2013).

\section{Breastfeeding and Postpartum Depression}

Initially the relationship between breastfeeding and postpartum depression was conceptualized to be unidirectional with postpartum depression resulting in lower rates of breastfeeding initiation and early cessation (Seimyr, Edhborg, Lundh, \& Sjögren, 2004). More recently however, reports indicate that the relationship is likely bidirectional in nature, suggesting that while postpartum depression may reduce rates of breastfeeding, not engaging in breastfeeding may increase the risk of postpartum depression. Additionally, there is some evidence that breastfeeding may protect against postpartum depression or assist in a swifter recovery from symptoms (Figueiredo, Canário, \& Field, 2013).

The association between breastfeeding and postpartum depression has been studied by a number of investigators but the direction of this relationship and confirmation of whether it is a direct relationship still eludes us. Numerous studies on the topic of breastfeeding and postpartum depression have come to contrasting conclusions, likely a result of the interaction 
between the numerous and complex physiological, psychological, and sociocultural mechanisms responsible for the relationship (Hamdan \& Tamim, 2012), as well as the use of varying methods for studying the association.

Specifically, a number of researchers have reported that they found no relationship between breastfeeding and postpartum depression (e.g., Chaudron et al., 2001) and two early reports suggest that breastfeeding mothers have a higher risk of depression (Alder \& Bancroft, 1988; Alder \& Cox, 1983). In contrast, a number of more recent studies report that women who formula feed have higher rates of depression than women who breastfeed (e.g., Groer, 2005), while some others report that mothers who experience postpartum depression are at greater risk of early breastfeeding cessation (e.g., Dennis \& McQueen, 2007).

\section{Breastfeeding Intention and Initiation}

A number of studies have found no association between prenatal depressive symptoms and intention to breastfeed (Barnes, Stein, Smith, \& Pollock, 1997; Jacobson, Jacobson, \& Frye, 1991; Lee et al., 2005; McKee, Zayas, \& Jankowski, 2004). In contrast, Insaf and colleagues (2011) did find that women with prenatal depressive symptoms were less likely to intend to breastfeed, though this study did not follow the women through to childbirth to determine initiation rates. Similarly, Fairlie and colleagues (2009) also found that prenatal depressive symptoms were associated with a reduced intention to breastfeed (reported in the second trimester). However, follow-up in the postpartum period revealed that depressive symptoms during pregnancy were not associated with the actual initiation of breastfeeding, indicating that some of the women who initially reported that they did not intent to breastfeed changed their minds and attempted to breastfeed. Further, Pippins and colleagues (2006) found, in their longitudinal study following a large sample of pregnant women, that women with prenatal 
depressive symptoms were not significantly less likely to initiate breastfeeding. Thus it appears that women's prenatal intention to breastfeed fluctuates, perhaps due to breastfeeding encouragement or education in the third trimester. Moreover, while breastfeeding initiation may not be related to prenatal depressive symptoms, failure to breastfeed (when attempted) has been found to be associated with postpartum depressive symptoms (Davey et al., 2011). As well, women who never established breastfeeding are reported to have a 2.4-fold chance of developing depressive symptoms at 16 weeks postpartum compared to breastfeeding women (Nielsen Forman et al., 2000).

\section{Breastfeeding and Maternal Mood}

A number of studies report that women who are not breastfeeding are significantly more likely to have higher levels of depressive symptoms than women who are breastfeeding (AbouSaleh, Ghubash, Karim, Krymski, \& Bhai, 1998; Astbury, Brown, Lumley, \& Small, 1994; Green, Broome, \& Mirabella, 2006; Groër, 2005; Groër \& Morgan, 2007; Gross, Wells, Radigan-Garcia, \& Dietz, 2002; Hannah, Adams, Lee, Glover, \& Sandler, 1992; Jardri et al., 2006; Lane et al., 1997; Mancini, Carlson, \& Albers, 2007; McLearn et al., 2006; Nishioka et al., 2011; Tammentie, Tarkka, Åstedt-Kurki, \& Paavilainen, 2002; Tashakori, Behbahani, \& Irani, 2012; Warner, Appleby, Whitton, \& Faragher, 1996; Yonkers et al., 2001). For example, a recent longitudinal study by Nishioka and colleagues (2011) found that at 5 months postpartum the proportion of mothers with EPDS of $\geq 9$ (suggesting risk of postpartum depression) was significantly lower for women who were breastfeeding compared to women who were formula feeding $(p=.04)$. Moreover, this relationship has been found to persist even once age, education $(O R=0.28, p=.007 ;$ Dunn, Davies, McCleary, Edwards, \& Gaboury, 2006), income, race, previous history of depression, and current psychoactive medication use $(p<.001$; Hatton et al., 
2005) are controlled for. Interestingly one study found that depression severity was not related to breastfeeding status in a group of women diagnosed with postpartum depression (McCarterSpaulding \& Horowitz, 2007). This suggests that breastfeeding status did not influence the severity of depression when co-occurring with postpartum depression. Thus, while breastfeeding may be associated with depressive symptoms, it may not influence the severity of the symptoms.

While postpartum depression has been identified as a risk factor for early breastfeeding cessation (McLearn et al., 2006), early negative breastfeeding experience may be a risk factor for postpartum depression (Watkins, Meltzer-Brody, Zolnoun, \& Stuebe, 2011). Further, it has also been suggested that breastfeeding may offer protective benefits against postpartum depression (Figueiredo, Canário, \& Field, 2013). One study to report on the protective benefits of breastfeeding found lower levels of depressive symptoms in the prenatal but not postnatal period predicted exclusive breastfeeding. Further breastfeeding duration resulted in a significant decrease in depressive symptom scores from childbirth to 3-months postpartum when considering women who initiated breastfeeding. These investigators further found that women who did not initiate breastfeeding did not experience significant changes in depressive symptoms over the first three postpartum months. After considering the findings collectively, the investigators postulated that the results suggest that breastfeeding alleviates depressive symptomology over time (Figueiredo, Canário, \& Field, 2013).

Additionally, results from a study by Mezzacappa and Katlin (2002) lend further support to the premise that breastfeeding offers ameliorating effects on postpartum depressive mood symptoms. These investigators looked at the acute effects of breastfeeding on maternal mood and found that breastfeeding mothers experienced a decrease in negative mood from pre-feeding to post-feeding. Moreover, bottle-feeding mothers experienced a decrease in positive mood from 
pre-feeding to post-feeding. Thus, breastfeeding may offer both acute and long-term ameliorating effects on postpartum depression, however further research is required to substantiate these initial findings.

\section{Breastfeeding Duration}

Breastfeeding duration has been found to be inversely related to postpartum depressive symptoms. A relationship that has been found to persist even after controlling for socioeconomic status, age, and education level (Henderson, Evans, Straton, Priest, \& Hagan, 2003); as well as for past history of depression, increased life stress, and psychoactive medication use (Hatton et al., 2005). In particular, a number of studies have reported an association between postpartum depressive symptoms and early weaning (Akman et al., 2008; Bick, MacArthur, \& Lancashire, 1998; Cooper, Murray, \& Stein, 1993; Falceto, Giugliani, \& Fernandes, 2004; Fergerson, Jamieson, \& Lindsay, 2002; Papinczak \& Turner 2000; Pearlstein et al., 2009; Seimyr et al., 2004). In fact, McLearn, Minkovitz, Strobino, Marks, and Hou (2006) reported that mothers with depressive symptoms were less likely to continue breastfeeding through to two to four months postpartum compared to mothers without depressive symptoms $(A O R=0.73, p<.001)$.

A number of studies note that postpartum depressive symptoms preceded breastfeeding cessation (Henderson et al., 2003; Misri et al., 1997). In a large prospective study of postpartum women, Taveras and colleagues (2003) found that having higher depressive symptoms at two weeks postpartum was associated with discontinuation of breastfeeding at 12 weeks postpartum. Dennis and McQueen (2007) reported similar findings. Specifically, depressive symptomology in the early postpartum period predicted early cessation of breastfeeding at eight weeks postpartum. As well, in a smaller prospective study, Galler, Harrison, Biggs, Ramsey, and Forde 
(1999) found that depressive symptoms at seven weeks postpartum inversely predicted breastfeeding practices at seven weeks, three months, and six months postpartum, even after controlling for disadvantaged environmental conditions. Interestingly, these investigators did not find an association between depressive symptoms at six months postpartum and breastfeeding practices at the same time point.

More recently, Dennis and McQueen (2007) found that after controlling for baseline depressive symptoms there was no relationship between infant feeding outcome (feeding method used, satisfaction with method, breastfeeding difficulties, breastfeeding self-efficacy) at one week postpartum and the development of postpartum depressive symptoms (measured one and two months postpartum). However, the women in this study who reported high levels of postpartum depressive symptoms were significantly more likely to discontinue breastfeeding. These women were also more likely to report being unsatisfied with their infant-feeding method, experience breastfeeding difficulties, and report lower breastfeeding self-efficacy. Taken together, these findings suggested that over time depressive symptoms can influence infant feeding outcomes to a point of discontinuation.

\section{Breastfeeding Dose-Response Effect}

A dose response effect of breastfeeding with regards to the association with postpartum depression has been proposed. In a large study of women evaluated between 8 and 12 weeks postpartum, Thome, Alder, and Ramel (2006) found that exclusively breastfeeding mothers had lower mean depressive symptom scores compared to partial breastfeeding mothers. Relatedly, Ystrom (2012) found that at six months postpartum, both partially breastfeeding and exclusively bottle-feeding were significantly related to higher levels of depressive symptoms in postpartum women compared to those who exclusively breastfed. Furthermore, bottle-feeding was related to 
postpartum depression to a greater degree than partial breastfeeding. As well, when the investigator adjusted for baseline prenatal anxiety and depression (measured at 30 weeks gestation) the relationship persisted, indicating that breastfeeding may reduce depressive symptoms or depressive symptoms may result in breastfeeding titration.

One other study compared exclusive breastfeeding to exclusive bottle-feeding (FloresQuijano et al., 2008). These investigators found an inverse association between postpartum depression and exclusive breastfeeding continuation. As well, it has also been found that as early as one week postpartum, levels of depressive symptoms are inversely related to exclusive breastfeeding (Clifford, Campbell, Speechley, \& Gorodzinsky, 2006). Moreover, KendallTackett, Cong, and Hale (2013) investigated the effects of breastfeeding on women at high risk for postpartum depression and sleep difficulties due to a history of being victims of sexual assault. These investigators reported that breastfeeding appeared to offer some protective benefits, compared to partial breastfeeding and bottle-feeding, as it was associated with a reduction in sleep difficulties and depression.

\section{Reciprocal Relational Findings}

In light of conflicting reports that postpartum depression leads to early breastfeeding cessation (e.g., McLearn et al., 2006) and that breastfeeding leads to a reduction in postpartum depressive symptoms (e.g., Mezzacappa \& Katlin, 2002), recent investigations have looked further into a reciprocal relationship. Specifically, it is now proposed that postpartum depression can lead to early breastfeeding cessation but breastfeeding continuation may also reduce levels of postpartum depressive symptoms (Figueiredo, Canário, \& Field, 2013). To date, two studies help to explicate this reciprocal relationship. A study by Hamdan and Tamim (2012) supports the reciprocal relationship hypothesis. These investigators found that women who were 
breastfeeding at two months postpartum had a lower risk of postpartum depression at four months postpartum. On the other hand women who had postpartum depression at two months postpartum were less likely to be breastfeeding at four months postpartum. As well, HahnHolbrook, Haselton, Dunkel Schetter, and Glynn (2013) found that prenatal depressive symptoms predicted a reduced frequency of breastfeeding and earlier cessation within the first three months postpartum. As well, more frequent breastfeeding at three months postpartum was associated with greater subsequent declines in depressive symptom levels up to two years postpartum.

\section{No Association or Non-Significant Trends}

A number of studies have reported no significant relationship between postpartum depression and breastfeeding status (Bogen et al., 2010; Chaudron et al., 2001; Chung, McCollum, Elo, Lee, \& Culhane ,2004; Cox, Connor, \& Kendell, 1982; Josefsson et al., 2002; Lau \& Chan, 2007; McKee, Zayas, \& Jankowski, 2004; O'Neill, Murphy, \& Greene, 1990; Ramsay, Gisel, McCusker, Bellavance, \& Platt, 2002). However, two of these studies did report finding a non-significant trend suggestive of an inverse association (Chung et al 2004; Lau \& Chan, 2007). In any case, most of these findings were incidental; the primary purpose of those investigations was not to evaluate the association between breastfeeding and postpartum depression.

\section{Mechanism of Action}

The mechanism by which breastfeeding is affected by, or affects, postpartum depression have been assessed in a number of studies. Breastfeeding self-efficacy and negative breastfeeding perceptions has been implicated as playing a primary role in the relationship. Specifically, during the first week postpartum, depressed mothers have been found to be at 
increased risk for feeling unsatisfied with breastfeeding and were experiencing significant breastfeeding problems. They are also at risk for experiencing lower levels of breastfeeding selfefficacy compare to non-depressed mothers (Dennis \& McQueen, 2007).

Further, mothers' postpartum depressive symptoms was found in one study to be inversely related to the belief that breastfeeding is the best option for infant feeding and positively related to the beliefs that breastfeeding is private and breastfeeding is restrictive (Galler, Harrison, Ramsey, Chawla, \& Taylor, 2006). Additionally, in a study that did not find a relationship between breastfeeding and depressive symptoms, women who worried about breastfeeding were significantly more likely to develop depression than women who did not worry (Chaudron et al., 2001). Similarly, Tamminen (1988) found that women with more depressive symptoms also reported more breastfeeding difficulties, and Dennis (2003) noted that level of depressive symptoms at one, four, and eight weeks postpartum was inversely related to breastfeeding self-efficacy at the corresponding time periods. This is a similar finding to that recorded by Dai and Dennis (2003). Collectively, this research suggests that it is not necessarily the postpartum depression per se that leads to reduced breastfeeding, but rather it might be a consequence of the negative cognitions and perceptions of breastfeeding that are characteristic of postpartum depression.

Alternatively, complications with the mother infant interaction may also play a role. One study reported that breastfeeding led to less burping, less intrusive stimulation (e.g., mother poking the infant or moving) during nipple-in and nipple-out periods, and more stroking (by the mother to their infant) as well as superior mother-infant interaction rating scores as rated by an observer. Further, these benefits were found to extend to both the depressed and non-depressed 
breastfeeding women (Field et al., 2010). Thus, breastfeeding may enhance the mother-child interaction, which may lead to improved maternal mental health.

Breastfeeding difficulties and lack of breastfeeding confidence are reported as common concerns for mothers with postpartum depressive symptoms (Edhborg, Matthiesen, Lundh, \& Widström, 2005). Dennis and McQueen (2007) suggested that the factors underlying the relationship between breastfeeding duration and postpartum depression are multifactorial. In other words, it is likely that the interplay between the mothers' negative cognitions and impaired mother-infant interaction, in addition to other factors, such as underlying physiological processes, are responsible for the emergence of postpartum depression. Moreover, depressive symptoms in the early postpartum period resulted in the mother being more vulnerable to feelings of low self-esteem and self-efficacy. As a consequence, the depressive symptoms and accompanying negative cognitions may reinforce perceived breastfeeding difficulties or may reduce the mothers' ability to accurately interpret infant cues, further perpetuating actual breastfeeding difficulties (Dennis \& McQueen, 2007). As well, breastfeeding is suggested to attenuate neuro-endocrine responses to stress and may act to enhance maternal mood. Specifically, oxytocin and prolactin, hormones responsible for lactation, are suggested to have mood-ameliorating effects. Oxytocin in particular is a hormone that promotes feelings of nurturance and relaxation, during nursing (Matthiesen, Ransjö-Arvidson, Nissen, \& UvnäsMoberg, 2001; Skalkidou, Hellgren, Comasco, Sylvén, \& Sundström Poromaa, 2012; Viero et al., 2010). As well, lactation is suggested to attenuate cortisol stress responses (Figueiredo, Dias, Brandão, Canário, \& Nunes-Costa, 2013) by decreasing stress hormone levels (especially cortisol) and enhancing sleep (Tu, Lupien, \& Walker, 2006). 


\section{Conflicting Research Findings}

A majority of studies do report some association between breastfeeding and postpartum depression, however the direction of the relationship is unclear and some of the findings conflict with one another. This is likely a reflection of both the complex processes responsible for the association between breastfeeding and postpartum depression as well as the differences between the study designs and the samples used. Dennis and McQueen (2009) suggested that the contrasting findings may be due to differences in research methodology or study limitations. Some of the limitations include differences in definition and criteria for assessing breastfeeding and/or depressive symptomology. That is, a number of studies only classified breastfeeding as a "yes" or "no" dichotomy, failing to take into account partial breastfeeding (e.g., Chaudron et al., 2001; Cox, Connor, \& Kendell, 1982; Josefsson et al., 2002; McKee, Zayas, \& Jankowski, 2004; ONeill, Murphy, \& Greene, 1990). As well, some studies used assessment instruments nonspecific to depression (e.g., Cox, Connor, \& Kendell, 1982) or used lower cut-off scores (e.g., Lau \& Chan, 2007; Josefsson et al., 2002) compared to most investigations. Furthermore, some studies used samples with higher than normal rates of women reporting postpartum depression. For instance, Lau and Chan (2007) found the rate of postpartum depression in their sample to be $34 \%$ which is about double the estimated prevalence (O'Hara \& McCabe, 2013), likely a result of the low cut-off score they used. As well, some studies used women at high risk for postpartum depression. For instance Kendall-Tackett, Cong, and Hale's (2013) investigation used women who reported a history of sexual assault, a known risk factor for postpartum depression (Vliegen, Casalin, \& Luyten, 2014). Furthermore, for many of the studies, the primary focus was not to delineate the relationship between breastfeeding and depression 
(Dennis \& McQueen, 2009), which likely explains many of the methodological or interpretive shortfalls noted.

\section{Current Investigation}

Specific conclusions regarding the association between breastfeeding and postpartum depression have not been obtained due to the nature of the phenomena being studied. Namely, randomized controlled trials of this relationship are not possible due to obvious ethical concerns. This being said, studying the association in naturalistic ways has provided valuable information regarding this relationship. While numerous studies have evaluated the association between postpartum depression and breastfeeding, few studies (Davey et al., 2011; Nielsen Forman et al., 2000) have looked at the rate of postpartum depression in women who never initiated (or failed to initiate) breastfeeding. Further, none of the studies have looked at postpartum depression rates in women who made the decision prenatally not to breastfeed and did not attempt to breastfeed. In response, the current study aimed to add to this available research by assessing if the risk of postpartum depression differed as a result of women's intention and/or initiation of breastfeeding. That is, if women who intended to breastfeed but do not initiate breastfeeding had an increased risk for the development of postpartum depression compared to women whose intent corresponds with their feeding practices (both intend and initiate breastfeeding / both intend and initiate bottle-feeding). Such information will clarify if the relationship between breastfeeding and postpartum depression is the result of the act of breastfeeding itself or the result of a failed attempt to initiate breastfeeding, which is often associated with negative selfevaluation. 


\section{Specific Aims}

The primary aim of this study was to add to the existing literature on the association between breastfeeding and postpartum depression by assessing: 1) if women who did not attempt breastfeeding were at greater risk of postpartum depression compared to women who attempted breastfeeding, and if intent to breastfeed influenced these association; and 2) if breastfeeding duration was related to the experience of postpartum depressive symptoms.

\section{Hypotheses}

Given the available literature on the reciprocal nature of the relationship between breastfeeding and postpartum depression, it was predicted that women who report that they did not initiate breastfeeding, regardless of prenatal breastfeeding intention, would be at greater risk for postpartum depression compared to women who did initiate breastfeeding (Hypothesis 1). As well, it was predicted that shorter breastfeeding duration would put women at increased risk for postpartum depressive symptoms (Hypothesis 2). Disappointment and stress related to being unable to breastfeed, when this was the intention, are potential mediating variables found in some of the past literature. By including a group of women who did not intend to breastfeed, this study was better able to control for such extraneous variables and thus better able to explicate the relationship between breastfeeding and postpartum depression

\section{Method}

\section{Procedure}

This study was based on a cross-sectional design utilizing survey data derived as part of the Canadian Maternity Experience Survey (CMES; Public Health Agency of Canada, 2009). Permission to access the CMES raw data set was obtained from the Social Sciences and Humanities Research Council, a division of the Government of Canada. The data was accessed 
through the Research Data Centre (RDC) at Western University in London, Ontario. Western University's Academic Director approved the use of the institution's RDC for the purposes of this investigation. This study was approved by the Department of Psychology at Lakehead University and ethical approval was obtained from the Lakehead University Research Ethics Board.

\section{Participants}

A stratified sample of 8542 postpartum women were identified based on their 2006 Canadian Census survey responses, of which 6421 (78\%) completed the survey. At the time of interviewing, women were found to be, on average, 7.3 months postpartum with $84.6 \%$ being between six and nine months postpartum. In $96.9 \%$ of cases the interviews were conducted between five and nine months postpartum for women residing in the provinces, and $10-14$ months for women residing in the territories.

Eligible participants were birth mothers who were 15 years of age and older, who had a singleton live birth in Canada (between February 15, 2006 and May 15, 2006 for provinces or between November 1, 2005 and February 1, 2006 for territories), and who lived with their infant at the time of the interview. Due to what Statistics Canada refers to as "operational reasons", birth mothers were not eligible to participate if they were under 15 years of age at the time of giving birth, lived on a First Nations reserve at the time of data collection, or lived in an institution at the time of data collection. As well, mothers who had a multiple birth, a stillbirth, or had experienced an infant death, were not eligible as the survey did not focus on birth mothers who experienced those specific circumstances. In total the data from 6421 birth mothers were available for analysis. For continuity, only women who were five to seven months postpartum were considered in this analysis $(N=2848)$. The mean age of women included in this analysis 
was $30.39(S D=5.11)$. Table 1 presents descriptive statistics for the women included in the analyses as part of this study.

\section{Materials}

\section{Canadian Maternity Experience Survey (CMES; Public Health Agency of Canada,} 2009). The CMES was developed and implemented by the Public Health Agency of Canada in collaboration with Statistics Canada. The survey was an initiative to acquire representative panCanadian data on women's experiences during pregnancy and the postpartum period. Approximately 70 trained female interviewers conducted the approximately 45 minute long interviews between October 23, 2006 and January 31, 2007, using a computer-assisted telephone interview application. The surveys were mostly administered by telephone (with a few being administered in person) in both official languages, English and French, as well as in 13 other languages.

Demographics and sociocultural characteristics, intention, initiation, and duration of breastfeeding were obtained from the raw survey data. This extraction resulted in the following breastfeeding variables being included in the analysis: Breastfeeding Intent $(1=$ formula feeding alone; 2 = a combination of formula and breastfeeding; 3 = breastfeeding alone), Breastfeeding Attempt $(1=$ attempted; 2 = did not attempt); Duration of Exclusive Breastfeeding (ranging from 0-32 weeks); Duration of Any Breastfeeding (ranging from 0-32 weeks). As well, the following risk factors variables were also included: Social Support $(1=$ none of the time; $2=a$ little of the time; 3 = some of the time; 4 = most of the time; $5=$ all of the time), Stress in Past Year ( 1 = not stressful; 2 = somewhat stressful; 3 = very stressful $),$ Wanted Pregnancy $(1=$ no; 2 = yes), Previous Depression or Antidepressant Use ( $1=$ yes; 2 =no), Current Smoker ( 1 = yes; 2 = no), Drinking During Pregnancy $(1=$ yes; $2=$ no), Number of Live Births (range: $1-12$ live 
births), History of Abuse in the Last Two Years $(1=$ yes; $2=$ no $)$, Mother's Education ( $1=$ grade 8 or lower; 2 = any high school; $3=$ high school graduate; $4=$ some post-secondary; $5=$ college or trade or university certificate; 6 = university bachelors; 7 = graduate degree), Marital Status ( 1 $=$ married $/$ common law; $2=$ widowed/separated $/$ divorced; $3=$ single/never married), Baby Age when Returned to Work (range: 0 - 32 weeks), Household Income ( $1=$ Less than $\$ 10000 ; 2=$ $\$ 10000$ to less than $\$ 15000 ; 3=\$ 15000$ to less than $\$ 20000 ; 4=\$ 20000$ to less than $\$ 30000 ; 5$ $=\$ 30000$ to less than $\$ 40000 ; 6=\$ 40000$ to less than $\$ 50000 ; 7=\$ 50000$ to less than $\$ 60000$; $8=\$ 60000$ to less than $\$ 80000 ; 9=\$ 80000$ to less than $\$ 100000 ; 10=\$ 100000$ to less than $\$ 150000 ; 11=\$ 150000$ to less than $\$ 200000 ; 12=\$ 200000$ or more $)$, and Rural $(1=$ rural; $2=$ urban). See Appendix 1 for a copy of the complete survey (reprinted with permission).

\section{Measures}

Edinburgh Postnatal Depression Scale (EPDS; Cox, Holden, \& Sagovsky, 1987). Postpartum depression was measured based on the women's scores on the EPDS, a scale widely used to assess for postpartum depression and postpartum depression risk (Beck, 2001). The EPDS is a 10 item self-report scale which asks women to report the extent to which they have experienced specific depressive symptoms within the past seven days on a four point Likert-type scale $(0=$ no presence of the symptom, $3=$ marked presence or change; Appendix 1 includes a copy of the EPDS questionnaire). The cut-off classifications are based on literature which suggests that total scores of 0-9 indicate not depressed, 10-12 some depressive symptoms present, and 13-30 indicative of a greater number/ severity of depressive symptoms which may indicate postpartum depression (the EPDS total score ranges from 0 to 30; Cox, Holden, \& Sagovsky, 1987). When using a cut-off score of $12 / 13$ the EPDS is reported to have satisfactory sensitivity (68-95\%) and specificity (78-96\%) for the purposes of this investigation. The 
Table 1

Descriptive Statistics of Women in the Sample

\begin{tabular}{|c|c|}
\hline Variable & Relative frequency \\
\hline \multicolumn{2}{|l|}{ Marital Status $(N=2847)$} \\
\hline Married & $2632(92.4 \%)$ \\
\hline Widowed, separated, or divorced & $57(2.0 \%)$ \\
\hline Single & $158(5.6 \%)$ \\
\hline \multicolumn{2}{|l|}{$\operatorname{Parity}(N=2845)$} \\
\hline Primiparous & $1311(46.1 \%)$ \\
\hline Multiparous & $1533(53.8 \%)$ \\
\hline \multicolumn{2}{|l|}{ Education $(N=2831)$} \\
\hline Did not graduate high school & $182(6.4 \%)$ \\
\hline Graduated high school & $382(13.4 \%)$ \\
\hline Some postsecondary & $179(6.3 \%)$ \\
\hline Completed postsecondary education & $2088(73.3 \%)$ \\
\hline \multicolumn{2}{|l|}{ Household Income $(N=2703)$} \\
\hline$<\$ 10000$ & $61(2.2 \%)$ \\
\hline$\$ 10000-\$ 15000$ & $87(3.2 \%)$ \\
\hline$\$ 15000-\$ 20000$ & $95(3.5 \%)$ \\
\hline$\$ 20000-\$ 30000$ & $196(7.2 \%)$ \\
\hline$\$ 30000-\$ 40000$ & $264(9.8 \%)$ \\
\hline$\$ 40000-\$ 50000$ & $241(8.9 \%)$ \\
\hline$\$ 50000-\$ 60000$ & $279(10.3 \%)$ \\
\hline$\$ 60000-\$ 80000$ & $541(20.0 \%)$ \\
\hline$\$ 80000-\$ 100000$ & $374(13.8 \%)$ \\
\hline$\$ 100000-\$ 150000$ & $425(15.7 \%)$ \\
\hline$\$ 150000-\$ 200000$ & $85(3.1 \%)$ \\
\hline$>\$ 200000$ & $56(2.1 \%)$ \\
\hline \multicolumn{2}{|c|}{ History of depression or antidepressant use* $(N=2844)$} \\
\hline Yes & $432(15.2 \%)$ \\
\hline No & $2412(84.8 \%)$ \\
\hline \multicolumn{2}{|l|}{ History of abuse (past two years) $(N=2846)$} \\
\hline Yes & $304(10.7 \%)$ \\
\hline No & $2542(89.3 \%)$ \\
\hline \multicolumn{2}{|l|}{ Social support availability $(N=2839)$} \\
\hline None of the time & $40(1.4 \%)$ \\
\hline A little of the time & $125(4.4 \%)$ \\
\hline Some of the time & $283(10.0 \%)$ \\
\hline Most of the time & $912(32.1 \%)$ \\
\hline All of the time & $1479(52.1)$ \\
\hline \multicolumn{2}{|c|}{ Stress in the past year prior to delivery $(N=2840)$} \\
\hline Not stressful & $1213(42.7 \%)$ \\
\hline Somewhat stressful & $1267(44.6 \%)$ \\
\hline Very stressful & $360(12.7 \%)$ \\
\hline
\end{tabular}

* Prior to pregnancy 
Cronbach alpha coefficient is reported to be .87 (Cox, Holden, \& Sagovsky, 1987; Dennis, 2004; Harris et al., 1989; Murray \& Carothers, 1990). The EPDS has been translated across a number of languages and has shown to have satisfactory reliability and validity across cultures (Lau et al., 2007). The scale takes less than five minutes to complete (Cox, Holden, \& Sagovsky, 1987) and was completed by participants in this study as part of the phone interview.

\section{Statistical Analysis}

IBM SPSS (version 22) was used to perform all statistical analyses. Descriptive statistics for the full sample population were calculated first and can be found in a preceding section in Table 1. Next, the data were examined for apparent errors. Women were stratified into three groups based on their EPDS score, using the cut-off scores suggested by Cox, Holden, and Sagovsky (1987). Although we recognize that categorizing a dimensional entity may impose restrictions on the information obtained (Streiner, 2002), doing so improved the clinical relevance and interpretability of the results. Specifically, in this particular investigation we were less interested in explaining subclinical variations in mood as we were in explaining which variables would predict clinical levels of postpartum depression (in the absence of a clinical diagnostic interview). A categorical approach allowed us to reduce the ambiguity that may result from not clearly delineating between levels of depression indicative of a clinical syndrome and subclinical levels of depressive symptomology [symptomatology] by comparing women who were almost certainly not depressed to women whose symptom endorsement would almost certainly be indicative of postpartum depression (Tuohy \& McVey, 2008).

For the purposes of our analyses some of the variables needed to be recoded. Information pertaining to recoding can be found in Appendix 2. Any variables coded as not applicable, refused, or unknown were treated as missing data. 
Due to the categorical nature of the outcome measure and the variations expected in sample size for each condition, a statistical method which does not require the assumption of normality, namely logistic regression analysis, was employed to test our hypotheses. While initially multinominal logistic regression was chosen for our main analyses, it became clear when conducting the analysis that binary logistic regression was a more appropriate statistical method for our purposes. The binary logistic regression enhanced the interpretability of the analysis as it compared women with no/low endorsement of depressive symptoms (indicative of no depression) to those with high endorsement of symptoms (indicative of a postpartum depression episode), removing individuals with moderate, sub-clinical symptom expression from the outcome variable.

Main effects to determine the risk for postpartum depression due to both feeding intention and attempt to breastfeed were then examined using logistic regression. The outcome variable was level of depressive symptoms based on the participants' scores on the EPDS comparing women with scores indicative of no/low depressive symptoms reported (score 0-9) to women with scores indicative of a greater number/ severity of depressive symptoms which may indicate postpartum depression (score 13-30).

In order to account for variance resulting from a number of known risk factors for postpartum depression and early breastfeeding cessation (younger age, lower level education, being single/divorced/separated, not wanting the pregnancy, lower socioeconomic status/income, . primiparity, smoking, history of alcohol use, history of physical or sexual abuse, the experience of birth and postpartum stressors, history of depression and antidepressant use, residing in large urban areas, plan to return to work in the early postpartum, and poor social support; Dagher \& Shenassa, 2012; O’Hara \& McCabe, 2013), the binary logistic regression analysis was repeated 
with the addition of variables related to these known risk factors. History of substance use has also been identified in past literature as a risk factor for postpartum depression (Chapman \& Wu, 2013), however as the endorsement rate of street drug use during pregnancy was negligible in this sample $(n=18,0.6 \%)$, this variable was not considered in the analyses. All analyses were weighted in accordance with guidelines issued by Statistics Canada to account for oversampling conducted in some geographic locations. In each analysis the Enter method was selected as this method enters all the predictor variables into the equation simultaneously and evaluates each as though it were entered into the equation last. This method of analysis is preferred when there is no specific hypothesis regarding the order or importance of the variables (Tabachnick \& Fidell, 2014), as is the case in the current investigation.

\section{Results}

\section{Descriptive Statistics}

As can be seen in Table $2,77.1 \%$ of women in this sample intended to exclusively breastfeed (including pumping breast milk), $13.5 \%$ intended to breastfeed and bottle-feed in combination, and $9.5 \%$ intended to exclusively bottle-feed. Of all the women included in the analysis $90.1 \%$ attempted to breastfeed and $57.4 \%$ were still breastfeeding at least occasionally at the time of the interview, $15.2 \%$ of whom were still exclusively breastfeeding.

\section{Reliability Analyses}

Mean score on the EPDS in this sample was $5.19(S D=4.38)$ and Cronbach's $\alpha=.81$. Table 3 provides all inter-item correlations for the EPDS items for this study. As can be seen from the chart, most (but not all) individual inter-item correlations fell between the generally accepted cut-off of .20 and .65 , with the range of .16 (item 3 and 10) to .58 (item 8 and 9). 
Table 2

Descriptive Statistics of Depression and Breastfeeding Variables

\begin{tabular}{lrr}
\hline Variable & Mean $(S D)$ & $\begin{array}{r}\text { Relative } \\
\text { Frequency }\end{array}$ \\
\hline Edinburgh Postnatal Depression Scale score $(N=2817)$ & $5.19(4.38)$ & \\
EPDS score $>12$ & & $203(7.2 \%)$ \\
EPDS score $10-12$ (inclusive) & $233(8.3 \%)$ \\
EPDS score $<10$ & $2381(84.5 \%)$ \\
Breastfeeding intention $(N=2838)$ & \\
$\quad$ Exclusive breastfeeding & $2187(77.1 \%)$ \\
$\quad$ Combination feeding & $383(13.5 \%)$ \\
Exclusive formula feeding & $269(9.5 \%)$ \\
Breastfeeding attempt $(N=2848)$ & \\
$\quad$ Attempted to breastfeed & & $2589(90.9 \%)$ \\
Did not attempt to breastfeed & $260(9.1 \%)$ \\
Intended to breastfeed/Attempted breastfeeding & $2169(76.4 \%)$ \\
Intended to combination feed/ Attempted breastfeeding & & $366(12.9 \%)$ \\
Intended to formula feed/ Attempted breastfeeding & $47(1.7 \%)$ \\
Intended to breastfeed/ Did not attempt to breastfeed & & $18(0.6 \%)$ \\
Intended to combination feed/ Did not attempt to breastfeed & & $17(0.6 \%)$ \\
Intended to formula feed/ Did not attempt to breastfeed & & $222(7.8 \%)$ \\
Exclusive breastfeeding duration in weeks $(N=2844)$ & $13.49(11.77)$ & \\
Any breastfeeding duration in weeks $(N=2844)$ &
\end{tabular}

Note. EPDS $=$ Edinburgh Postnatal Depression Scale 
Table 3

Edinburgh Postnatal Depression Scale (EPDS) Inter-Item Correlation Matrix

\begin{tabular}{llllllllll}
\hline $\begin{array}{l}\text { EPDS } \\
\text { Item }\end{array}$ & 1 & 2 & 3 & 4 & 5 & 6 & 7 & 8 & 9 \\
\hline 1 & .52 & & & & & & & & \\
2 & .20 & .22 & & & & & & & \\
3 & .23 & .24 & .40 & & & & & & \\
4 & .20 & .23 & .34 & .54 & & & & & \\
5 & .36 & .34 & .29 & .33 & .30 & & & & \\
6 & .32 & .35 & .27 & .32 & .33 & .34 & & & \\
7 & .38 & .37 & .33 & .39 & .37 & .42 & .47 & & \\
8 & .31 & .33 & .33 & .34 & .32 & .37 & .41 & .58 & \\
9 & .23 & .28 & .16 & .17 & .17 & .21 & .25 & .29 & .28 \\
10 & & & & & & & & & \\
\hline
\end{tabular}


Table 4

Edinburgh Postnatal Depression Scale (EPDS) Corrected Item Total Correlation

\begin{tabular}{ccc}
\hline & \multicolumn{2}{c}{$\begin{array}{c}\text { Original 10-Item } \\
\text { Scale (Cronbach's } \alpha=.83)\end{array}$} \\
\cline { 2 - 3 } & $\begin{array}{c}\text { Corrected Item Total } \\
\text { Correlation }\end{array}$ & $\begin{array}{c}\text { Cronbach's } \alpha \text { if } \\
\text { Item Deleted }\end{array}$ \\
\hline 1 & .46 & .80 \\
2 & .48 & .80 \\
3 & .46 & .80 \\
4 & .55 & .79 \\
5 & .52 & .79 \\
6 & .52 & .79 \\
7 & .53 & .79 \\
8 & .64 & .78 \\
9 & .58 & .79 \\
10 & .34 & .81 \\
\hline
\end{tabular}


The corrected item-total correlation for all items of the EPDS fell within acceptable ranges (ranging from .34 to .64 ). See Table 4 for all corrected item-total correlations and corresponding Cronbach's $\alpha$ if the item was deleted.

\section{Hypothesis 1}

Binary logistic regressions were first conducted to determine if main effects exist between breastfeeding intent (model 1) or breastfeeding attempt (model 2) with EPDS depressive symptom categories (not depressed, depressed). Next, the analysis was then run once more with breastfeeding intent and attempt, as well as their interaction along with variables related to a number of prominent postpartum depression risk factors included in the equation (model 3). The results of each set of analysis can be found in Table 5 .

As can be seen from the table, the univariate binary logistic regression results indicate that, compared to intent to exclusively breastfeed, intent to combination feed decreased the risk for meeting EPDS threshold criteria for depression at a level that is statistically significant $\left(\chi^{2}(1)\right.$ $=9.53, p=.001)$. However, when the analysis was repeated controlling for other prominent postpartum depression risk factors, these factors were no longer related.

When considering all risk factors, the model was significant and accounted for approximately $22 \%$ of the variance in explaining EPDS scores $>12$ (Nagelkerke R Squared). As can be seen from the table, when examined in the context of the other postpartum depression risk factors, intention to combination feed was no longer associated with meeting EPDS threshold criteria for depression. Moreover, the binary logistic regression results indicated that some, but not all, other risk factors included in the analysis were statistically significant in predicting risk of postpartum depression in this sample. In particular, when controlling for the other variables in the model, lower household income $\left(\chi^{2}(1)=22.50, p<.001\right)$, higher perceived 
Table 5

Binary Logistic Regression Analysis of Breastfeeding Intent, Attempt, and Postpartum

Depression Risk Factors with Depression Scores

$95 \%$ Confidence

Interval for OR [IOR]

\begin{tabular}{|c|c|c|c|c|c|c|c|}
\hline Model & Variable & $\mathrm{B}$ & OR & $\mathrm{IOR}^{\mathrm{a}}$ & Sig. & Lower & Upper \\
\hline 1 & Intent (intend to exclusively breastfeed) & & & & & & \\
\hline & Intend to exclusively formula feed & 0.44 & 1.55 & & .159 & 0.84 & 2.86 \\
\hline & Intended to combination feed & -0.57 & 0.57 & 1.75 & $.002 *$ & $0.40[1.25]$ & $0.81[2.50]$ \\
\hline 2 & Breastfeeding Attempt (attempted) & & & & & & \\
\hline & Did not attempt breastfeed & 0.32 & 1.37 & & .268 & 0.78 & 2.40 \\
\hline 3 & Mother's age & -0.03 & 0.97 & & .165 & 0.94 & 1.01 \\
\hline & Education & 0.02 & 1.02 & & .807 & 0.88 & 1.17 \\
\hline & Marital status (married) & & & & & & \\
\hline & never married & 0.42 & 1.52 & & .284 & 0.71 & 3.26 \\
\hline & widowed/separated & -0.21 & 0.81 & & .649 & 0.34 & 1.98 \\
\hline & Did not want pregnancy & -0.24 & 1.26 & & .502 & 0.64 & 2.50 \\
\hline & Household income & 0.18 & 1.19 & 0.84 & $<.001 * *$ & $1.11[0.78]$ & $1.28[0.90]$ \\
\hline & Number of live births & -0.11 & 0.90 & & .211 & 0.76 & 1.06 \\
\hline & Currently smoke & -0.03 & 0.97 & & .889 & 0.61 & 1.54 \\
\hline & Drinking during pregnancy & -0.05 & 0.95 & & .850 & 0.56 & 1.60 \\
\hline & History of abuse & -0.47 & 0.63 & 1.59 & $.044^{*}$ & $0.40[1.01]$ & $0.99[2.50]$ \\
\hline & Level of stress past year & -0.66 & $\mathbf{0 . 5 2}$ & 1.92 & $<.001 * *$ & $0.41[1.52]$ & $0.66[2.44]$ \\
\hline & History depression/antidepressants & -1.01 & 0.36 & 2.78 & $<.001 * *$ & $0.25[1.89]$ & $0.53[4.00]$ \\
\hline & Urban versus rural & 0.43 & 1.54 & & .096 & 0.93 & 2.57 \\
\hline & Level of social support & 0.69 & 1.98 & 0.51 & $<.001 * *$ & $1.70[0.43]$ & $2.31[0.59]$ \\
\hline & Time returned to work postpartum & -0.03 & 0.97 & & .081 & 0.94 & 1.00 \\
\hline & Breastfeeding intent & -0.07 & 0.93 & & .745 & 0.61 & 1.42 \\
\hline & Breastfeeding attempt & 0.59 & 1.81 & & .514 & 0.31 & 10.69 \\
\hline & Interaction intent \& attempt & -0.45 & 0.64 & & .363 & 0.24 & 1.69 \\
\hline
\end{tabular}

Note. OR = Odds Ratio; IOR = Inverted Odds Ratio.

a. Odds ratio values were manually inverted (formula $1 / \mathrm{OR}=\mathrm{IOR}$ ) to enhance the interpretability of the data. Inverted variables reflect how the risk factor relates to endorsement of depression. (i.e., to reflect if the dependant variable was inverted where not depressed was coded 0 and depressed was coded 1 ).

$* p<.05$

$* * p<.001$ 
level of stress $\left(\chi^{2}(1)=28.71, p<.001\right)$, and lower social support $\left(\chi^{2}(1)=77.99, p<.001\right)$ significantly predicted meeting EPDS threshold criteria for depression in this sample. As well, contrary to what would be expected based on existing literature, we found that no history of abuse $\left(\chi^{2}(1)=4.05, p<.05\right)$ or no history of depression $\left(\chi^{2}(1)=26.92, p<.001\right)$ significantly predicted meeting EPDS threshold criteria for depression in this sample. In other words, contrary to what has been reported, having a history of abuse or depression reduced the risk for postpartum depression in this sample.

\section{Hypothesis 2}

Correlation analysis was conducted to determine if a linear association existed between duration of exclusive or any breastfeeding and EPDS scores in this sample. Results of this analysis are presented in Table 6. As can be seen in the table, the relationship between duration of exclusive breastfeeding is associated with EPDS scores at a level that is statistically significant $(p<.05)$. This suggests that shorter duration of exclusive breastfeeding increased the risk for postpartum depression. However, the effect size of this association is negligible. An association between any breastfeeding and EPDS scores was not supported in this analysis.

In order to assess if there was an association between the duration of exclusive or any breastfeeding between women who were depressed (EPDS > 12) compared to women who were not depressed (EPDS score $<9$ ) a binary logistic regression was conducted. Results are reported in Table 7. Neither of these variables significantly predicted meeting EPDS threshold criteria for depression. 
Table 6

Correlations for Breastfeeding Duration with Edinburgh Postnatal Depression Scale (EPDS) scores

\begin{tabular}{cccc}
\hline & & \multicolumn{2}{c}{$95 \%$ Confidence Interval } \\
Variable & EPDS score & Lower & Upper \\
\hline Duration of exclusive breastfeeding & $-.046^{*}$ & -.08 & -.01 \\
Duration of any breastfeeding & -.024 & -.06 & .01 \\
\hline
\end{tabular}

${ }^{*} p<.05$ 
Table 7

Binary Logistic Regression Analysis of Breastfeeding Duration and Edinburgh Postnatal

Depression Scale (EPDS) Scores

95\% Confidence

Interval for OR

\begin{tabular}{lccccc}
\hline Variable & B & OR & Sig. & Lower & Upper \\
\hline Duration of exclusive breastfeeding & 0.001 & 1.01 & .466 & 0.99 & 1.02 \\
Duration of any breastfeeding & -0.002 & 1.00 & .732 & 0.99 & 1.01 \\
\hline Note & & & &
\end{tabular}

Note. $\mathrm{OR}=$ Odds Ratio 


\section{Discussion}

The primary purpose of this study was to determine if women who did not attempt to breastfeed were at an increased risk for postpartum depression. As well, we sought to determine if prenatal intention to breastfeed influenced the association between breastfeeding and postpartum depression. The results of this study, derived from a large population-based sample, failed to support findings of previous literature which suggested an association between breastfeeding and postpartum depression. Specifically, when other risk factors were considered, breastfeeding attempt or intention to breastfeed did not reduce the risk for postpartum depression. Thus, when other risk factors are considered, we failed to reject the null hypothesis that women who attempted to breastfeed differed from women who did not attempt to breastfeed for risk of postpartum depression at five to seven months postpartum. Moreover, when other risk factors are considered, we failed to reject the null hypothesis that women who intended to breastfeed differed from women who did not intend to breastfeed or intended to combination feed in risk for postpartum depression. As well, no interaction effect was evident between breastfeeding attempt and intent when other potential risk factors were considered in the equation.

As well, previous research has suggested a dose response effect of breastfeeding with postpartum depression (Hahn-Holbrook et al., 2013). That is, women who breastfeed more or for longer periods of time are reported to be at a reduced risk for postpartum depression (e.g., Thome, Alder, \& Ramel, 2006; Ystrom, 2012). In this study, we examined the dose response effect in two ways: first, by examining duration of exclusive breastfeeding, and second, by examining duration of any breastfeeding. Correlational analysis revealed that duration of exclusive breastfeeding was negatively associated with scores on the EPDS. However, the effect 
size of this association was negligible and supplementary examination with binary logistic regression did not show a significant association between duration of exclusive breastfeeding, comparing women who were not depressed to women who were depressed using EPDS threshold criteria. Further, in contrast with other research, the results of the present study did not reveal an association between duration of any breastfeeding and risk of postpartum depression when examined by correlational analysis or binary logistic analysis. Thus, the results of the current study align with that of the prospective study by Bogen and colleagues (2010) who also failed to find an association between breastfeeding intention, initiation, or duration and postpartum depressive symptoms measured at 2 and 12 weeks postpartum. The study by Bogen and colleagues was also designed to control for some of the limitations in previous research. Primarily, the investigators controlled for a number of potential covariates in their analysis and used clinician rated measures to assess for postpartum depression.

As well, large sample sizes, such as that used in the current investigation, allow for detection of even smaller differences, and minimize the likelihood of a Type II error in equivalency testing (Streiner, 2003). Moreover, an extreme group approach, which excluded individuals endorsing subclinical levels of depression from the analysis, was used in this study. Such an approach upwardly biased estimates of standardized effect size and increased the likelihood of detecting a significant difference between groups (Preacher, Rucker, MacCallum, \& Nicewander, 2005). Thus, while non-significant findings do not assure that no association exists, when viewed in light of the considerably large sample size and method of categorization that encouraged differences to be detected, the results of this study strongly suggest breastfeeding status does not act as a standalone risk factor for the experience of postpartum depression. As stated, the correlational analysis suggested a negative relationship between 
duration of exclusive breastfeeding and postpartum depression; however, the small magnitude of the effect size suggests that this association is unlikely to translate into clinically relevant observations. This assertion is further supported by the binary logistic regression which did not reveal a significant association in either duration of exclusive breastfeeding or duration of any breastfeeding with increased risk for postpartum depression.

The contrast between the results of this study and previous literature could be due to a number of methodological differences. For instance, in this study we investigated the experience of depression at five to seven months postpartum in contrast to other studies that have used an earlier time point in the postpartum period (e.g., Thome, Alder, \& Ramel, 2006). However, Ystrom (2012) used a similar timeframe and, in contrast to our findings, found that women who exclusively breastfed were at a reduced risk for postpartum depression compared to women who combination fed or did not breastfeed at all. As well, in contrast to a number of the previous studies (e.g., Akman et al., 2008) we evaluated the association of breastfeeding and postpartum depression in a large population-based sample. However, Davey and colleagues (2011) examined the relationship between not breastfeeding at eight weeks postpartum and depression at eight weeks postpartum in a large sample of 1403 perinatal women and found that risk for postpartum depression was significantly increased in women who did not breastfeed. In spite of the large sample size, the study by Davey and Colleagues had a number of other disparities when contrasted with the current study. Namely, the time frame they used was much earlier in the postpartum period ( 8 weeks) and the dependent (EPDS score) and independent (breastfeeding status) variables were collected in reference to the same time period ( 8 weeks) making interpretation regarding the directionality of the relationship impossible. 
Discerning whether breastfeeding is associated with decreased risk for postpartum depression has implications for postpartum depression interventions. For instance, some women may be advised to change their breastfeeding practiced to help address symptoms associated with postpartum depression, such as trouble sleeping, or to increase the ability for others to assist in infant feedings (Pope, Sharma, \& Mazmanian, 2014b). If in fact early breastfeeding cessation does increase a mother's risk for postpartum depression, then clinical recommendations such as the preceding examples may jeopardize the mother's mental health. As well, some experts have proposed that early breastfeeding cessation may be a non-invasive indicator for clinicians to identify women at risk of postpartum depression (Davey et al., 2011). However, the results of this study are not in agreement with previous literature and indicate that breastfeeding status alone is not a significant risk factor for postpartum depression. Thus, if a relationship does exist it is more complicated than the current way the relationship is conceptualized.

As part of this investigation the association of other factors (previously identified in existing literature as risk factors for postpartum depression) was also examined. Interestingly, not all of the risk factors identified in previous research were found to be significant risk factors for postpartum depression in this sample. In particular, when considering all potential risk factors in the model, mothers' age, education level, marital status, smoking and drinking status were not found to be significantly associated with depression status. Nor was not wanting the pregnancy, urban living, number of previous live births, or the time postpartum the mother returned to work. This suggests that when other risk factors are considered, these specific factors may not in fact put women at increased risk for postpartum depression.

However, in agreement with the previous literature some risk factors were found to be significantly related to depression status. Specifically, when considering all potential risk factors 
included in the binary logistic regression model in this study, decrease in household income, higher perceived stress, and lower perceived social support were associated with meeting study threshold criteria for depression. In contrast with previous research no history of depression or antidepressant use increased the risk of endorsing an EPDS score, while not endorsing the experience of abuse in the past two years increased the risk of endorsing an EPDS score $>12$.

As of 2014, in Canada, the low income cut-off (LICO), for a two person household was $\$ 29,706$ (Government of Canada, 2015), which captures approximately $16 \%$ of the women in this study. Consistent with past research (e.g., Galler et al., 1999), low household income was a risk factor for postpartum depression in this sample. This finding highlights that of previous research which suggests that women of low SES are at an increased risk for postpartum depression (Hamdan \& Tamim, 2012; Jacobson et al., 1991; O’Hara \& McCabe, 2013).

As well, for women in this sample, the experience of higher perceived stress in the 12 months prior to delivery of the index child and lower perceived social support during the postpartum period was associated with an elevated risk of postpartum depression. Congruent findings regarding the association between stress and postpartum depression have been reported by other investigators (e.g., Davey et al., 2011; Giallo, Cooklin, \& Nicholson, 2014). Moreover, the finding that lower perceived social support was associated with postpartum depression is consistent with a number of studies that suggest social support may reduce the risk of, or protect against, postpartum depression (e.g., Leahy-Warren et al., 2012; Nielsen et al, 2000; Surkan et al., 2006). For instance, perceived social support from partners, other family members, and/or friends has been shown to be inversely related to postpartum depression (Leahy-Warren et al., 2012). Further, the availability of at least two individuals to provide a mother with social support has been reported to be significantly related to lower depressive scores compared to 
mothers who reported having one or no friends or relatives available (Surkan et al., 2006). Taken together with the results of the current investigation, it appears that efforts to reduce a mother's perceived stress and strengthen a mother's available social support may improve maternal mental health outlook, specifically with regards to the experience of postpartum depression.

In contrast to other research, results of the current study suggest that women who do not report a recent experience of abuse (within two years) are at increased risk for postpartum depression compared to women who do endorse a recent history of abuse. This finding is counterintuitive to what would be hypothesized based on the existing research (e.g., MeltzerBrody et al., 2013). In fact, a recent systematic review found that women who had a history of intimate-partner violence had a 1.5 to 2.0 fold increased risk for postpartum depression (Beydoun et al., 2012). The current study considered abuse by various perpetrators (a partner, family member, friend or stranger) and considered various forms of abuse (including verbal, physical, and sexual) which may account for the discrepancies seen between the current study and past research that used more specific criteria. It is possible that the broad classification of abuse used in the current study may have overshadowed an effect that may have been observed had each category of abuse (verbal, physical, sexual) been considered in isolation.

In addition, it has been well documented in the research literature that a history of depression increases the risk for the subsequent experience of depression (Colman et al., 2011) especially during the perinatal period (Davey et al., 2011; Freeman et al., 2002). However, in the current study, having no history of depression or antidepressant use increased the odds of women's relative risk of depression when other potential risk factors were also considered. It is possible that the results observed in the current study speak to a potential preventative effect. 
That is, identification or treatment of depression prior to pregnancy may reduce the risk that a new mother will experience postpartum depression or may allow for swifter identification and treatment when it does occur. However, future research is required to test this conjecture.

It is notable that some of the risk factors identified in the current investigation are similar to factors that have been found by previous research to predict a more chronic course of postpartum depression. Specifically, lower family income, less perceived social support, and stressful life circumstances (Giallo, Cooklin, \& Nicholson, 2014; Seto et al., 2005; Vliegen, Casalin, \& Luyten, 2014) are implicated in more chronic postpartum depression. Thus, the current investigation may have captured women with a more persistent form of postpartum depression.

Finally, in the current study, we included a large number of risk factors identified by the empirical literature. Interestingly, the results of the current study suggest that even with the inclusion of many empirically supported risk factors, there is still a large proportion of variance unaccounted for (approximately 78\%). However, in binary logistic regression an equivalent statistic to $R$-squared does not exist, so this estimate is based on a pseudo $R$ square value (Tabachnick \& Fidell, 2014). Based on this estimate it appears that even when we consider a number of empirically supported risk factors, the factors leading to postpartum depression are still largely unknown. However, more recent research points at potential underlying biological mechanisms, such as alterations in hormonal levels, inflammation, and genetic predisposition (Skalkidou et al., 2012). As well, differences in the type or form of depression experienced may also hinder our ability to detect significant predictive factors. For instance it is possible that the factors that increase the risk for postpartum unipolar depression differ from those that increase the risk for postpartum bipolar depression. 


\section{Strengths}

The large population-based sample of postpartum women used in this study is a notable strength of this investigation. A larger sample size promotes more precise estimates of the magnitude of an association and the ability to detect small but statistically significant associations that may be overlooked when smaller sample sizes are used. Larger sample sizes have a reduced potential for producing false-positive results than do smaller samples and allows for covariates to be assessed in a manner that encourages more interpretable results (Hackshaw, 2008). As stated earlier, while the nonsignificant findings do not assure that no relationship exists, the extensive sample size of this study does allow for some confidence in the interpretation that breastfeeding practices are not a standalone risk factor for postpartum depression.

The sizable number of mothers included in this sample also allowed for the inclusion of multiple covariates without the risk of overfitting (models with too many variables for the number of outcome events; Babyak, 2004). The inclusion of several additional known risk factors for postpartum depression is another significant strength of this study. This provided two advantages. First, it allowed for the interpretation of the relationship, or lack thereof, of breastfeeding practices and postpartum depression after controlling the potential influence of other prominent risk factors. Second, it allowed us to examine what alternative covariate factors may be associated with an increased risk for postpartum depression in our sample. As a result, we were able to provide evidence for some, but not all, postpartum depression risk factors identified in the past literature.

The use of the EPDS (Cox, Holden, \& Sagovsky, 1987) was also a significant strength of this study. The EPDS is one of the most commonly used instruments in research for the 
assessment of postpartum depression (Beck, 2001). While the EPDS is not a clinical diagnostic instrument, the psychometric properties of the measure are well supported in the existing literature (Cox, Holden, \& Sagovsky, 1987; Dennis, 2004; Harris et al., 1989; Murray \& Carothers, 1990). In the current study, the reliability measures were good and consistent with values provided by past researchers.

The statistical method chosen in this study, logistic regression, is commonly used in the analysis of epidemiologic data to investigate the association between potential risk factors and a disorder or disease. The advantage of this type of analysis is that it can enhance our understanding of the circumstances regarding postpartum depression, because the coefficient of each risk factor or predictors explicitly describes the relative contribution of each risk factor in relation to the dependant variable, automatically controlling for the contribution of the other risk factors (Bagley, White, \& Golomb, 2001). As well, results from binary logistic regression analysis are readily translated into clinically useful information regarding risk. However, we recognize that categorizing a dimensional entity does pose restrictions on the information that could be obtained from a continuous measure (Streiner, 2002).

\section{Limitations}

The findings of this study should be viewed in light of the following considerations. The measure of postpartum depression taken in this sample was not a clinical diagnostic instrument. However, currently there is no gold standard for measuring postpartum depression (Vliegen et al., 2014) and the EPDS is currently the most commonly used screening instrument for assessing depression throughout the perinatal period (Hewitt et al., 2009). Nonetheless, the EPDS only identifies the risk for having a disorder and diagnostic assessment is further required for a formal diagnosis (Wisner et al., 2013). However, administering a clinical interview to a population- 
based sample comes with obvious practical restraints, as they require that interviewers be appropriately trained and requires much more time to administer. Moreover, exclusion of individuals scoring in the intermediate range on the EPDS (10-12) may limit the generalizability of our findings as they do not include information about women meeting subclinical criteria. In the current study the goal was to delineate if breastfeeding factors or other risk factors predicted postpartum depression when compared to women who were not depressed. However, future research should evaluate to what extent these results also apply to women endorsing subclinical postpartum depression symptoms.

In the current study, depression scores were derived from women at five to seven months postpartum which does not comply with the definitions of postpartum depression according to the current diagnostic criteria. However, there is currently a lack of consensus regarding the time frame to reference for a diagnosis of postpartum depression (Sharma \& Mazmanian, 2014; Vliegen et al., 2014). For instance, currently the DSM-5 requires that a major depressive episode with peripartum onset begin during pregnancy or during the first four weeks following childbirth (APA, 2013), while the ICD classifies postpartum depression as occurring within the first six weeks postpartum (World Health Organization, n.d.). Further, a number of researchers argue that these time frames are arbitrary and longer time frames that range up to one year postpartum are more reflective of clinical practice (Sharma \& Mazmanian, 2014; O’Hara \& McCabe, 2013). This controversy is also reflected in the research literature as many investigations do not adhere to the four to six weeks following childbirth criterion (e.g., Hamdan \& Tamim, 2012; Nielsen Forman et al., 2000). As there is currently no consensus regarding time frame for differentiating a postpartum depressive episode from a major depressive episode (Vliegen et al., 2014), and full comprehension of the natural course of postpartum disorder still 
eludes experts, it is hoped that the current study might contribute to a better understanding of what puts women at risk for postpartum depression, with particular reference to the later postpartum period.

The method by which the data were derived also resulted in a few limitations. In particular, the questions used to obtain data in this research were developed for the purposes of the CMES. Thus, the current study was restricted to the use of data collected as part of this survey. The CMES was a rather comprehensive survey of women's experiences during the postpartum period which allowed for many risk variables identified by the literature to be examined as part of this study. However, as a consequence of having no control over the survey material there was some information missing from the analysis that would have been informative. Specifically, while women who had a history of depression or antidepressant use could be identified, information regarding when they were diagnosed or prescribed medication was not available, nor was information regarding use of psychoactive medication during pregnancy and the postpartum period. As medication use has implications for both breastfeeding practices and the experience of depressive symptoms (Bogen et al., 2010), this omission is a limitation of the current investigation. Based on available estimates provided in the existing research, we can infer that approximately $1.2 \%$ of our sample was being treated with antidepressant medication at the time of the survey (Munk-Olsen, Gasse, \& Laursen, 2012). A further consideration that was not accounted for in this study was a distinction between unipolar and bipolar postpartum depression. This distinction is important as the causal factors may differ between these two disorders. Based on available estimates provided in the existing research, we can infer that approximately $1.3 \%$ of our sample who endorsed postpartum depression would 
meet criteria for the bipolar variant (López-Zurbano, González-Pinto, \& López, 2015). Unfortunately symptoms of bipolar disorder were not assessed for as part of the CMES.

Findings from this study should also be considered is light of the typical limitations imposed by retrospective studies and studies relying on participant self-report measures. That is, both studies rely on participant recall of past events. Some of the women in this study may have inaccurately recalled some past experiences. However, most of the retrospective information that the women in this study were asked to provide regarded salient events from their pregnancy or following childbirth (e.g., when they stopped breastfeeding, when they returned to work) which might minimize recall error. Another potential issue with self-report measures is a risk that some participants may skew their answers to be viewed as more social desirability. This study did not contain any measures of social desirability that could address this limitation. However, women were assured by the interviewers that their answers would remain strictly confidential to encourage more forthcoming responses.

\section{Future Research}

It would be ideal if future research could attempt to replicate the results of this study with other large population-based samples. It would also be interesting to see if similar results are seen when considering other time points during the postpartum. Considering the hormonal shifts that accompany cessation of breastfeeding, it would also be interesting to further assess if recent cessation is associated with an increase in depressive symptoms. If so how long do the symptoms persist for and do they correspond with hormonal changes? Such research would add to our knowledge regarding the potential for hormonal shifts to result in adverse physical and psychological symptoms in susceptible women. It is also possible that breastfeeding cessation is 
associated with an increase in depressive symptoms in a subset of women as part of a Hormonal Sensitivity Syndrome (HSS; Pope, Oinonen, Mazmanian, \& Stone, 2015).

The contrast between the current study and that of other research may also reside in the directionality of the relationship. For instance, researchers such as Dennis and McQueen (2007) found that depressive symptomology in the early postpartum predicted early cessation of breastfeeding at eight weeks postpartum. Not only do these results suggest that postpartum depression may contribute to early weaning, their findings further suggested that depressive symptoms may take several weeks to influence infant feeding outcomes to a point of discontinuation. This is encouraging because it means that if postpartum depression is caught and managed early, it may be less likely to adversely influence breastfeeding practices (Dennis, \& McQueen, 2007; Taveras et al., 2003). Future research should look to corroborate these findings, throughout the postpartum period, perhaps using a longitudinal repeated measures approach. Such research would be especially useful in determining if there is a critical period during the postpartum period where postpartum depression influences breastfeeding practices.

While the current study did not look at course of treatment, the observation that the risk factors identified in this sample may suggest a more chronic course of depression brings light to the need for more research regarding the course of postpartum depression. Further, research investigating the factors that increase the risk of earlier versus later onset of the disorder as well as factors that may predict a longer course is also needed. This information may be valuable in guiding clinical decision making regarding: 1) which women require more careful monitoring, 2) the length of time women should be monitored for as informed by research and risk factors, and 3) which women are at risk of a more chronic course as this may be particularly important when considering pharmacological interventions. 
Finally, it would also be clinically useful for future research to seek to identify factors that protect women from experiencing postpartum depression when they are at increased risk. While some research has looked at this topic, especially in relation to perceived social support, it would be ideal to better understand what factors protect against postpartum depression. Potential factors may be situational or environmental, such a perceived social support, or may be internal, such as personality characteristics (e.g., extraversion) or habits (e.g., exercise). As there may be little a clinician can offer to directly change past or current life circumstances that increase risk (e.g., poverty, stressful life events), it would be advantageous to know what modifiable factors (e.g., increased social support) may decrease the chances that a women will experience postpartum depression, even in the face of these challenges. This would allow clinicians to make recommendations to help prevent postpartum depression.

\section{Conclusions}

In spite of the growing empirical evidence regarding breastfeeding and postpartum depression, there is still a lot we do not know. As well, interpretations of research are impeded by many of the same conundrums that exist when attempting to empirically understand postpartum depression in general. For instance, much of the research is naturalistic in nature, restricting the ability to make causal inferences. As well, the physiological changes that occur over the course of pregnancy and the postpartum are not completely understood and the hormonal shifts during pregnancy may influence a women's mental health and well-being in different ways depending on the time period referenced. Hopefully, with further empirical study the existing gaps in our knowledge regarding postpartum depression will decrease and our ability to prevent postpartum depression will become more effective. 
The current study set out to determine if a relationship between breastfeeding practices and postpartum depression observed by previous researchers was evident when controlling for other factors. In particular, the aim was to determine if not being able to breastfeed as intended, may augment the relationship between breastfeeding and postpartum depression. The rationale was that women who were unable to breastfeed in accordance with their intention may be more likely to experience depression due to psychosocial factors associated with the disappointment from not breastfeeding their baby as they had hoped and the decreased self-efficacy or feelings of inadequacy that may result. In contrast to previous research and the hypotheses of this study, when controlling for other risk factors, breastfeeding attempt and duration was not associated with the experience of postpartum depression at five to seven months postpartum.

As well, while the analysis did show a relationship between the intention to combination feed and postpartum depression, these variables were no longer related once other potential risk factors were controlled. As this study used a very large sample, our results add to the existing research as they imply that breastfeeding practices themselves may not contribute to an increased risk for postpartum depression, in contrast to findings by other investigations. Of course, these implications must be interpreted with considerations made for postpartum time frame as this investigation used depression scores derived at five to seven months postpartum.

This study offers a further contribution to the empirical literature, as it provided evidence regarding other risk factors for postpartum depression. Specifically, lower income, higher perceived stress, and lower perceived social support significantly predicted risk for postpartum depression at five to seven months postpartum. This aligns with research which suggests that these risk factors may predict a more chronic course of the disorder. In contrast to previous research, a history of depression or a recent history abuse decreased the risk for postpartum 
depression. These findings may reflect the broad way by which the variables were measured or perhaps indicate a certain degree of resiliency or preparedness that may have evolved from such circumstances, especially a past history of depression. However, this conjecture must be substantiated or clarified by future research.

The prognosis of a disorder is especially important to consider when determining treatment recommendations. Results of the current study support previous research which suggests that women who are diagnosed with postpartum depression and endorse certain life experiences (e.g., low social support) are at an increased risk for a more chronic disorder. However, in contrast to previous research, findings from the current investigation suggest that the association between breastfeeding cessation and increased risk for postpartum depression reported by previous researchers may in fact be due to alternative risk factors. 


\section{References}

Abou-Saleh, M., Ghubash, R., Karim, L., Krymski, M., \& Bhai, I. (1998). Hormonal aspects of postpartum depression. Psychoneuroendocrinology, 23(5), 465-475. doi: 10.1016/S03064530(98)00022-5

Abramowitz, J. S., Meltzer-Brody, S., Leserman, J., Killenberg, S., Rinaldi, K., Mahaffey, B. L., \& Pedersen, C. (2010). Obsessional thoughts and compulsive behaviors in a sample of women with postpartum mood symptoms. Archives of Women's Mental Health, 13(6), 523-530. doi: 10.1007/s00737-010-0172-4

Akman, I., Kuscu, M. K., Yurdakul, Z., Özdemir, N., Solakoğlu, M., Orhon, L., . . Özek, E. (2008). Breastfeeding duration and postpartum psychological adjustment: Role of maternal attachment styles. Journal of Paediatrics and Child Health, 44(6), 369-373. doi: 10.1111/j.1440-1754.2008.01336.x

Alder, E., \& Bancroft, J. (1988). The relationship between breast feeding persistence, sexuality and mood in postpartum women. Psychological Medicine, 18(2), 389-396. doi: $10.1016 / 0022-3999(83) 90090-9$

Alder, E. M., \& Cox, J. L. (1983). Breast feeding and post-natal depression. Journal of Psychosomatic Research, 27(2), 139-144. doi: 10.1016/0022-3999(83)90090-9 American Psychiatric Association. (2013). Diagnostic and Statistical Manual of Mental Disorders (5th ed.). Washington, DC: Author.

Astbury, J., Brown, S., Lumley, J., \& Small, R. (1994). Birth events, birth experiences and social differences in postnatal depression. Australian Journal of Public Health, 18(2), 176-84. doi: $10.1111 /$ j.1753-6405.1994.tb00222.x 
Babyak, M. A. (2004). What you see may not be what you get: A brief, nontechnical introduction to overfitting in regression-type models. Psychosomatic Medicine, 66(3), 411-421. Retrieved from: http://www.google.ca/url?sa=t\&rct=j\&q=\&esrc=s\&source $=$ web\&cd $=2 \&$ cad $=$ rja\&uact $=8 \&$ ved $=0 \mathrm{CCcQFjAB} \&$ url=http $\% 3 \mathrm{~A} \% 2 \mathrm{~F} \% 2 \mathrm{Fwww} . \mathrm{cs}$. vu.nl \%2F eliens\%2Fsg\%2Flocal\%2Ftheory\%2Foverfitting.pdf\&ei=BqfBVOidMIGlgwTxwI PICQ\&usg=AFQjCNGQx1ZN7q3EGQDzqkwayRUEg2Xs-Q

Bagley, S.C., White, H., \& Golomb, B. A. (2001). Logistic regression in the medical literature. Journal of Clinical Epidemiology, 54(10), 979-985. Retrieved from http://resolver.scholarsportal.info/resolve/08954356/v54i0010/979_lritml

Barnes, J., Stein, A., Smith, T., \& Pollock, J.I. (1997). Extreme attitudes to body shape, social and psychological factors and a reluctance to breast feed. ALSPAC Study Team. Avon Longitudinal Study of Pregnancy and Childhood. Journal of the Royal Society of Medicine, 90(10), 551-559. Retrieved from http://www.ncbi.nlm.nih.gov/pmc/articles/ PMC1296597 /pdf/jrsocmed00035-0029.pdf

Beck, C.T. (2001). Predictors of postpartum depression: An update. Nursing Research, 50(5), 275-285. Retrieved from: http://journals.lww.com/nursingresearchonline/ pages/default.aspx

Bernard, J. Y., De Agostini, M., Forhan, A., Alfaiate, T., Bonet, M., Champion, V., . . Heude, B. (2013). Breastfeeding duration and cognitive development at 2 and 3 years of age in the EDEN Mother-Child cohort. Journal of Pediatrics, 163(1), 36-42. doi: 10.1016/j.jpeds.2012.11.090 
Bick, D.E., MacArthur, C., \& Lancashire, R.J. (1998). What influences the uptake and early cessation of breast feeding? Midwifery, 14(4), 242-247. doi: 10.1016/S02666138(98)90096-1

Bilszta, J. L. C., Tang, M., Meyer, D., Milgrom, J., Ericksen, J., \& Buist, A. E. (2008). Single motherhood versus poor partner relationship: Outcomes for antenatal mental health. Australian and New Zealand Journal of Psychiatry, 42(1), 56-65. doi: $10.1080 / 00048670701732731$

Bloch, M., Schmidt, P. J., Danaceau, M., Murphy, J., Nieman, L., \& Rubinow, D. R. (2000). Effects of gonadal steroids in women with a history of postpartum depression. The American Journal of Psychiatry, 157(6), 924-930. doi: 10.1176/appi.ajp.157.6.924

Bogen, D. L., Hanusa, B. H., Moses-Kolko, E., \& Wisner, K. L. (2010). Are maternal depression or symptom severity associated with breastfeeding intention or outcomes? Journal of Clinical Psychiatry, 71(8), 1069-1078. doi: 10.4088/JCP.09m05383blu

Buttner, M. M., O'Hara, M. W., \& Watson, D. (2012). The structure of women's mood in the early postpartum. Assessment, 19(2), 247-256. doi:10.1177/1073191111429388

Britton, J.R. (2011). Infant temperament and maternal anxiety and depressed mood in the early postpartum period. Women's Health, 51(1), 55-71. doi: 10.1080/03630242.2011.540741

Brockington, I. (2004). Postpartum psychiatric disorders. Lancet, 363(9405), 303-310. doi: $10.1016 / \mathrm{S} 0140-6736(03) 15390-1$.

Buttner, M. M., O'Hara, M. W., \& Watson, D. (2012). The structure of women's mood in the early postpartum. Assessment, 19(2), 247-256. doi: 10.1177/1073191111429388 
Castle, H., Slade, P., Barranco-Wadlow, M., \& Rogers, M. (2008). Attitudes to emotional expression, social support and postnatal adjustment in new parents. Journal of Reproductive and Infant Psychology, 26(3), 180-194. doi: 10.1080/02646830701691319

Chapman, S. L. C., \& Wu, L. (2013). Postpartum substance use and depressive symptoms: A review. Women \& Health, 53(5), 479-503. doi:10.1080/03630242.2013.804025

Chaudron, L.H., Klein, M.H., Remington, P., Palta, M., Allen, C., \& Essex, M.J. (2001). Predictors, prodromes and incidence of postpartum depression. Journal of Psychosomatic Obstetrics \& Gynaecology, 22(2),103-112. doi: 10.3109/01674820109049960

Chen, A., \& Rogan, W.J. (2004). Breastfeeding and the risk of postneonatal death in the United States. Pediatrics, 113(5), e435-e439. Retrieved from http://pediatrics.aappublications. org /content /113/5/e435.full.pdf + html

Chung, E.K., McCollum, K.F., Elo, I.T., Lee, H.J., \& Culhane, J.F. (2004). Maternal depressive symptoms and infant health practices among low-income women. Pediatrics, 113(6), e523-e529. Retrieved from http://pediatrics.aappublications.org/content/113/6/e523 .full.pdf + html

Colman, I., Naicker, K., Zeng, Y., Ataullahjan, A., Senthilselvan, A., \& Patten, S. B. (2011). Predictors of long-term prognosis of depression. CMAJ : Canadian Medical Association Journal, 183(17), 1969-1976. doi:10.1503/cmaj.110676

Clifford, T.J., Campbell, M.K., Speechley, K.N., \& Gorodzinsky, F. (2006). Factors influencing full breastfeeding in a southwestern Ontario community: Assessments at 1 week and at 6 months postpartum. Journal of Human Lactation, 22(3), 292-304. doi: 10.1177/0890 334406290043 
Cooper, P. J., Murray, L., \& Stein, A. (1993). Psychosocial factors associated with the early termination of breast-feeding. Journal of Psychosomatic Research, 37(2), 171-176. doi: $10.1016 / 0022-3999(93) 90084-S$

Cox, J.L., Connor, Y., \& Kendell, R.E. (1982). Prospective study of the psychiatric disorders of childbirth. British Journal of Psychiatry, 140, 111-117. doi: 10.1192/bjp.140.2.111

Cox, J.L., Holden, J.M., \& Sagovsky, R. (1987). Detection of postnatal depression: Development of the 10-item Edinburgh Postnatal Depression Scale. British Journal of Psychiatry, 150, 782-786. doi: 10.1192/bjp.150.6.782

Csatordai, S., Kozinszky, Z., Devosa, I., Tóth, É., Krajcsi, A., Sefcsik, T., \& Pál, A. (2007). Obstetric and sociodemographic risk of vulnerability to postnatal depression. Patient Education and Counseling, 67(1-2), 84-92. doi: 10.1016/j.pec.2007.02.004

Dagher, R. K., \& Shenassa, E. D. (2012). Prenatal health behaviors and postpartum depression: is there an association?. Archives of Women's Mental Health, 15(1), 31-37. doi: $10.1007 / \mathrm{s} 00737-011-0252-0$

Dai, X., \& Dennis, C.L. (2003). Translation and validation of the Breastfeeding Self-Efficacy Scale into Chinese. Journal of Midwifery Women's Health, 48(5), 350-356. doi: $10.1016 / \mathrm{S} 1526-9523(03) 00283-6$

Davey, H.L., Tough, S.C., Adair, C.E., \& Benzies, K.M. (2011). Risk factors for sub-clinical and major postpartum depression among a community cohort of Canadian women. Maternal and Child Health Journal, 15(7):866-875. doi: 10.1007/s10995-008-0314-8.

Dennis, C.L. (2003). The breastfeeding self-efficacy scale: Psychometric assessment of the short form. Journal of Obstetric, Gynecologic, \& Neonatal Nursing, 32(6), 734-744. doi: $10.1177 / 0884217503258459$ 
Dennis, C. (2004). Can we identify mothers at risk for postpartum depression in the immediate postpartum period using the Edinburgh Postnatal Depression Scale? Journal of Affective Disorders, 78(2), 163-169. doi: 10.1016/S0165-0327(02)00299-9

Dennis, C., \& McQueen, K. (2007). Does maternal postpartum depressive symptomatology influence infant feeding outcomes? Acta Paediatrica, 96(4), 590-594. doi: $10.1111 / j .1651-2227.2007 .00184 . x$

Dennis, C., \& McQueen, K. (2009). The relationship between infant-feeding outcomes and postpartum depression: A qualitative systematic review. Pediatrics, 123(4), e736-e751. doi: $10.1542 /$ peds.2008-1629

Di Florio, A., Jones, L., Forty, L., Gordon-Smith, K., Robertson Blackmore, E., Heron, J., . . . Jones, I. (2014). Mood disorders and parity - A clue to the aetiology of the postpartum trigger. Journal of Affective Disorders, 152-154(6), 334-339. doi:10.1016/j.jad.2013.09.034

do Carmo França-Botelho, A., Ferreira, M.C., França, J.L., França, E.L., \& Honório-França, A.C. (2012). Breastfeeding and its relationship with reduction of breast cancer: A review. Asian Pacific Journal of Cancer Prevention, 13(11), 5327-5332. doi: 10.7314/APJCP. 2012.13.11.5327

Doan, T., Gardiner, A., Gay, C.L., \& Lee, K.A. (2007). Breast-feeding increases sleep duration of new parents. Journal of Perinatal and Neonatal Nursing, 21(3), 200-206. doi: 10.1097/01.JPN.0000285809.36398

Duijts, L., Ramadhani, MK., \& Moll, H.A. (2009). Breastfeeding protects against infectious diseases during infancy in industrialized countries. A systematic review. Maternal and Child Nutrition, 5(3), 199-210. doi: 10.1111/j.1740-8709.2008.00176.x. 
Dunn, S., Davies, B., McCleary, L., Edwards, N., \& Gaboury, I. (2006). The relationship between vulnerability factors and breastfeeding outcome. Journal of Obstetric, Gynecologic, \& Neonatal Nursing: Clinical Scholarship for the Care of Women, Childbearing Families, \& Newborns, 35(1), 87-97. doi: 10.1111/j.15526909.2006.00005.x

Edhborg, M., Matthiesen, A.S., Lundh, W., \& Widström, A.M. (2005). Some early indicators for depressive symptoms and bonding 2 months postpartum--a study of new mothers and fathers. Archives of Women's Mental Health, 8(4), 221-231. doi: 10.1007/s00737-0050097-5

Elisei, S., Lucarini, E., Murgia, N., Ferranti, L., \& Attademo, L. (2013). Perinatal Depression: A study of prevalence and of risk and protective factors. Psychiatria Danubina, 25, 258262. Retrieved from http://www.hdbp.org/psychiatria_danubina/pdf/dnb_vol25_ sup2/dnb_vol25_sup2_258.pdf

Fairlie, T. G., Gillman, M. W., \& Rich-Edwards, J. (2009). High pregnancy-related anxiety and prenatal depressive symptoms as predictors of intention to breastfeed and breastfeeding initiation. Journal of Women's Health, 18(7), 945-953. doi: 10.1089/jwh.2008.0998

Falceto, O.G., Giugliani, E.R., \& Fernandes, C.L. (2004). Influence of parental mental health on early termination of breast-feeding: A case-control study. The Journal of the American Board of Family Medicine, 17(3),173-183. doi: 10.3122/jabfm.17.3.173

Fergerson, S. S., Jamieson, D. J., \& Lindsay, M. (2002). Diagnosing postpartum depression: Can we do better? American Journal of Obstetrics \& Gynecology, 186(5), 899-902. doi: 10.1067/mob.2002.123404 
Field, T. (2010). Postpartum depression effects on early interactions, parenting, and safety practices: A review. Infant Behavior \& Development, 33(1), 1-6. doi: 10.1016/j. infbeh.2009.10.005

Field, T., Diego, M., Hernandez-Reif, M., Figueiredo, B., Ezell, S., \& Siblalingappa, V. (2010). Depressed mothers and infants are more relaxed during breastfeeding versus bottle feeding interactions: Brief report. Infant Behavior and Development, 33(2):241-4. doi: 10.1016/j.infbeh.2009.12.006

Figueiredo, B., Canário, C., \& Field, T. (2013). Breastfeeding is negatively affected by prenatal depression and reduces postpartum depression. Psychological Medicine, 3, 1-10. doi: $10.1017 / \mathrm{S} 0033291713001530$

Figueiredo, B., Dias, C. C., Brandão, S., Canário, C., \& Nunes-Costa, R. (2013). Breastfeeding and postpartum depression: State of the art review. Jornal de Pediatria, 89(4), 332-338. doi: $10.1016 /$ j.jpedp.2012.12.004

Flores-Quijano, M.E., Córdova, A., Contreras-Ramírez, V., Farias-Hernández, L., Cruz Tolentino, M., \& Casanueva, E. (2008). Risk for postpartum depression, breastfeeding practices, and mammary gland permeability. Journal of Human Lactation, 24(1), 50-57. doi: $10.1177 / 0890334407310587$.

Freeman, M.P., Smith, K.W., Freeman, S.A., McElroy, S.L., Kmetz, G.E., Wright, R., \& Keck, P.E. Jr. (2002). The impact of reproductive events on the course of bipolar disorder in women. Journal of Clinical Psychiatry, 63(4), 284-287.

Galler, J. R., Harrison, R. H., Biggs, M. A., Ramsey, F., \& Forde, V. (1999). Maternal moods predict breastfeeding in Barbados. Journal of Developmental and Behavioral Pediatrics, $20(2), 80-87$. 
Galler, J.R., Harrison, R.H., Ramsey, F., Chawla, S., \& Taylor, J. (2006). Postpartum feeding attitudes, maternal depression, and breastfeeding in Barbados. Infant Behavior and Development, 29(2), 189-203. doi: 10.1016/j.infbeh.2005.10.005

Ganjekar, S., Desai, G., \& Chandra, P. S. (2013). A comparative study of psychopathology, symptom severity, and short-term outcome of postpartum and nonpostpartum mania. Bipolar Disorders, 15(6), 713-718. doi: 10.1111/bdi.12076

Giallo, R., Cooklin, A., \& Nicholson, J. (2014). Risk factors associated with trajectories of mothers' depressive symptoms across the early parenting period: An Australian population-based longitudinal study. Archives of Women's Mental Health, 17(2), 115125. doi:10.1007/s00737-014-0411-1

Government of Canada. (2015). Sponsorship of Adopted Children and other Relatives - The Sponsor's Guide. Retrieved January 21, 2015 from http://www.cic.gc.ca/english/ information/applications/guides/5196ETOC.asp\#table3

Green, K., Broome, H., \& Mirabella, J. (2006). Postnatal depression among mothers in the United Arab Emirates: Socio-cultural and physical factors. Psychology, Health \& Medicine, 11(4), 425-431. doi: 10.1080/13548500600678164

Groër, M.W. (2005). Differences between exclusive breastfeeders, formula-feeders, and controls: A study of stress, mood, and endocrine variables. Biological Research for Nursing, 7(2):106-117. doi: $10.1177 / 1099800405280936$

Groër, M.W.,\& Morgan, K. (2007). Immune, health and endocrine characteristics of depressed postpartum mothers. Psychoneuroendocrinology, 32(2):133-139. doi: 10.1016/j. psyneuen.2006.11.007 
Gross, K.H., Wells, C.S., Radigan-Garcia, A., \& Dietz, P.M. (2002). Correlates of self-reports of being very depressed in the months after delivery: Results from the Pregnancy Risk Assessment Monitoring System. Maternal and Child Health Journal, 6(4):247-53. doi: 10.1023/A:1021110100339

Hahn-Holbrook, J., Haselton, M.G., Dunkel Schetter, C., \& Glynn, L.M. (2013). Does breastfeeding offer protection against maternal depressive symptomatology?: A prospective study from pregnancy to 2 years after birth. Archives of Women's Mental Health, 16(5), 411-422. doi: 10.1007/s00737-013-0348-9

Hackshaw, A. (2008). Small studies: Strengths and limitations. European Respiratory Journal, 32 (5), 1141-1143. doi: 10.1183/09031936.00136408.

Hannah, P., Adams, D., Lee, A., Glover, V., \& Sandler, M. (1992). Links between early postpartum mood and post-natal depression. The British Journal of Psychiatry, 160, 777-780. doi: $10.1192 /$ bjp. 160.6 .777

Harris, B., Huckle, P., Thomas, R., Johns, S., \& Fung, H. (1989). The use of rating scales to identify post-natal depression. The British Journal of Psychiatry, 154, 813-817. doi: 10.1192/bjp.154.6.813

Hatton, D.C., Harrison-Hohner, J., Coste, S., Dorato, V., Curet, L.B., \& McCarron, D.A. (2005). Symptoms of postpartum depression and breastfeeding. Journal of Human Lactation, 21(4), 444-449. doi 10.1177/0890334405280947

Health Canada. (2013). Infant Feeding. Retrieved November 2, 2013 from http://www.hcsc.gc.ca/fn-an/nutrition/infant-nourisson/index-eng.php. 
Hamdan, A., \& Tamim, H. (2012). The relationship between postpartum depression and breastfeeding. International Journal of Psychiatry in Medicine, 43(3), 243-259. doi: 10.2190/PM.43.3.d

Henderson, J. J., Evans, S. F., Straton, J. A. Y., Priest, S. R., \& Hagan, R. (2003). Impact of postnatal depression on breastfeeding duration. Birth: Issues in Perinatal Care, 30(3), 175-180. doi: 10.1046/j.1523-536X.2003.00242.x

Hendrick, V., Altshuler, L., Strouse, T., \& Grosser, S. (2000). Postpartum and nonpostpartum depression: Differences in presentation and response to pharmacologic treatment. Depression and Anxiety, 11, 66-72. doi: 10.1002/(SICI)1520-6394(2000)11:2<66::AIDDA3>3.0.CO;2-D

Heron, J., Haque, S., Oyebode, F., Craddock, N., \& Jones, I. (2009). A longitudinal study of hypomania and depression symptoms in pregnancy and the postpartum period. Bipolar Disorders, 11(4), 410 -417. doi: 10.1111/j.1399-5618.2009.00685.x

Horowitz, J.A., \& Goodman, J. (2004). A longitudinal study of maternal postpartum depression symptoms. Research and Theory for Nursing Practice, 18(2-3), 149-163. doi: 10.1891/rtnp.18.2.149.61285

Horowitz, J. A., Murphy, C. A., Gregory, K. E., \& Wojcik, J. (2011). A community based screening initiative to identify mothers at risk for postpartum depression. Journal of Obstetric, Gynecologic, \& Neonatal Nursing: Clinical Scholarship for the Care of Women, Childbearing Families, \& Newborns, 40(1), 52-61. doi: 10.1111/j.15526909.2010.01199.x 
Howell, E. A., Mora, P. A., Horowitz, C. R., \& Leventhal, H. (2005). Racial and ethnic differences in factors associated with early postpartum depressive symptoms. Obstetrics \& Gynecology, 105(6), 1442-1450. doi: 10.1097/01.AOG.0000164050.34126.37

Insaf, T. Z., Fortner, R. T., Pekow, P., Dole, N., Markenson, G., \& Chasan-Taber, L. (2011). Prenatal stress, anxiety and depressive symptoms as predictors of intention to breastfeed among Hispanic women. Journal of Women's Health, 20(8), 1183-1192. doi:

10.1089/jwh.2010.2276

Jacobson, S.W., Jacobson, J.L., \& Frye, K.F. (1991). Incidence and correlates of breast-feeding in socioeconomically disadvantaged women. Pediatrics, 88(4), 728-736.

Jardri, R., Pelta, J., Maron, M., Thomas, P., Delion, P., Codaccioni, X., \& Goudemand, M. (2006). Predictive validation study of the Edinburgh Postnatal Depression Scale in the first week after delivery and risk analysis for postnatal depression. Journal of Affective Disorders, 93(1-3), 169-176. doi: 10.1016/j.jad.2006.03.009

Jennings, K. D., Ross, S., Popper, S., \& Elmore, M. (1999). Thoughts of harming infants in depressed and nondepressed mothers. Journal of Affective Disorders, 54(1-2), 21-28. doi: $10.1016 / \mathrm{S} 0165-0327(98) 00185-2$

Jesse, D. E., Walcott-McQuigg, J., Mariella, A., \& Swanson, M. S. (2005). Risks and protective factors associated with symptoms of depression in low-income African American and Caucasian women during pregnancy. Journal of Midwifery \& Women's Health, 50(5), 405-410. doi: 10.1016/j.jmwh.2005.05.001

Josefsson, A., Angelsiöö, L., Berg, G., Ekström, C.M, Gunnervik, C., Nordin, C., \& Sydsjö, G. (2002). Obstetric, somatic, and demographic risk factors for postpartum depressive symptoms. Obstetrics \& Gynecology, 99(2), 223-228. 
Kendall-Tackett, K., Cong, Z., \& Hale, T.W. (2013). Depression, sleep quality, and maternal well-being in postpartum women with a history of sexual assault: A comparison of breastfeeding, mixed-feeding, and formula-feeding mothers. Breastfeeding Medicine, 8(1), 16-22. doi: $10.1089 / \mathrm{bfm} .2012 .0024$

Korhonen, M., Luoma, I., Salmelin, R., \& Tamminen, T. (2012). A longitudinal study of maternal prenatal, postnatal and concurrent depressive symptoms and adolescent wellbeing. Journal of Affective Disorders, 136(3), 680-692. doi: 10.1016/j.jad.2011.10.007

Lane, A., Keville, R., Morris, M., Kinsella, A., Turner, M., \& Barry, S. (1997). Postnatal depression and elation among mothers and their partners: Prevalence and predictors. The British Journal of Psychiatry, 171, 550-555. doi: 10.1192/bjp.171.6.550

Lau Y, \& Chan KS. (2007). Influence of intimate partner violence during pregnancy and early postpartum depressive symptoms on breastfeeding among Chinese women in Hong Kong. Journal of Midwifery Women's Health, 52(2), e15-e20. doi: 10.1016/j.jmwh. 2006.09.001

Leahy-Warren, P., McCarthy, G., \& Corcoran, P. (2012). First-time mothers: Social support, maternal parental self-efficacy and postnatal depression. Journal of Clinical Nursing, 21(3-4), 388-397. doi:10.1111/j.1365-2702.2011.03701.x

Lee, H. J., Rubio, M. R., Elo, I. T., McCollum, K. F., Chung, E. K., \& Culhane, J. F. (2005). Factors associated with intention to breastfeed among low-income, inner-city pregnant women. Maternal and Child Health Journal, 9(3), 253-261. doi: 10.1007/s10995-005$0008-5$ 
Lindahl, V., Pearson, J. L., \& Colpe, L. (2005). Prevalence of suicidality during pregnancy and the postpartum. Archives of Women's Mental Health, 8(2), 77-87. doi: 10.1007/s00737005-0080-1

López-Zurbano, S., González-Pinto, A., \& López, P. (2015). Gender Differences in Bipolar Disorder. In M. Sáenz-Herrero (Ed.) Psychopathology in Women. Springer International Publishing. New York. pp. 641-659.

Luan, N.N., Wu, Q.J., Gong, T.T., Vogtmann, E., Wang, Y.L., \& Lin, B. (2013). Breastfeeding and ovarian cancer risk: A meta-analysis of epidemiologic studies. American Journal of Clinical Nutrition, 98(4), 1020-1031. doi: 10.3945/ajcn.113.062794

Mancini, F., Carlson, C., \& Albers, L. J (2007). Use of the Postpartum Depression Screening Scale in a collaborative obstetric practice. Midwifery Women's Health, 52(5), 429-434. doi: 10.1016/j.jmwh.2007.03.007

Matthiesen, A.S., Ransjö-Arvidson, A.B., Nissen, E., \& Uvnäs-Moberg, K. (2001). Postpartum maternal oxytocin release by newborns: Effects of infant hand massage and sucking. Birth, 28(1), 13-19. doi: 10.1046/j.1523-536x.2001.00013.x

Mayberry, L. J., Horowitz, J. A., \& Declercq, E. (2007). Depression symptom prevalence and demographic risk factors among U.S. women during the first 2 years postpartum. Journal of Obstetric, Gynecologic, \& Neonatal Nursing: Clinical Scholarship for the Care of Women, Childbearing Families, \& Newborns, 36(6), 542-549. doi:10.1111/j.15526909.2007.00191.x

McCarter-Spaulding, D., \& Horowitz, J. A. (2007). How does postpartum depression affect breastfeeding? MCN: The American Journal of Maternal/Child Nursing, 32(1), 10-17. doi: 10.1097/00005721-200701000-00004 
McKee, M. D., Zayas, L. H., \& Jankowski, K. R. B. (2004). Breastfeeding intention and practice in an urban minority population: Relationship to maternal depressive symptoms and mother-infant closeness. Journal of Reproductive and Infant Psychology, 22(3), 167-181. doi: $10.1080 / 02646830410001723751$

McLearn, K.T., Minkovitz, C.S., Strobino, D.M., Marks, E., \& Hou, W. (2006). Maternal depressive symptoms at 2 to 4 months postpartum and early parenting practices. Archives of Pediatrics and Adolescent Medicine, 160(3), 279-284. doi: 10.1001/archpedi.160.3.279.

Meltzer-Brody, S., Boschloo, L., Jones, I., Sullivan, P.F., \& Penninx, B.W. (2013). The EPDSLifetime: Assessment of lifetime prevalence and risk factors for perinatal depression in a large cohort of depressed women. Archives of Women's Mental Health, 16(6), 465-473. doi: 10.1007/s00737-013-0372-9.

Mezzacappa, E.S., \& Katlin, E.S. (2002). Breast-feeding is associated with reduced perceived stress and negative mood in mothers. Health Psychology, 21(2), 187-193. doi: 10.1037/0278-6133.21.2.187

Miranda, A. M., Soares, C. N., Moraes, M. L., Fossaluza, V., Serafim, P. M., \& Mello, M. F. (2012). Healthy maternal bonding as a resilience factor for depressive disorder. Psychology \& Neuroscience, 5(1), 21-25. doi: 10.3922/j.psns.2012.1.04

Misri, S., Sinclair, D. A., \& Kuan, A. J. (1997). Breast-feeding and postpartum depression: Is there a relationship? The Canadian Journal of Psychiatry / La Revue Canadienne De Psychiatrie, 42(10), 1061-1065.

Moehler, E., Brunner, R., Wiebel, A., Reck, C., \& Resch, F. (2006). Maternal depressive symptoms in the postnatal period are associated with long-term impairment of mother- 
child bonding. Archives of Women's Mental Health, 9(5), 273-278. doi: 10.1007/s00737006-0149-5

Morgan, V. A., Croft, M. L., Valuri, G. M., Zubrick, S. R., Bower, C., McNeil, T. F., \& Jablensky, A. V. (2012). Intellectual disability and other neuropsychiatric outcomes in high-risk children of mothers with schizophrenia, bipolar disorder and unipolar major depression. The British Journal of Psychiatry, 200(4), 282-289. doi:

10.1192/bjp.bp.111.093070

Murray, L., \& Carothers, A .D. (1990). The validation of the Edinburgh Post-Natal Depression Scale on a community sample. The British Journal of Psychiatry, 157, 288-290. doi: 10.1192/bjp.157.2.288

Murphy, K. R., \& Davidshofer, C. O. (2005). Psychological Testing: Principles and Applications ( $6^{\text {th }}$ ed.). Pearson, New Jersey. pp. 197.

Nishioka, E., Haruna, M., Ota, E., Matsuzaki, M., Murayama, R., Yoshimura, K., \& Murashima, S. (2011). A prospective study of the relationship between breastfeeding and postpartum depressive symptoms appearing at 1-5 months after delivery. Journal of Affective Disorders, 133(3), 553-559. doi: 10.1016/j.jad.2011.04.027.

Nielsen Forman, D., Videbech, P., Hedegaard, M., Dalby, J., \& Secher, N. J. (2000). Postpartum depression: Identification of women at risk. BJOG: An International Journal of Obstetrics \& Gynaecology, 107(10), 1210-1217. doi: 10.1111/j.14710528.2000.tb11609.x

Niers, L., Stasse-Wolthuis, M., Rombouts, F.M., Rijkers, G.T. (2007). Nutritional support for the infant's immune system. Nutrition Reviews, 65(8 Pt 1), 347-360. doi: 10.1111/j.17534887.2007.tb00313.x 
O'Brien, M., Buikstra, E., \& Hegney, D. (2008). The influence of psychological factors on breastfeeding duration. Journal of Advanced Nursing, 63(4), 397-408. doi: 10.1111/ j.1365-2648.2008.04722x

O’Hara, M.W., Schlechte, J.A., Lewis, D.A., \& Wright, E.J. (1991). Prospective study of postpartum blues. Biologic and psychosocial factors. Archives of General Psychiatry. 48(9), 801-806. doi: 10.1001/archpsyc.1991.01810330025004

O’Hara, M.W., \& McCabe, J.E. (2013). Postpartum depression: Current status and future directions. Annual Review of Clinical Psychology, 9, 379-407. doi: 10.1146/annurevclinpsy-050212-185612

O'Neill, T., Murphy, P., \& Greene, V.T. (1990). Postnatal depression--aetiological factors. Irish Medical Journal, 83(1), 17-18. Retrieved from http://www.imj.ie/Archive/Postnatal \%20depression.pdf

Papinczak, T.A., \& Turner, C.T. (2000). An analysis of personal and social factors influencing initiation and duration of breastfeeding in a large Queensland maternity hospital. Breastfeeding Review, 8(1), 25-33.

Pearlstein, T., Howard, M., Salisbury, A., \& Zlotnick, C. (2009). Postpartum depression. American Journal of Obstetrics \& Gynecology, 200(4), 357-364. doi: 10.1016/j.ajog.2008.11.033.

Pippins, J.R., Brawarsky, P., Jackson, R.A., Fuentes-Afflick, E., \& Haas, J.S. (2006). Association of breastfeeding with maternal depressive symptoms. Journal of Women's Health (Larchmt), 15(6), 754-762. doi: 10.1089/jwh.2006.15.754. 
Pope, C.J., Oinonen, K.A, Mazmanian, D., \& Stone, S. (2015). The Hormonal Sensitivity Hypothesis in Women: Data from Across the Lifespan. Manuscript submitted for publication.

Pope, C.J., Sharma, V, \& Mazmanian, D. (2014a). Recognition, diagnosis, and treatment of postpartum bipolar depression. Expert Review of Neurotherapeutics, 14(1), 19-28. doi:10.1586/14737175.2014.846219

Pope, C.J., Sharma, V., \& Mazmanian, D. (2014b). Bipolar disorder in the postpartum period: Management strategies and future directions. Women's Health, 10(4), 359-371. doi: 10.2217/whe.14.33.

Pope, C.J., Xie, B., Sharma, V., \& Campbell, M.K. (2013). A prospective study of thoughts of self-harm and suicidal ideation during the postpartum period in women with mood disorders. Archives of Women's Mental Health, 16(6), 483-488. doi: 10.1007/s00737013-0370-y

Preacher, K.J., Rucker, D.D., MacCallum, R.C., \& Nicewander, W.A. (2005). Use of the Extreme Groups Approach: A Critical Reexamination and New Recommendations. Psychological Methods, 10(2), 178-192. doi: 0.1037/1082-989X.10.2.178

Public Health Agency of Canada. (2009). What Mothers Say: The Canadian Maternity Experiences Survey. Retrieved October 6, 2013 from http://www.phac-aspc.gc.ca/rhsssg/survey-eng.php

Ramsay, M., Gisel, E. G., McCusker, J., Bellavance, F., \& Platt, R. (2002). Infant sucking ability, non-organic failure to thrive, maternal characteristics, and feeding practices: $\mathrm{A}$ prospective cohort study. Developmental Medicine \& Child Neurology, 44(6), 405-414. doi: $10.1017 / \mathrm{S} 0012162201002286$ 
Riskin, A., Almog, M., Peri, R., Halasz, K., Srugo, I., \& Kessel, A. (2012). Changes in immunomodulatory constituents of human milk in response to active infection in the nursing infant. Pediatric Research, 71(2), 220-225. doi: 10.1038/pr.2011.34.

Robinson, S., \& Fall, C. (2012). Infant nutrition and later health: A review of the current evidence. Nutrients, 4, 859-874. doi: 10.3390/nu4080859

Robertson, E., Jones, I., Haque, S., Holder, R., \& Craddock, N. (2005). Risk of puerperal and non-puerperal recurrence of illness following bipolar affective puerperal (post-partum) psychosis. The British Journal of Psychiatry, 186(3), 258-259. doi: 10.1192/bjp. 186.3.258

Ross, L. E., Campbell, V. L. S., Dennis, C., \& Blackmore, E. R. (2006). Demographic characteristics of participants in studies of risk factors, prevention, and treatment of postpartum depression. The Canadian Journal of Psychiatry, 51(11), 704-710. Retrieved from:

http://eds.b.ebscohost.com.ezproxy.lakeheadu.ca/ehost/pdfviewer/pdfviewer?sid=d9fcb7 49-b39e-4063-8eeb-c479ad97efdf\%40sessionmgr 110\&vid=1\&hid=112

Russell, E., Fawcett, J., \& Mazmanian, D. (2013). Risk of obsessive-compulsive disorder in pregnant and postpartum women: A meta-analysis. Journal of Clinical Psychiatry, 74(4), 377-385. doi: 10.4088/JCP.12r07917

Seimyr, L., Edhborg, M., Lundh, W., \& Sjögren, B.J. (2004). In the shadow of maternal depressed mood: Experiences of parenthood during the first year after childbirth. Journal of Psychosomatic Obstetrics \& Gynaecology, 25(1), 23-34. doi: 10.1080/016748 20410001737414 
Segre, L. S., O'Hara, M. W., Arndt, S., \& Stuart, S. (2007). The prevalence of postpartum depression. Social Psychiatry and Psychiatric Epidemiology, 42(4), 316-321. doi: $10.1007 / \mathrm{s} 00127-007-0168-1$

Seto, M., Cornelius, M. D., Goldschmidt, L., Morimoto, K., \& Day, N. L. (2005). Long-term effects of chronic depressive symptoms among low-income childrearing mothers. Maternal and Child Health Journal, 9(3), 263-271. doi:10.1007/s10995-005-0002-x

Sharma, V., \& Mazmanian, D. (2014). The DSM-5 peripartum specifier: Prospects and pitfalls. Archives of Women's Mental Health.17(2), 171-173. doi: 10.1007/s00737-013-0406-3

Skalkidou, A., Hellgren, C., Comasco, E., Sylvén, S., \& Sundström Poromaa I. (2012). Biological aspects of postpartum depression. Women's Health (Lond Engl). 8(6), 659672. doi: $10.2217 /$ whe. 12.55

Spinelli, M. G. (2004). Maternal infanticide associated with mental illness: Prevention and the promise of saved lives. The American Journal of Psychiatry, 161(9), 1548-1557. doi: 10.1176/appi.ajp.161.9.1548

Streiner, D. L. (2002). Breaking up is hard to do: The heartbreak of dichotomizing continuous data. Canadian Journal of Psychiatry, 47(3), 262-265. Retrieved from: http://ww1.cpaapc.org:8080/Publications/Archives/CJP/2002/april/researchMethodsDichotomizingData 2.asp

Streiner, D. L. (2003). Unicorns do exist: a tutorial on "proving" the null hypothesis. Canadian Journal of Psychiatry, 48(11), 756-761. Retrieved from: http://eds.a.ebscohost.com. ezproxy.lakeheadu.ca/ehost/detail/detail?sid=5baf56fd-2fc0-45af-aeb465cd53a81609\%40sessionmgr4004\&vid=0\&hid=4102\&bdata=JnNpdGU9ZWhvc3QtbG $12 Z Q \% 3 d \% 3 d \# d b=a p h \& A N=11833756$ 
Surkan, P. J., Peterson, K. E., Hughes, M. D., \& Gottlieb, B. R. (2006). The role of social networks and support in postpartum women's depression: A multiethnic urban sample. Maternal and Child Health Journal, 10(4), 375-383. doi:10.1007/s10995-005-0056-9

Tabachnick , B.G., Fidell, L.S., 2014. Using Multivariate Statistics ( $6^{\text {th }}$ international ed.). Pearson, London. pp. 500,506.

Tamminen T. (1988). The impact of mother's depression on her nursing experiences and attitudes during breastfeeding. Acta Paediatrica Scandinavica, Suppl. 344, 87-94. doi: 10.1111/j.1651-2227.1988.tb10864.x

Tammentie, T., Tarkka, M., Åstedt-Kurki, P., \& Paavilainen, E. (2002). Sociodemographic factors of families related to postnatal depressive symptoms of mothers. International Journal of Nursing Practice, 8(5), 240-246. doi: 10.1046/j.1440-172X.2002.00373.x

Tashakori, A., Behbahani, A.Z., \& Irani, R.D. (2012). Comparison of prevalence of postpartum depression symptoms between breastfeeding mothers and non-breastfeeding mothers. Iran Journal of Psychiatry, 7(2), 61-65. Retrieved from http://www.ncbi.nlm.nih.gov/ pmc/articles/PMC3428639/

Taveras, E.M., Capra, A.M., Braveman, P.A., Jensvold, N.G., Escobar, G.J., \& Lieu, T.A. (2003). Clinician support and psychosocial risk factors associated with breastfeeding discontinuation. Pediatrics, $112(1 \mathrm{Pt} 1), 108-115$.

Tsvetov, G., Levy, S., Benbassat, C., Shraga-Slutzky, I., \& Hirsch D. (2013). Influence of number of deliveries and total breast-feeding time on bone mineral density in premenopausal and young postmenopausal women. Maturitas. Advanced online publication. doi: 10.1016/j.maturitas.2013.11.003 
Thome, M., Alder, E.M., \& Ramel, A. (2006). A population-based study of exclusive breastfeeding in Icelandic women: Is there a relationship with depressive symptoms and parenting stress? International Journal of Nursing Studies, 43(1), 11-20. doi: 10.1016/j.ijnurstu.2004.10.009

Tu, M.T., Lupien, S.J., \& Walker, C.D. (2006). Diurnal salivary cortisol levels in postpartum mothers as a function of infant feeding choice and parity. Psychoneuroendocrinology, 31(7), 812-824. doi: 10.1016/j.psyneuen.2006.03.006

Tuohy, A., \& McVey, C. (2008). Subscales measuring symptoms of non-specific depression, anhedonia, and anxiety in the Edinburgh Postnatal Depression Scale. British Journal of Clinical Psychology, 47(2), 153-169. doi: 10.1348/014466507X238608

Viero, C., Shibuya, I., Kitamura, N., Verkhratsky, A., Fujihara, H., Katoh, A., ... \& Dayanithi, G. (2010). Oxytocin: Crossing the bridge between basic science and pharmacotherapy. CNS Neuroscience \& Therapeutics, 16(5), e138-e156. doi: 10.1111/j.1755-5949.2010.00185.x

Vliegen, N., Casalin, S., \& Luyten, P. (2014). The course of postpartum depression: A review of longitudinal studies. Harvard Review of Psychiatry, 22(1), 1-22. doi: 10.1097/HRP. 0000000000000013

Walfisch, A., Sermer, C., Cressman, A., Koren, G. (2013). Breast milk and cognitive development--the role of confounders: A systematic review. British Medical Journal, 3(8), e003259. doi: 10.1136/bmjopen-2013-003259.

Warner, R., Appleby, L., Whitton, A., \& Faragher, B. (1996). Demographic and obstetric risk factors for postnatal psychiatric morbidity. The British Journal of Psychiatry, 168(5), 607-611. doi: 10.1192/bjp.168.5.607 
Watkins, S., Meltzer-Brody, S., Zolnoun, D., \& Stuebe, A. (2011). Early breastfeeding experiences and postpartum depression. Obstetrics \& Gynecology, 118(2 Pt 1), 214-221. doi: 10.1097/AOG.0b013e3182260a2d.

Wisner, K. L., Sit, D. K. Y., McShea, M. C., Rizzo, D. M., Zoretich, R. A., Hughes, C. L., . . Hanusa, B. H. (2013). Onset timing, thoughts of self-harm, and diagnoses in postpartum women with screen-positive depression findings. JAMA Psychiatry, 70(5), 490-498. doi: 10.1001/jamapsychiatry.2013.87

World Health Organization. (n.d.). The ICD-10 Classification of Mental and Behavioural Disorders. Retrieved January 25, 2014 from http://www.who.int/classifications/icd/en/

Yonkers, K. A., Ram in, S. M., Rush, A. J., Navarrete, C. A., Carmody, T., March, D., . . . Leveno, K. J. (2001). Onset and persistence of postpartum depression in an inner-city maternal health clinic system. The American Journal of Psychiatry, 158(11), 1856-1863. doi: 10.1176/appi.ajp.158.11.1856

Youash, S., Campbell, K., Avison, W., Peneva, D., Sharma, V., \& Xie, B. (2013). Influence of health information levels on postpartum depression. Archives of Women's Mental Health, 16(6), 489-498. doi: 10.1007/s00737-013-0368-5

Ystrom, E. (2012). Breastfeeding cessation and symptoms of anxiety and depression: A longitudinal cohort study. BMC Pregnancy and Childbirth, 12, 36 - 41. doi: $10.1186 / 1471-2393-12-36$ 
Appendix 1

Canadian Maternity Experience Survey 


\section{A Statistics Canada User Guide document for the Canadian Maternity Experience Survey}

Retrieved from: http://www23.statcan.gc.ca/imdb/p3Instr.pl?Function= getInstrumentList\&Item_Id=34371\&UL=1V\& 


\section{What Mothers Say: The Canadian Maternity Experiences Survey}

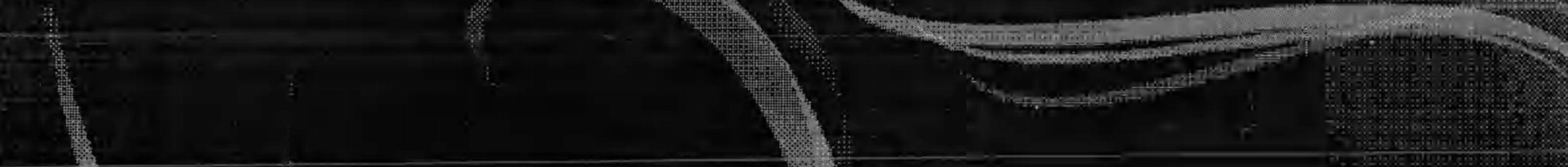


To promote and protect the health of Canadians through leadership, partnership, innovation and action in public health. - Public Health Agency of Canada

What Mothers Say: The Canadian Maternity Experiences Survey

is available on Internet at the following address:

http://www.publichealth.gc.ca/mes

Également disponible en français sous le titre:

Ce que disent les mères : l'Enquête canadienne sur l'expérience de la maternité

To obtain additional copies, please contact:

Maternal and Infant Health Section

Health Surveillance and Epidemiology Division

Centre for Health Promotion

Health Promotion and Chronic Disease Prevention Branch

200 Eglantine Driveway, Tunney's Pasture

Jeanne Mance Building, $10^{\text {th }}$ Floor, A.L. 1910D

Ottawa, Ontario K1A OK9

Tel.: (613) 941-2395

Fax: (613) 941-9927

E-Mail: mes@phac-aspc.gc.ca

This publication can be made available in alternative formats upon request.

Suggested Citation:

Public Health Agency of Canada. What Mothers Say: The Canadian Maternity Experiences Survey. Ottawa, 2009.

(C) Her Majesty the Queen in Right of Canada, 2009

Cat.: HP5-74/2-2009E-PDF

ISBN: $978-1-100-10828-5$ 

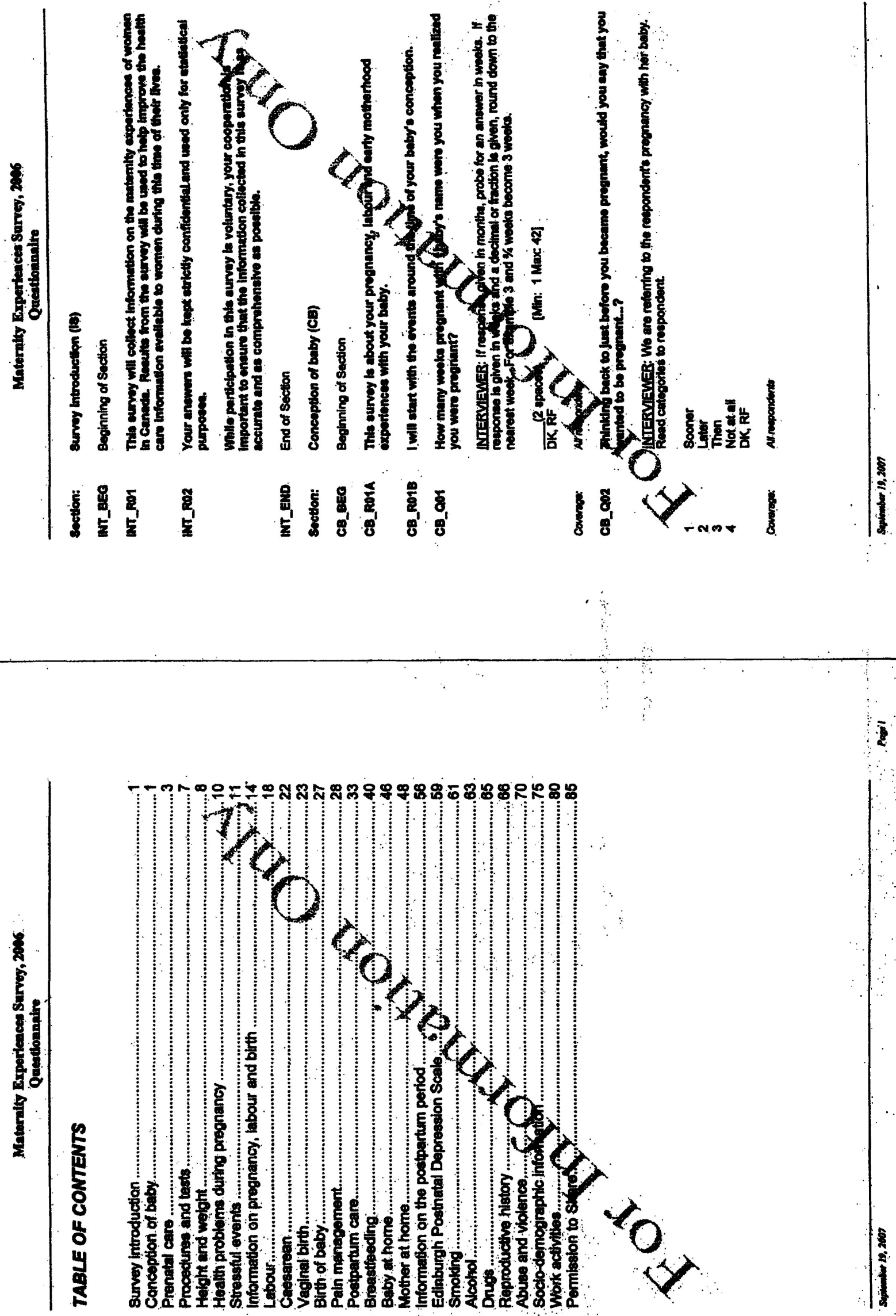


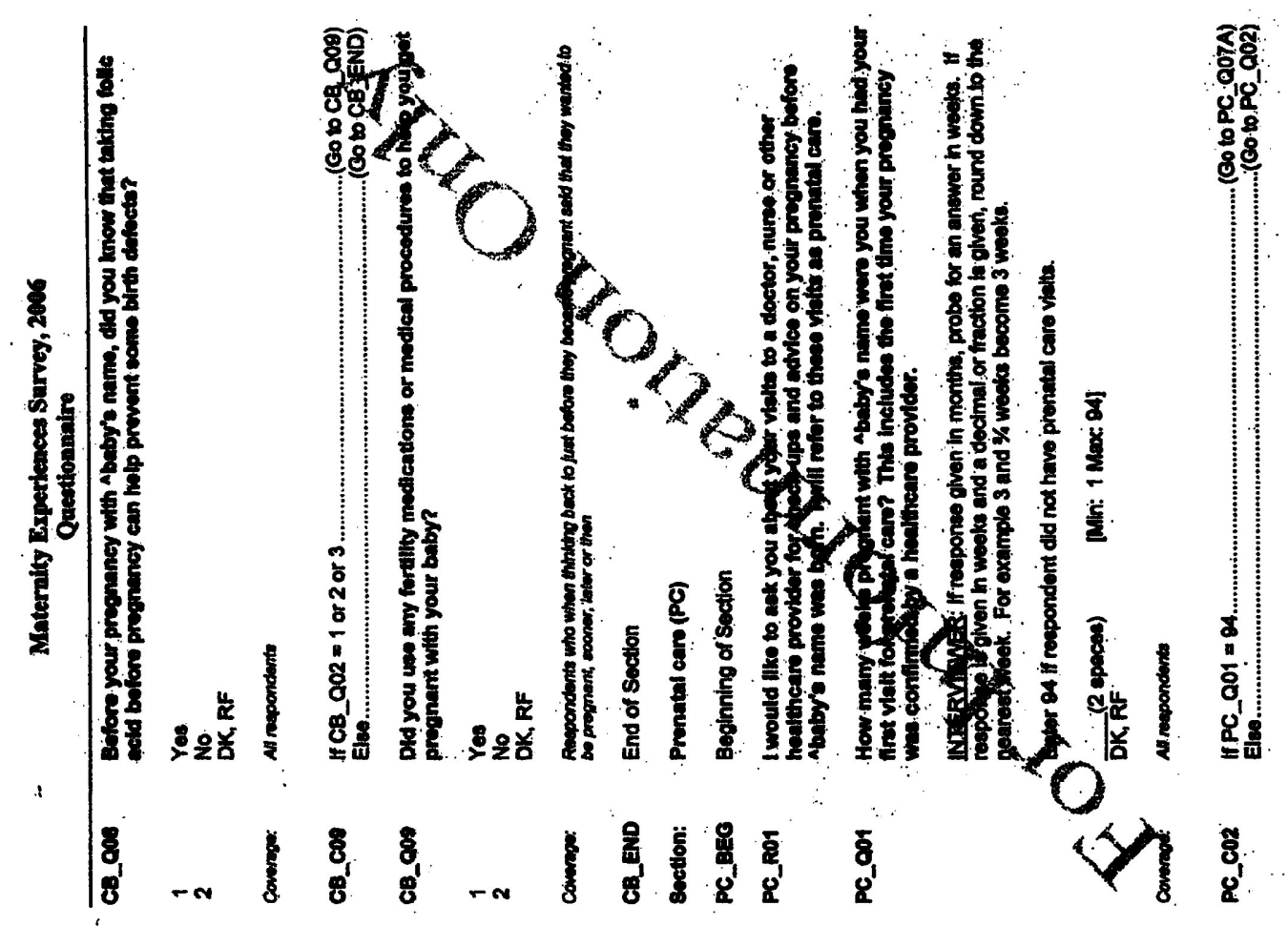

i

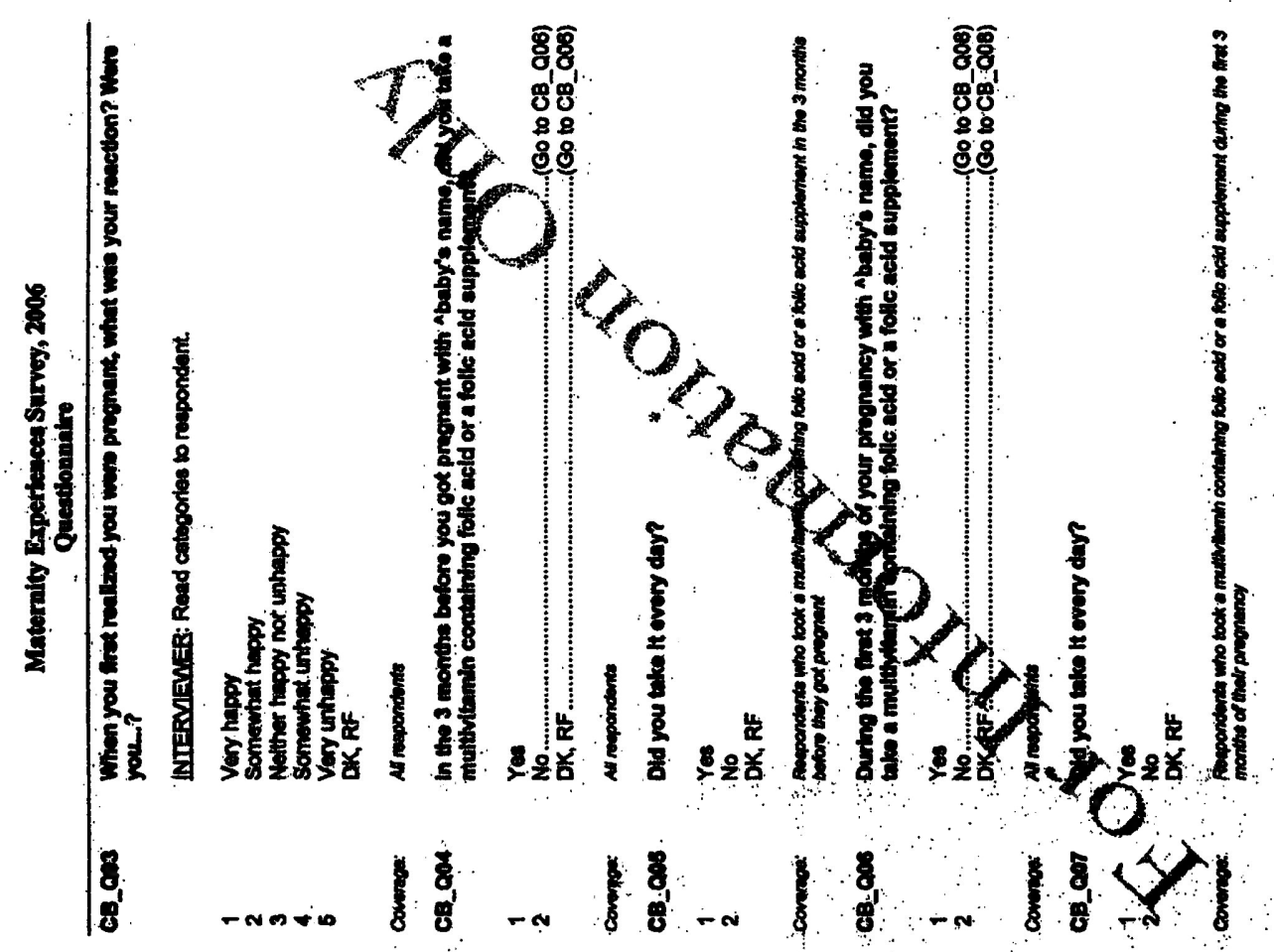



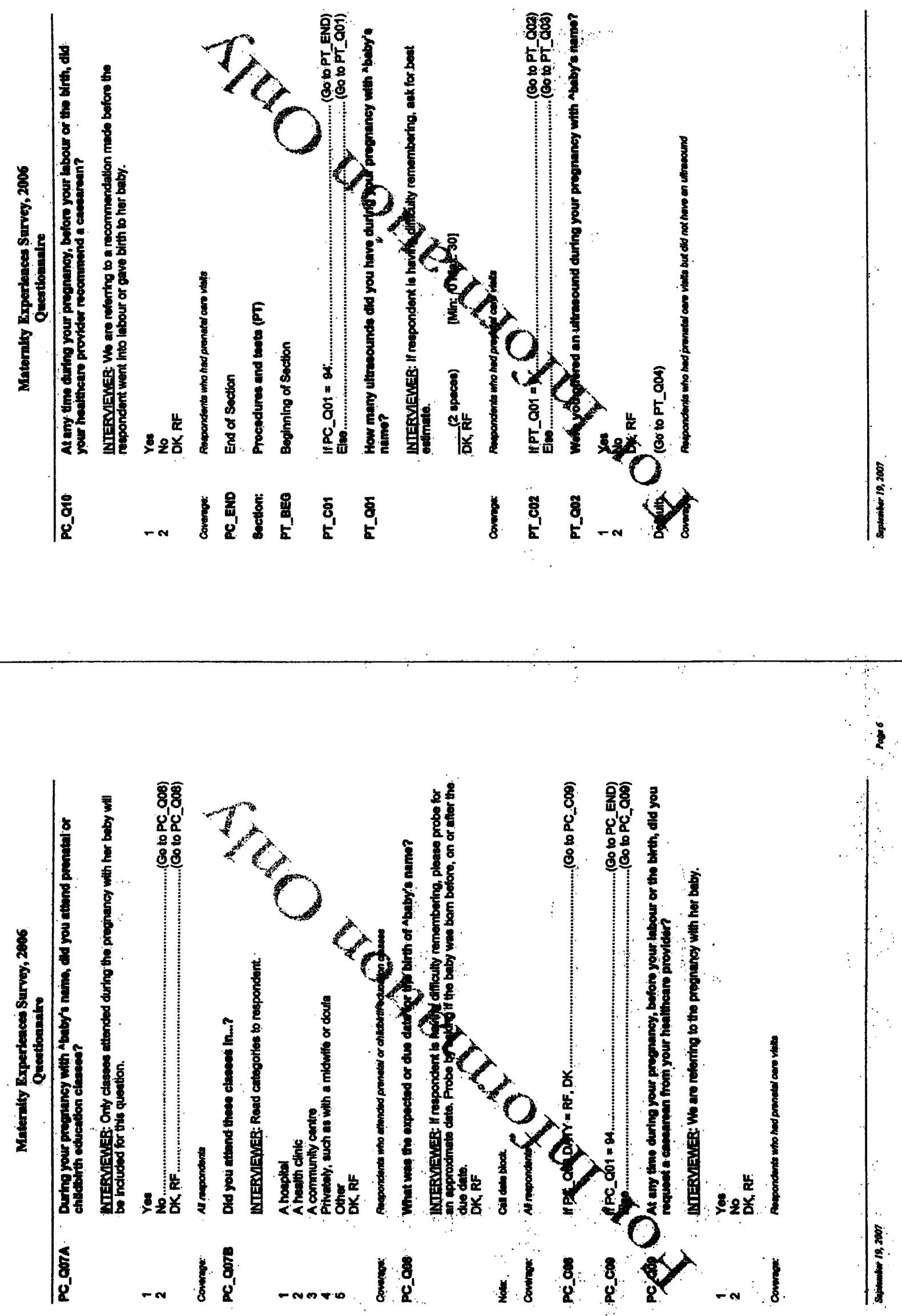



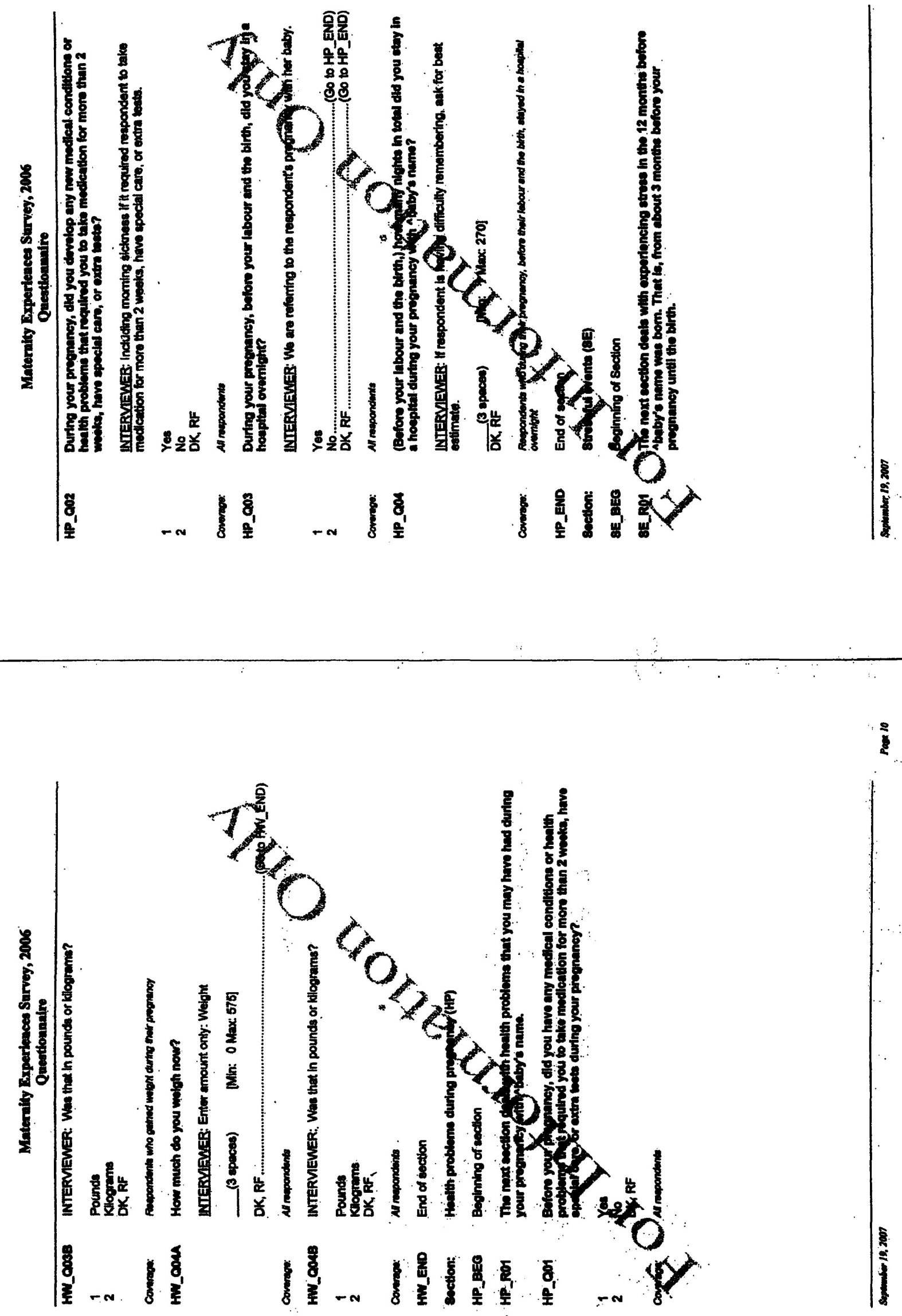

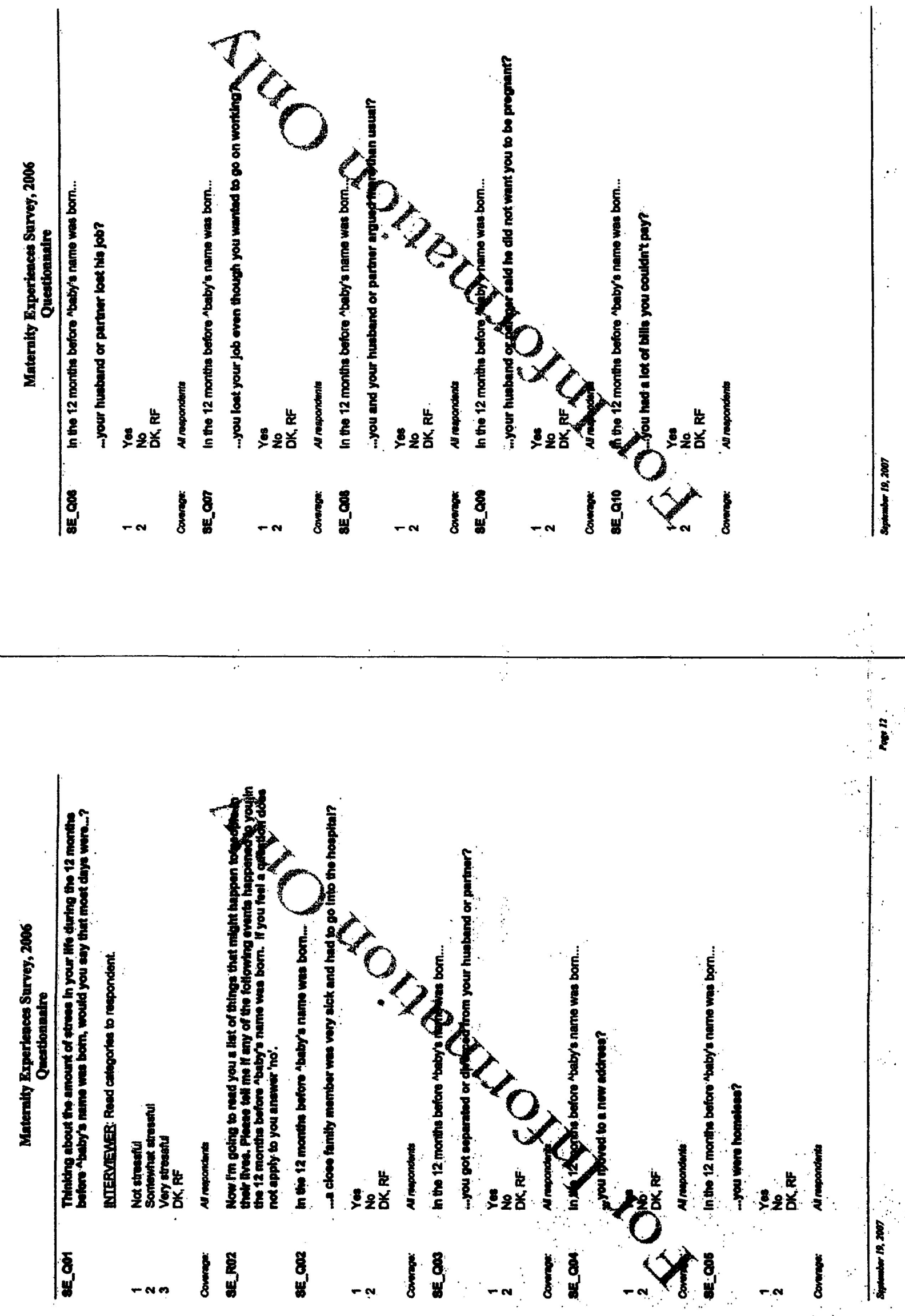

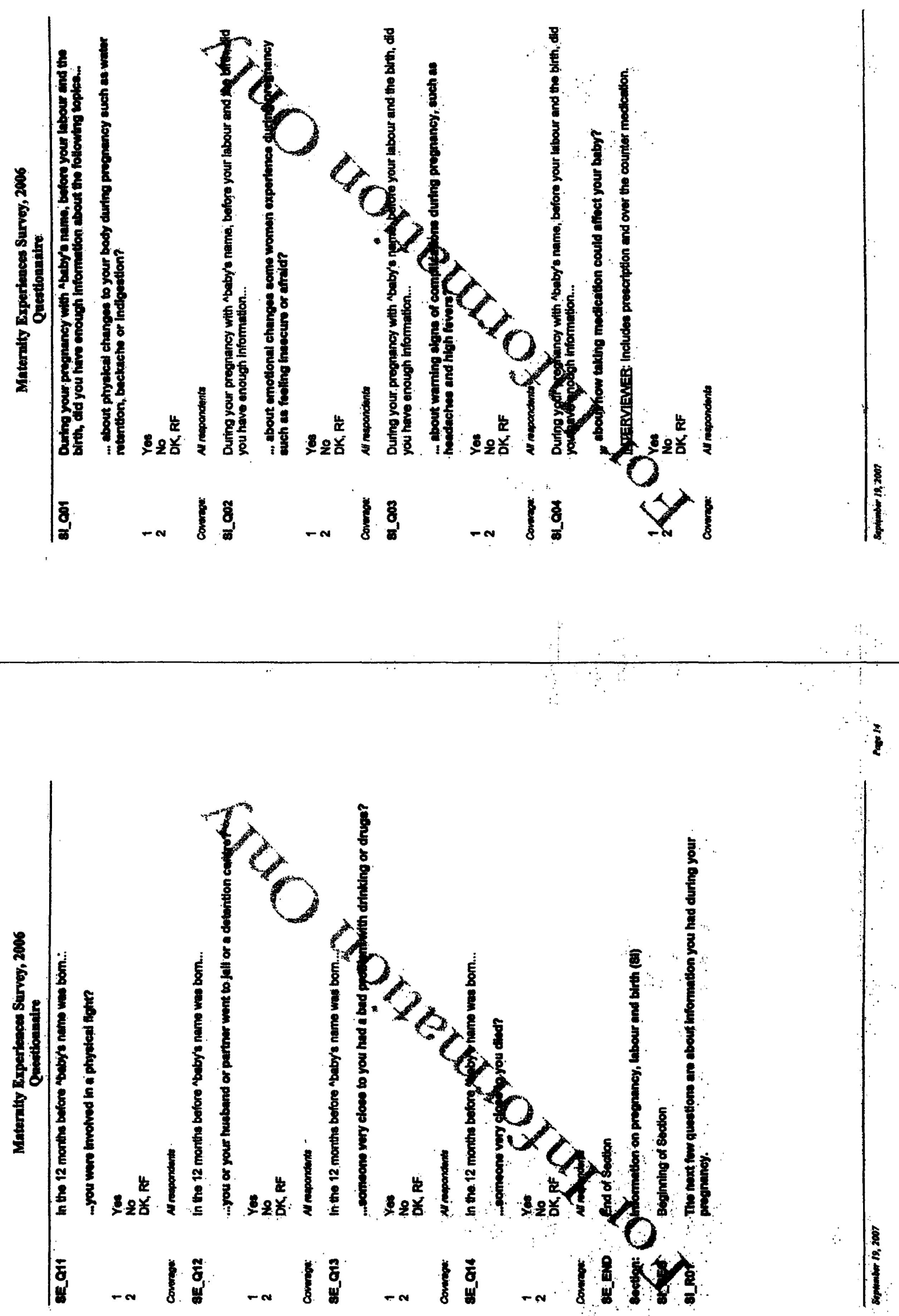

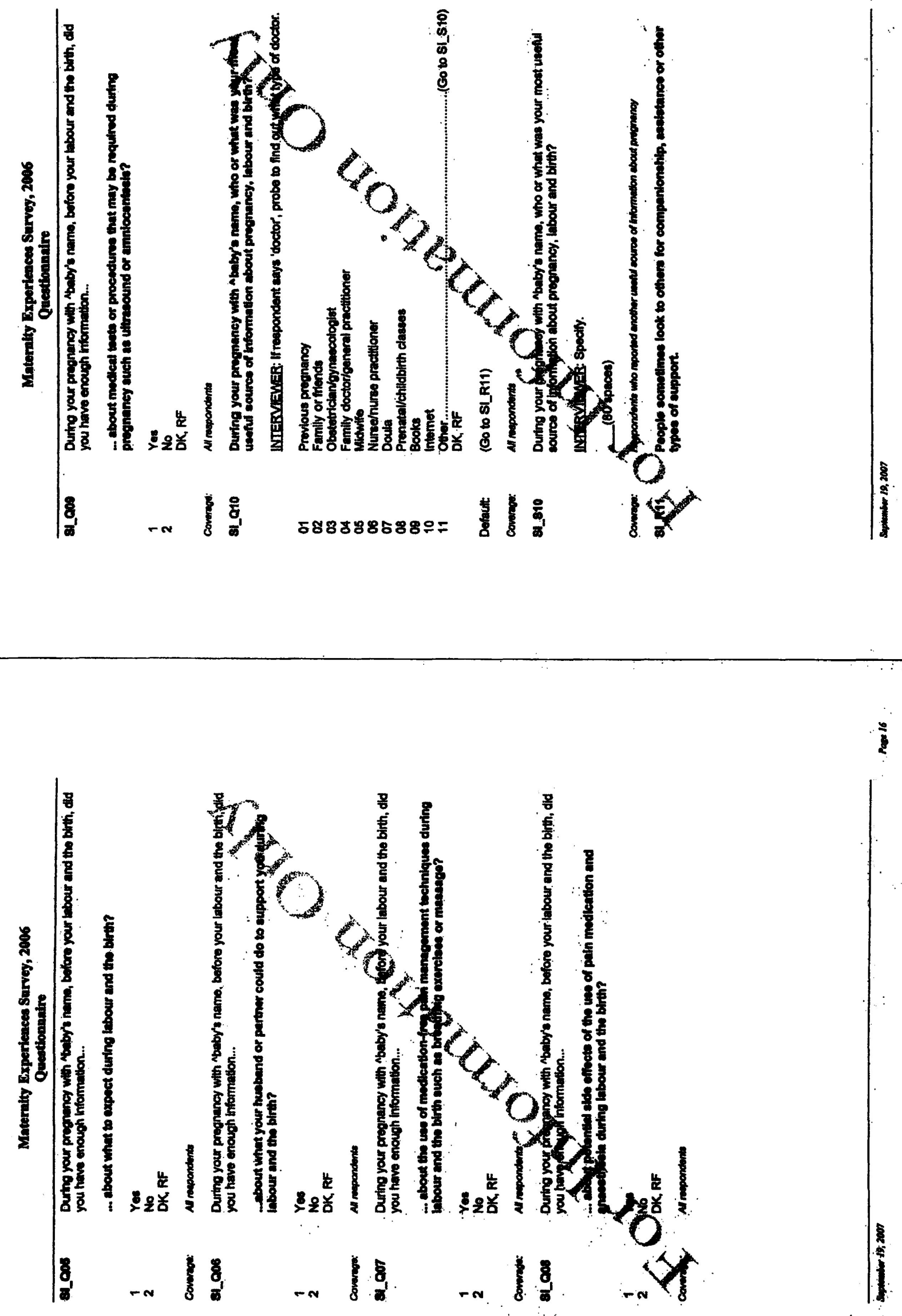

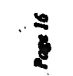



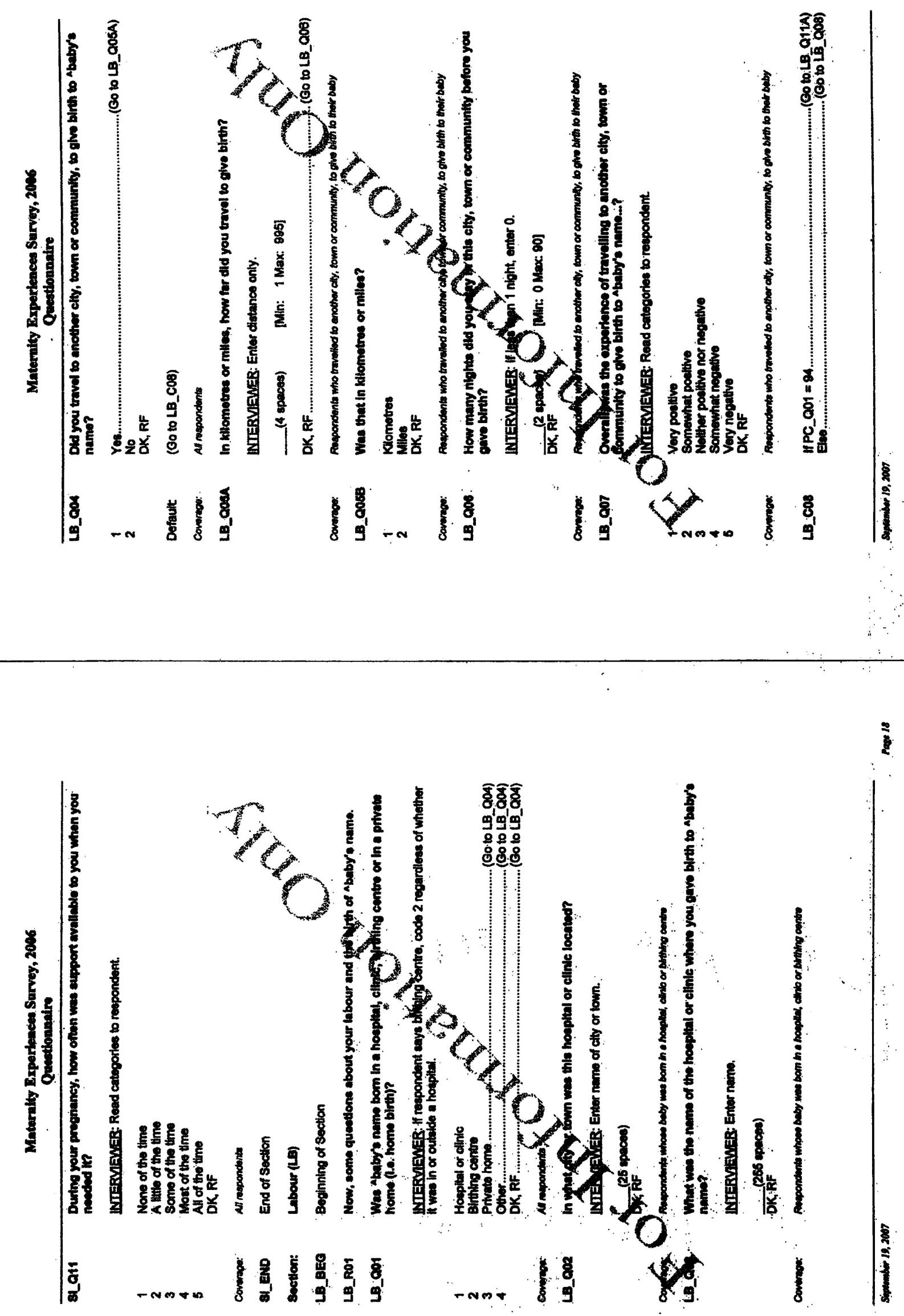

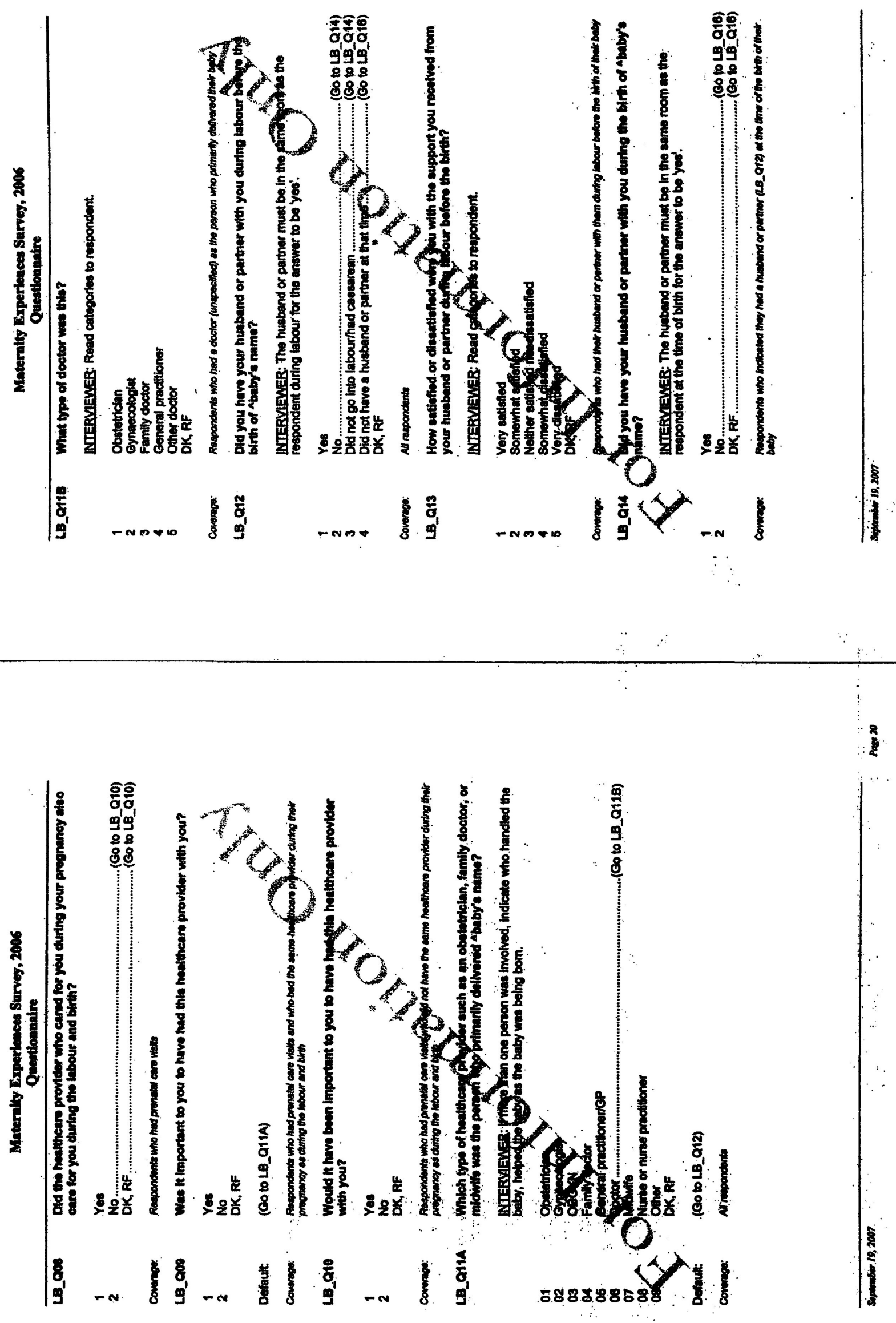

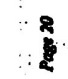



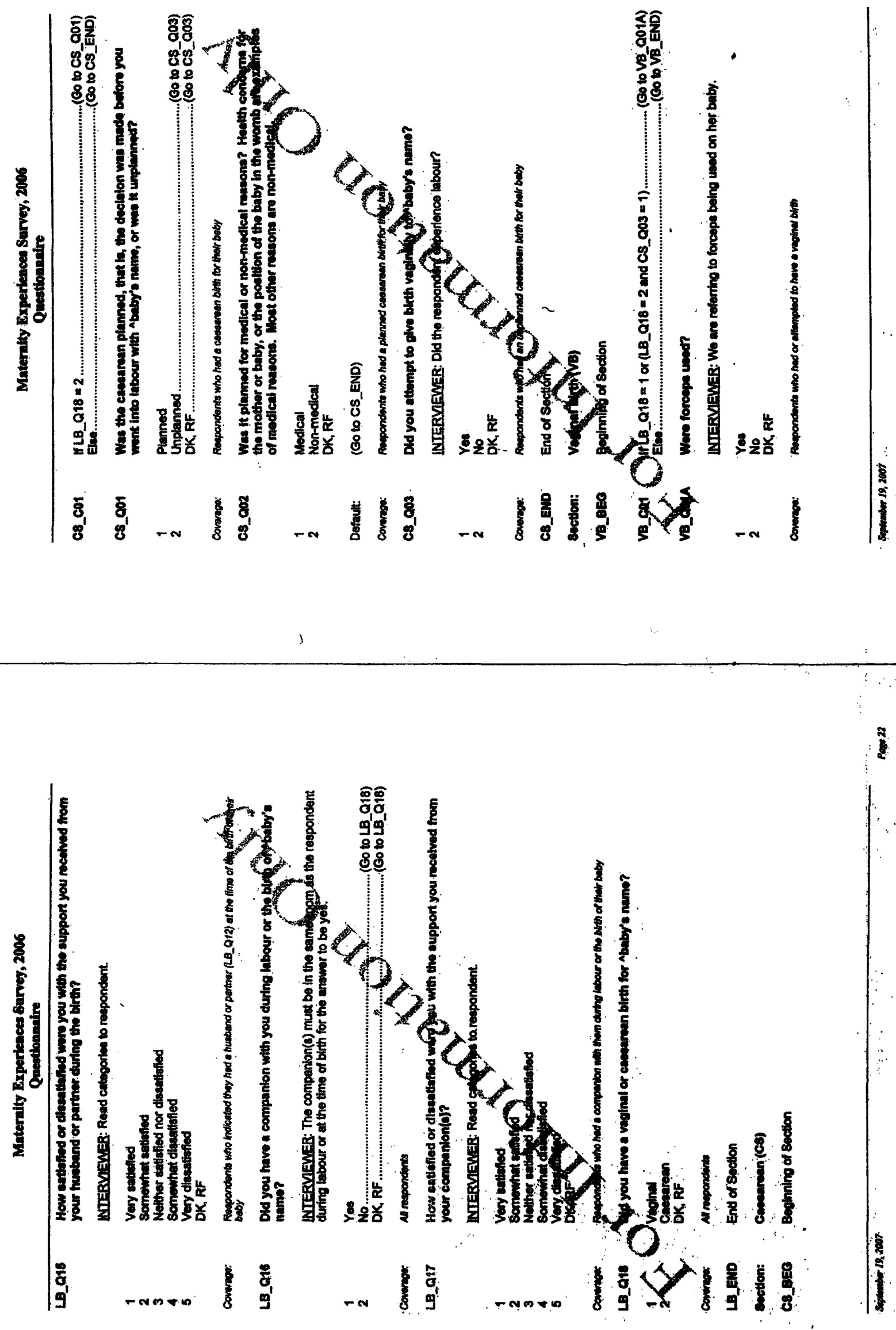

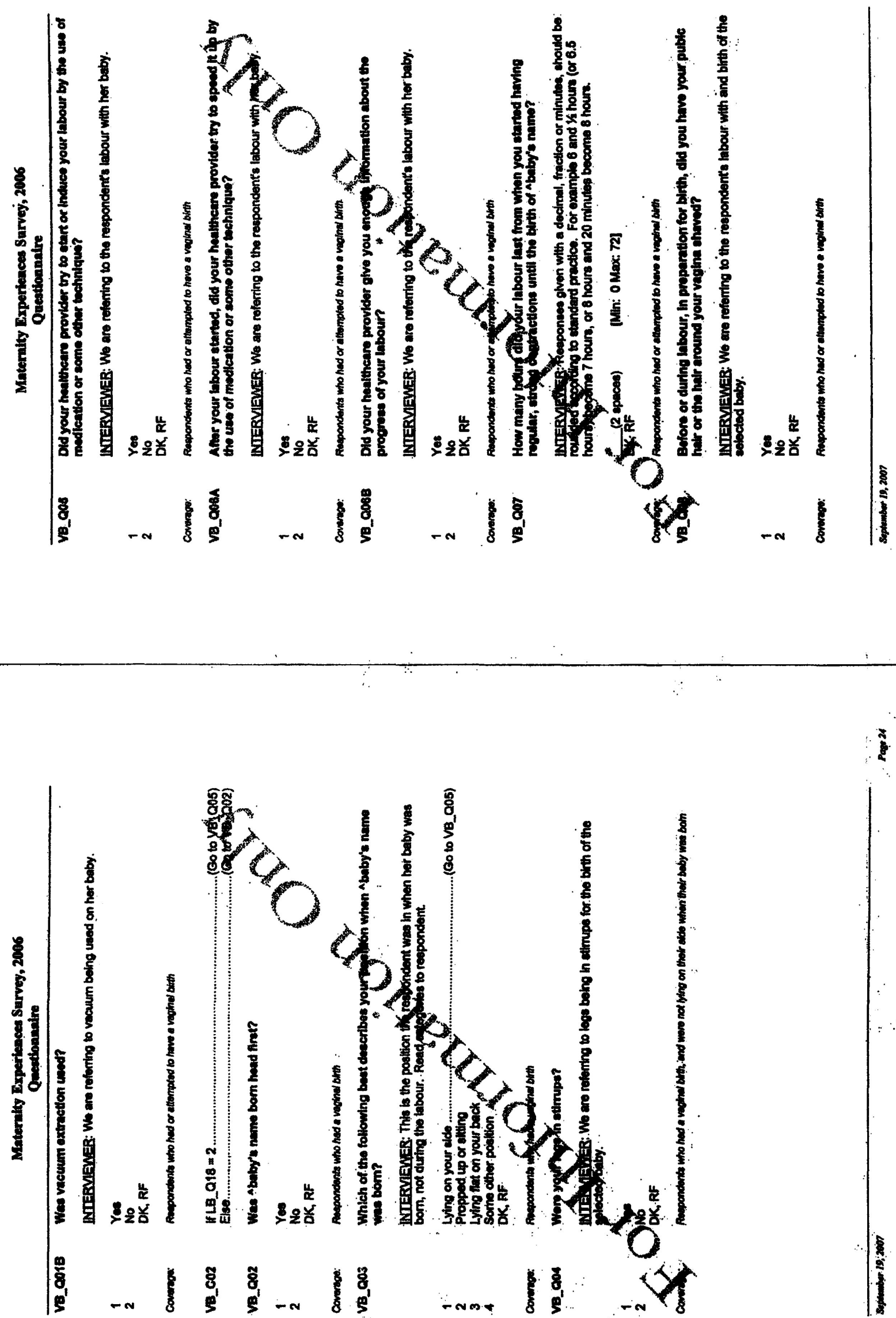

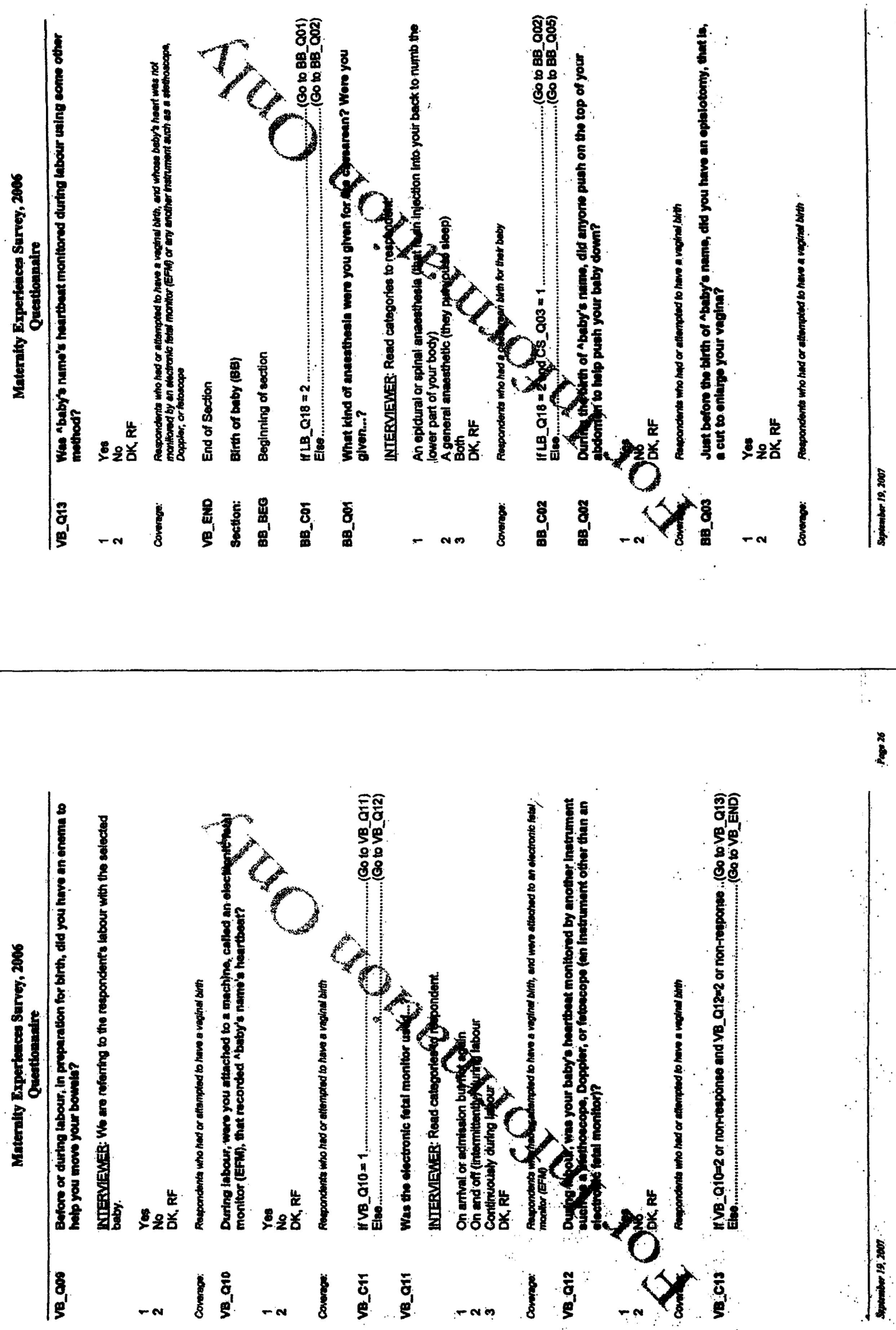

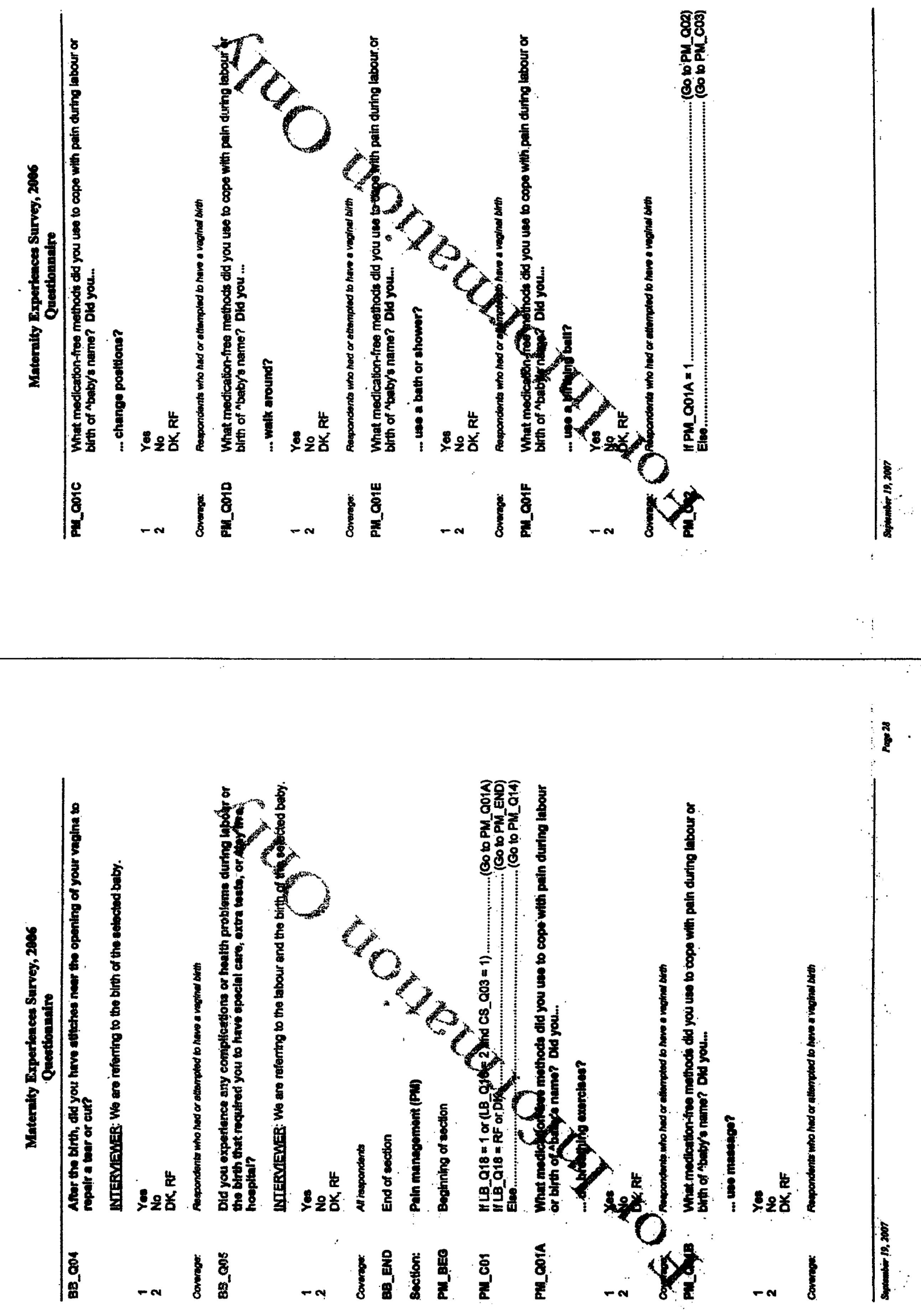

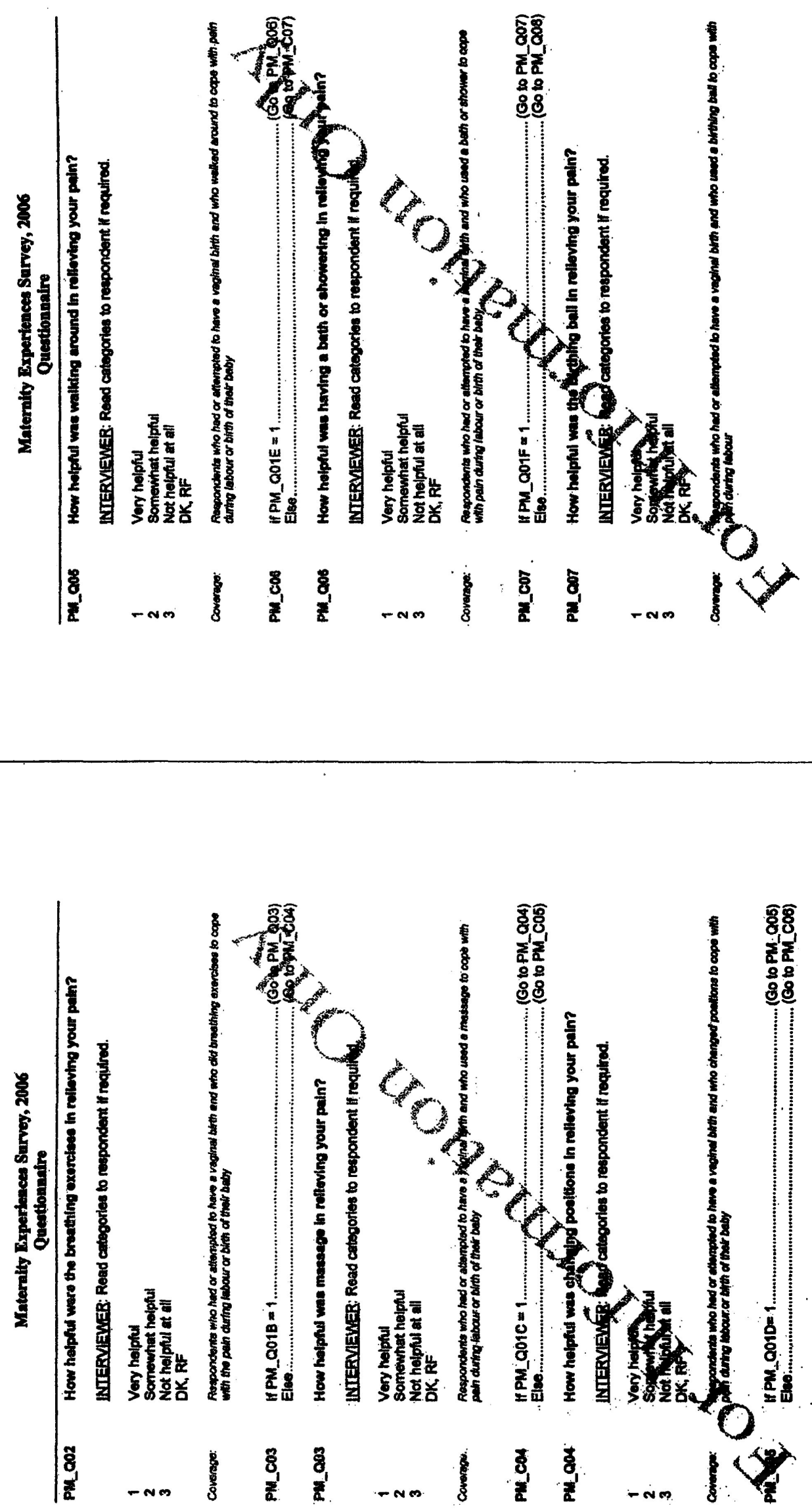

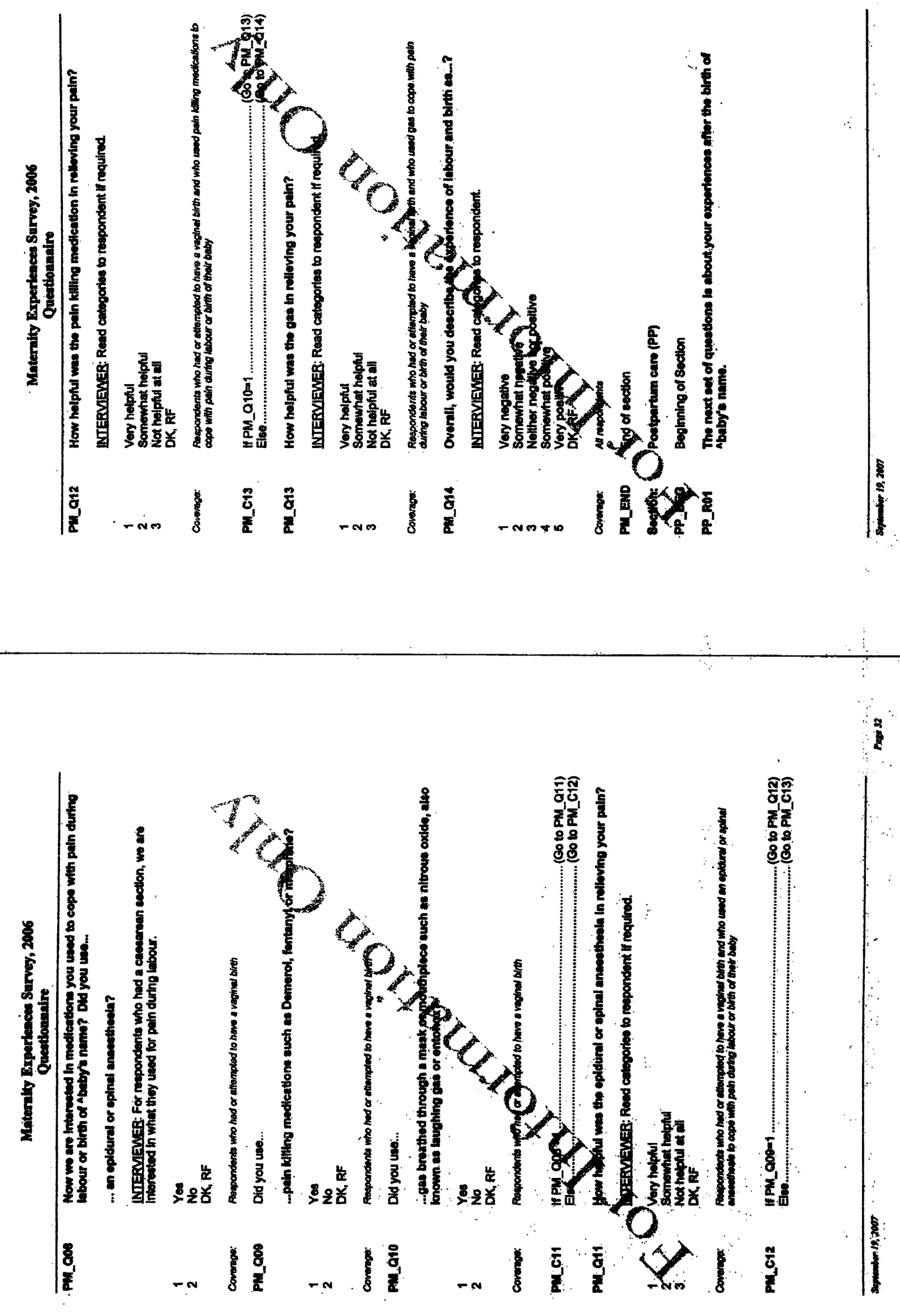

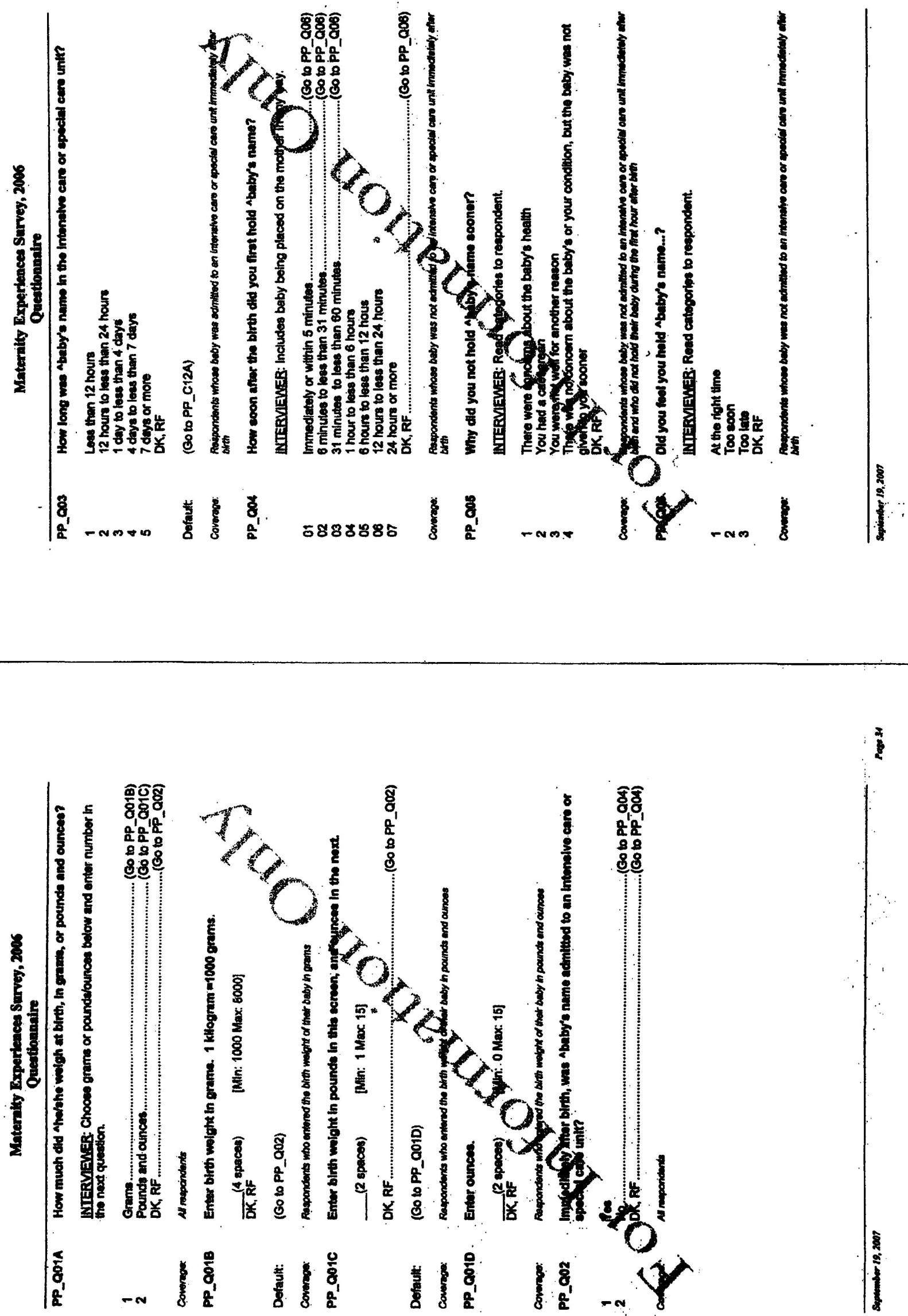

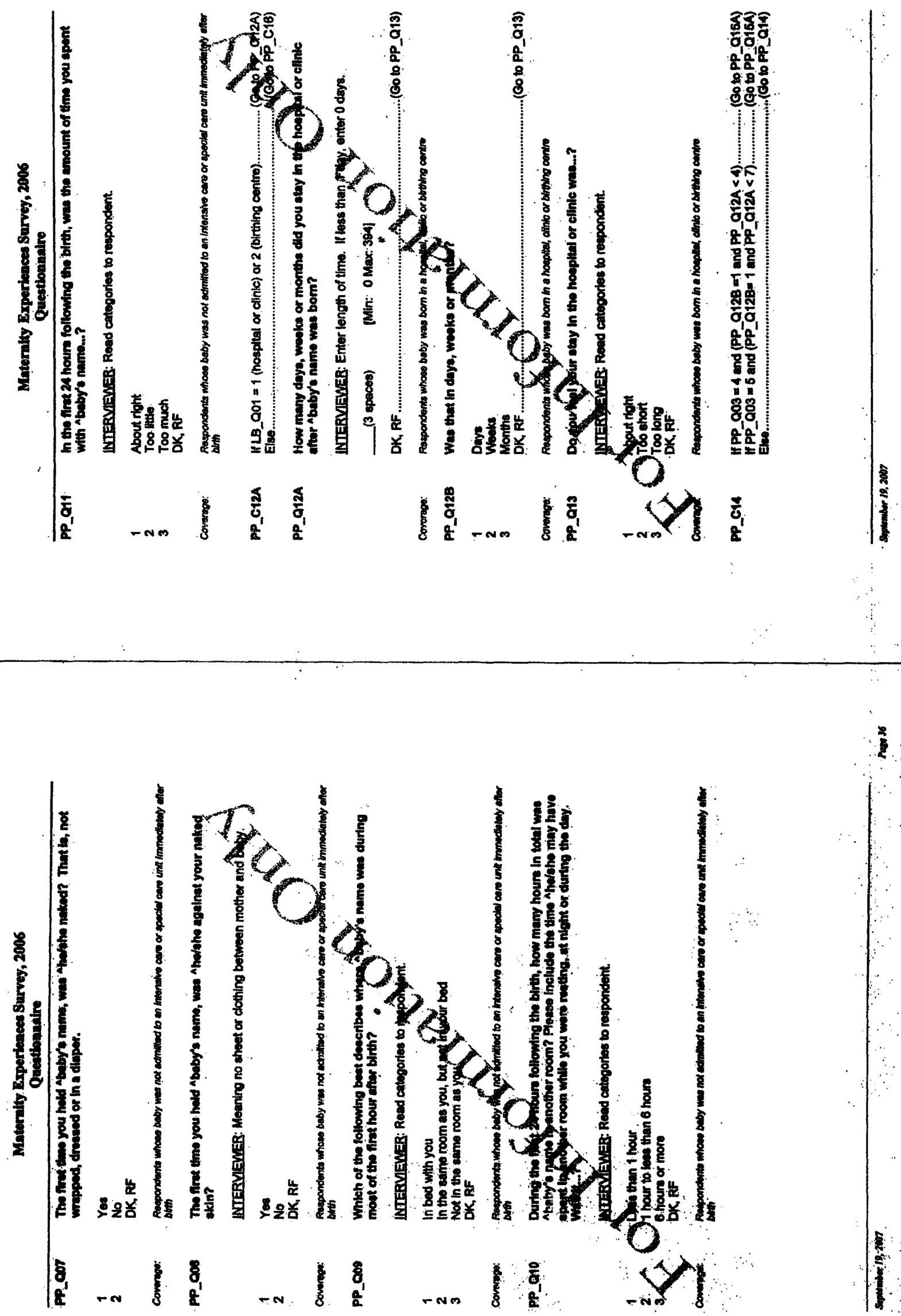

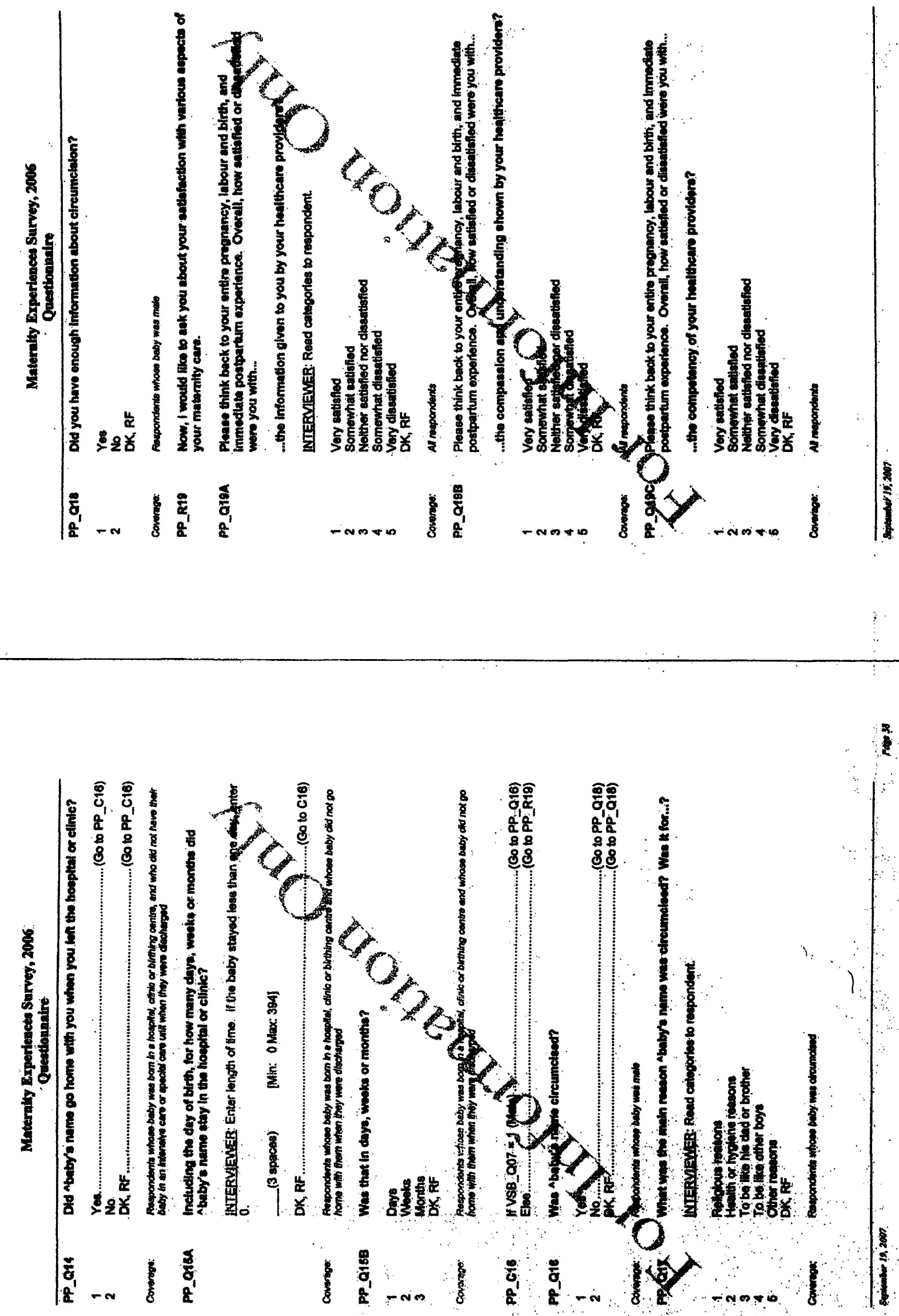

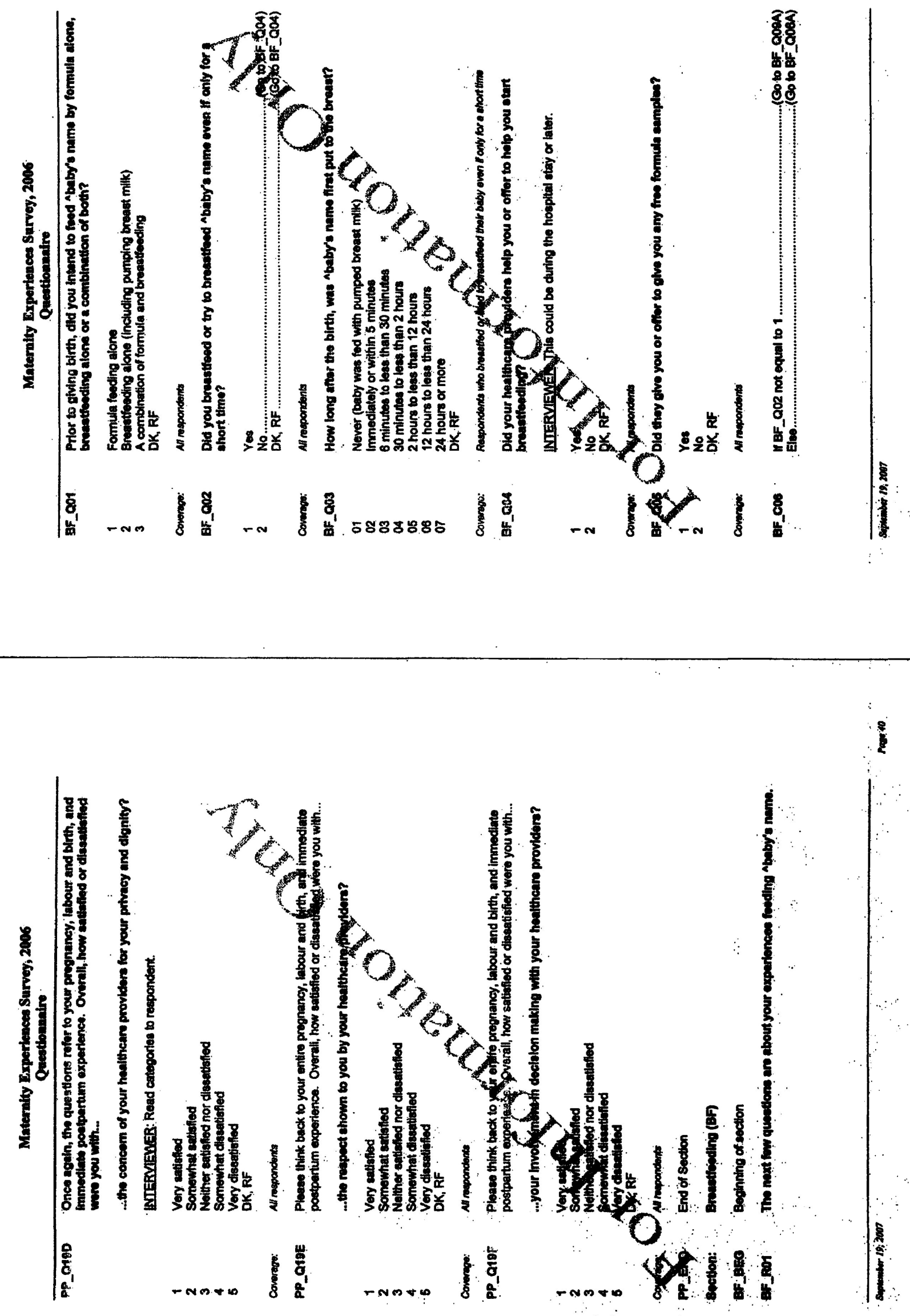

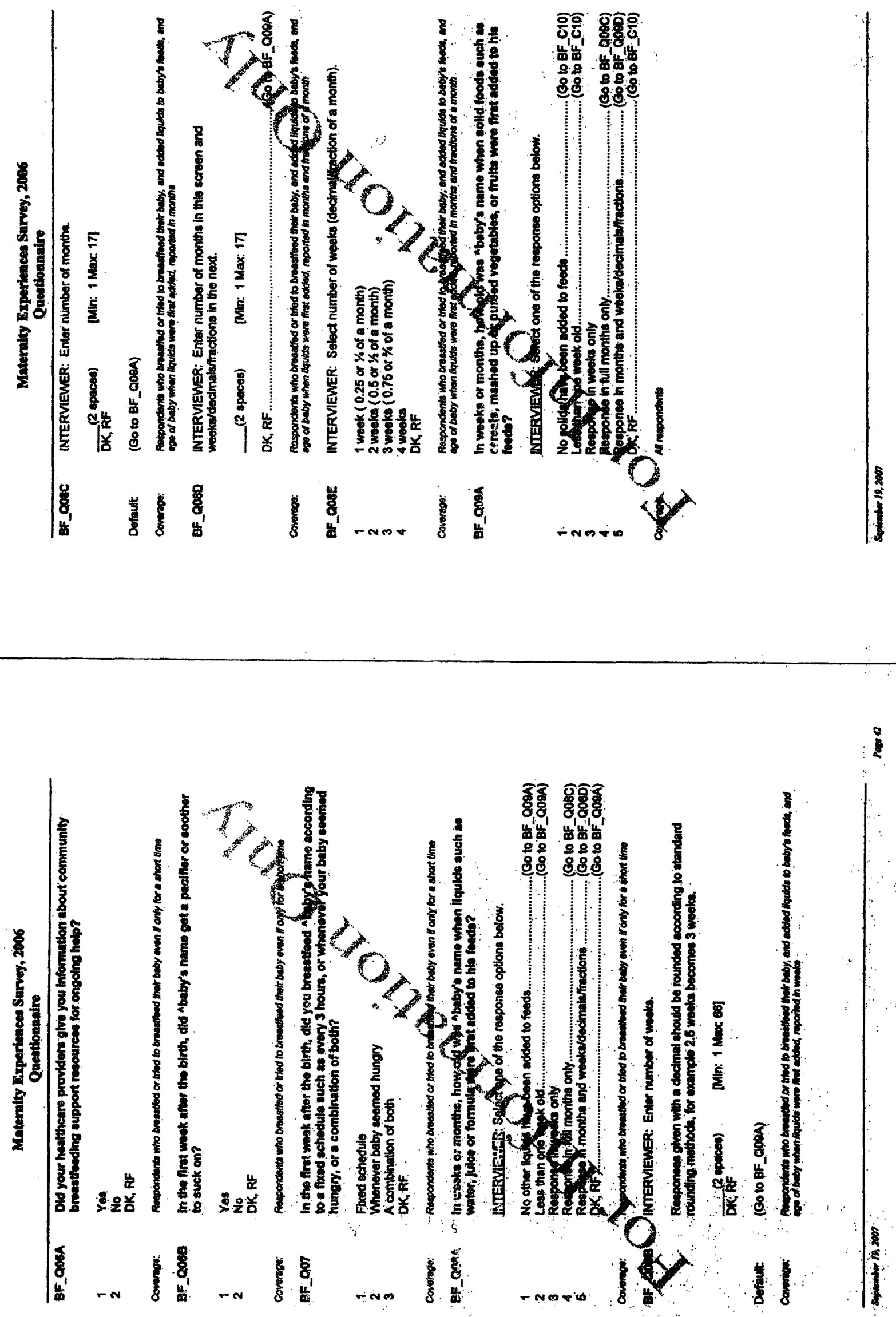

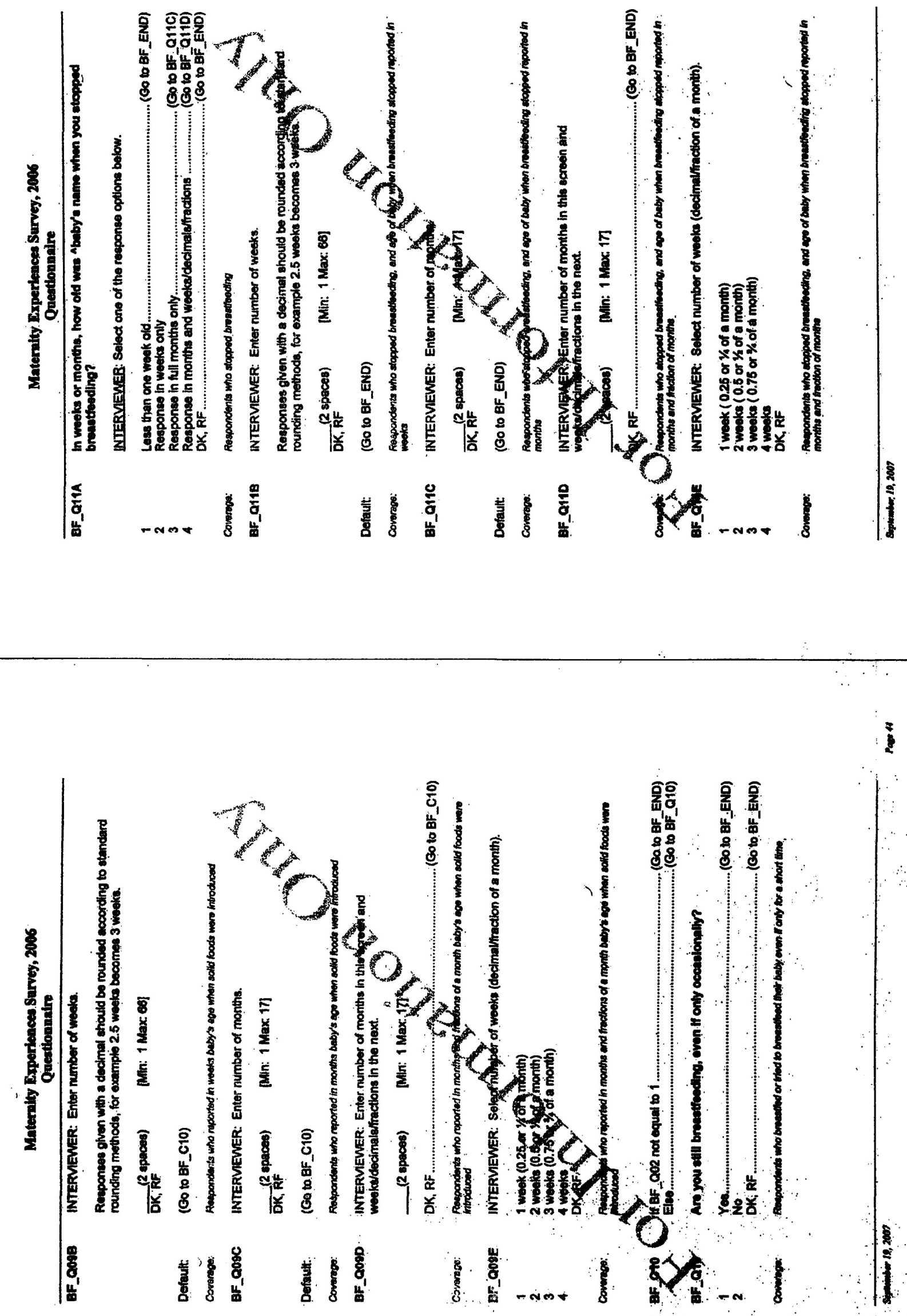

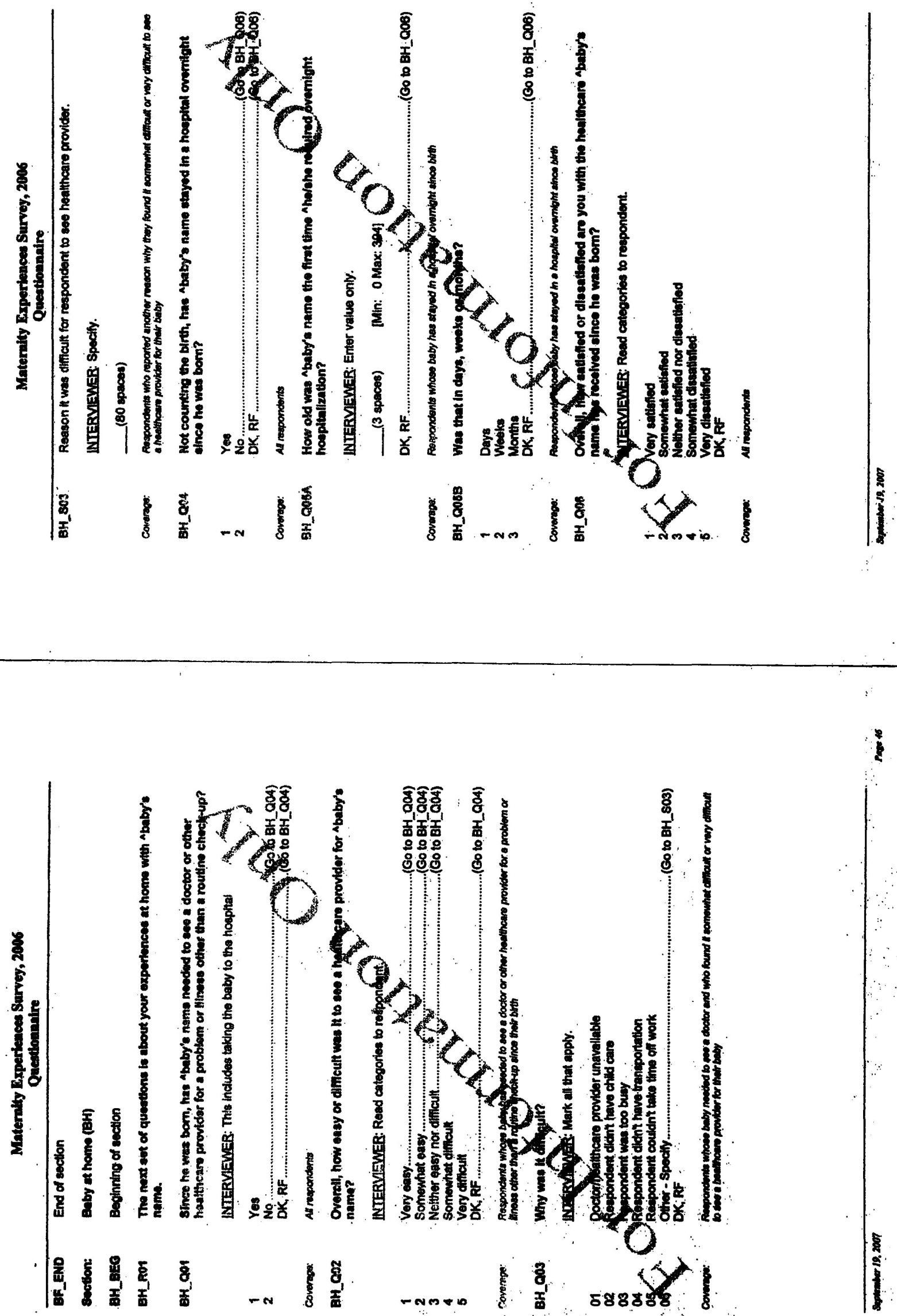

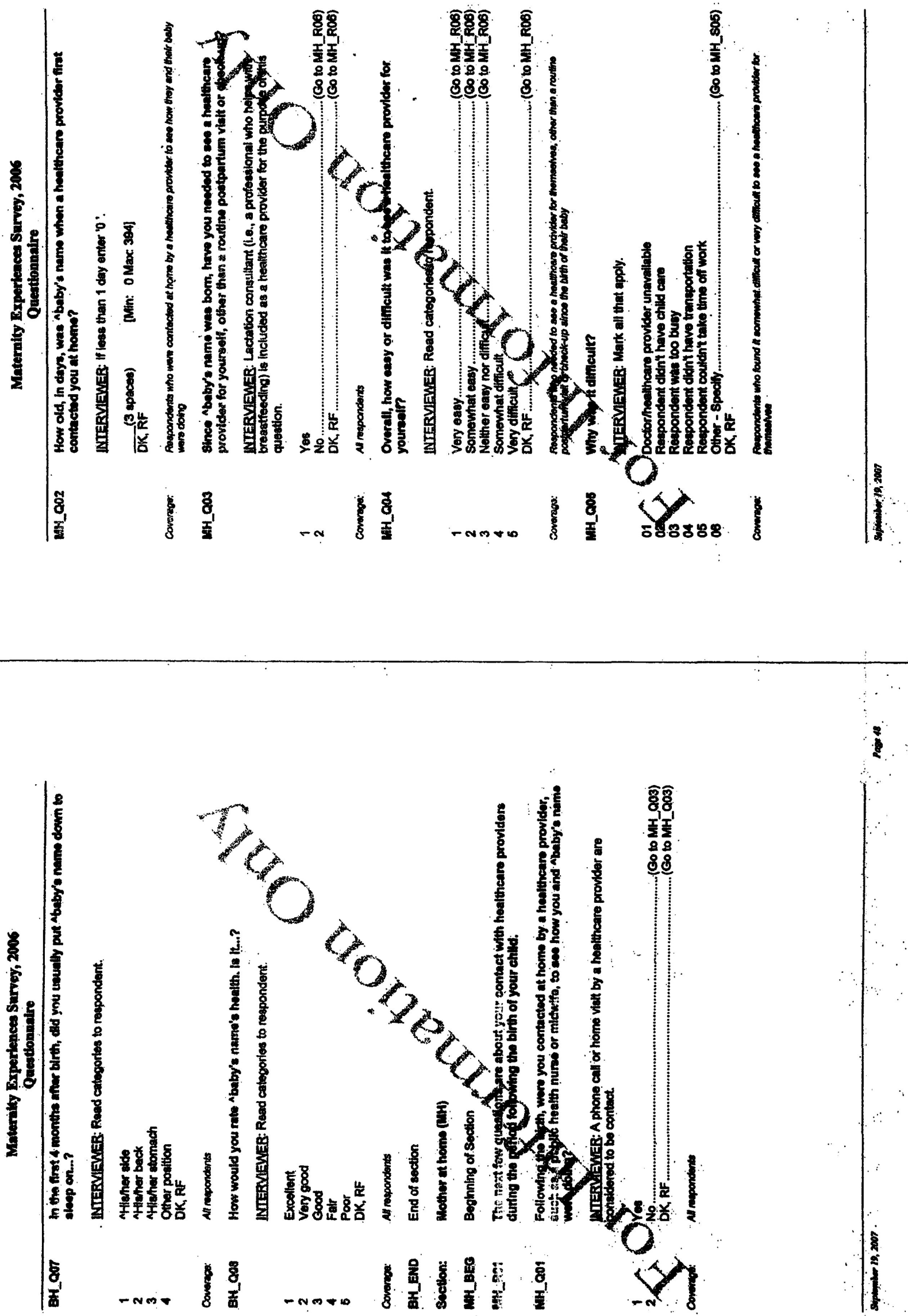


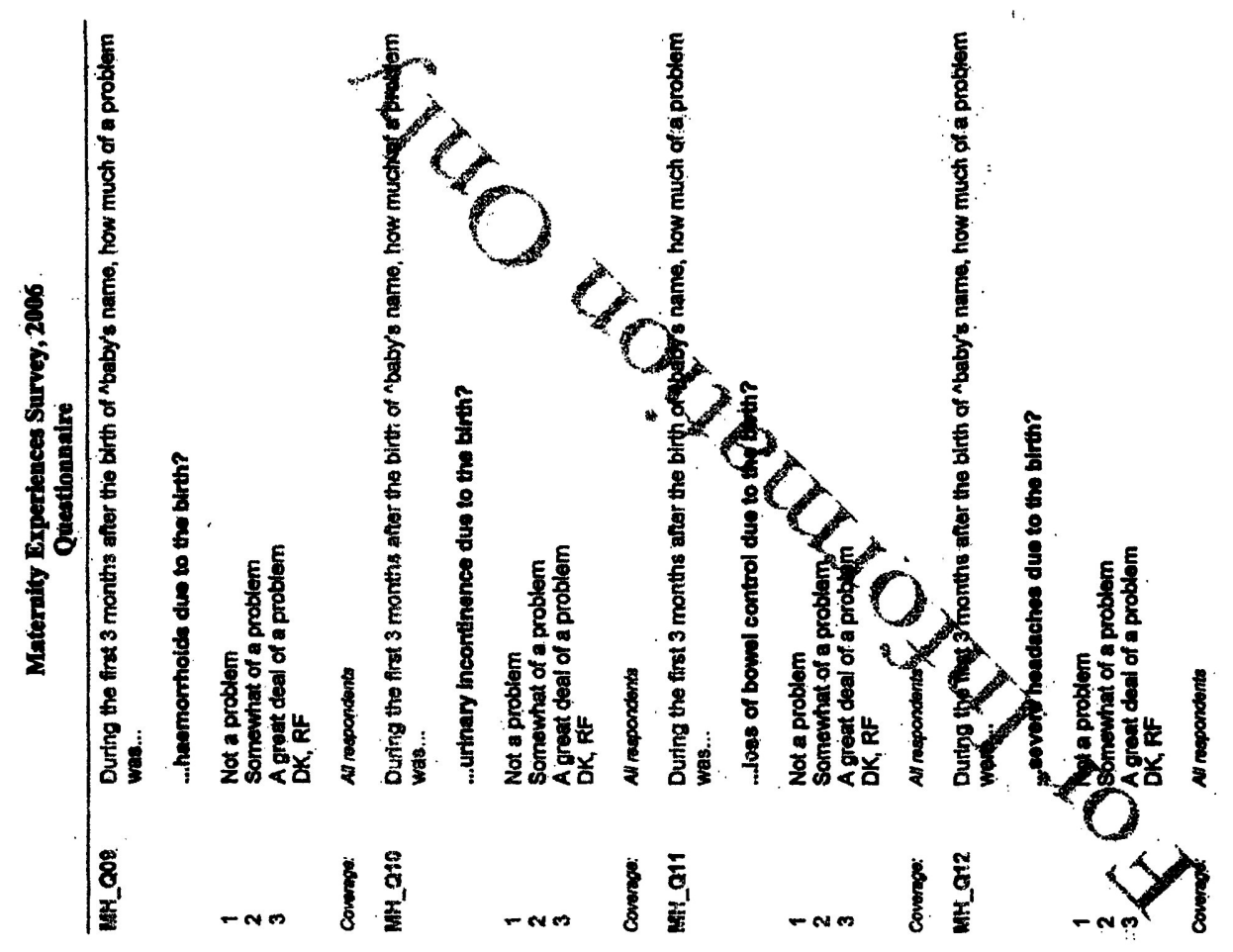

is

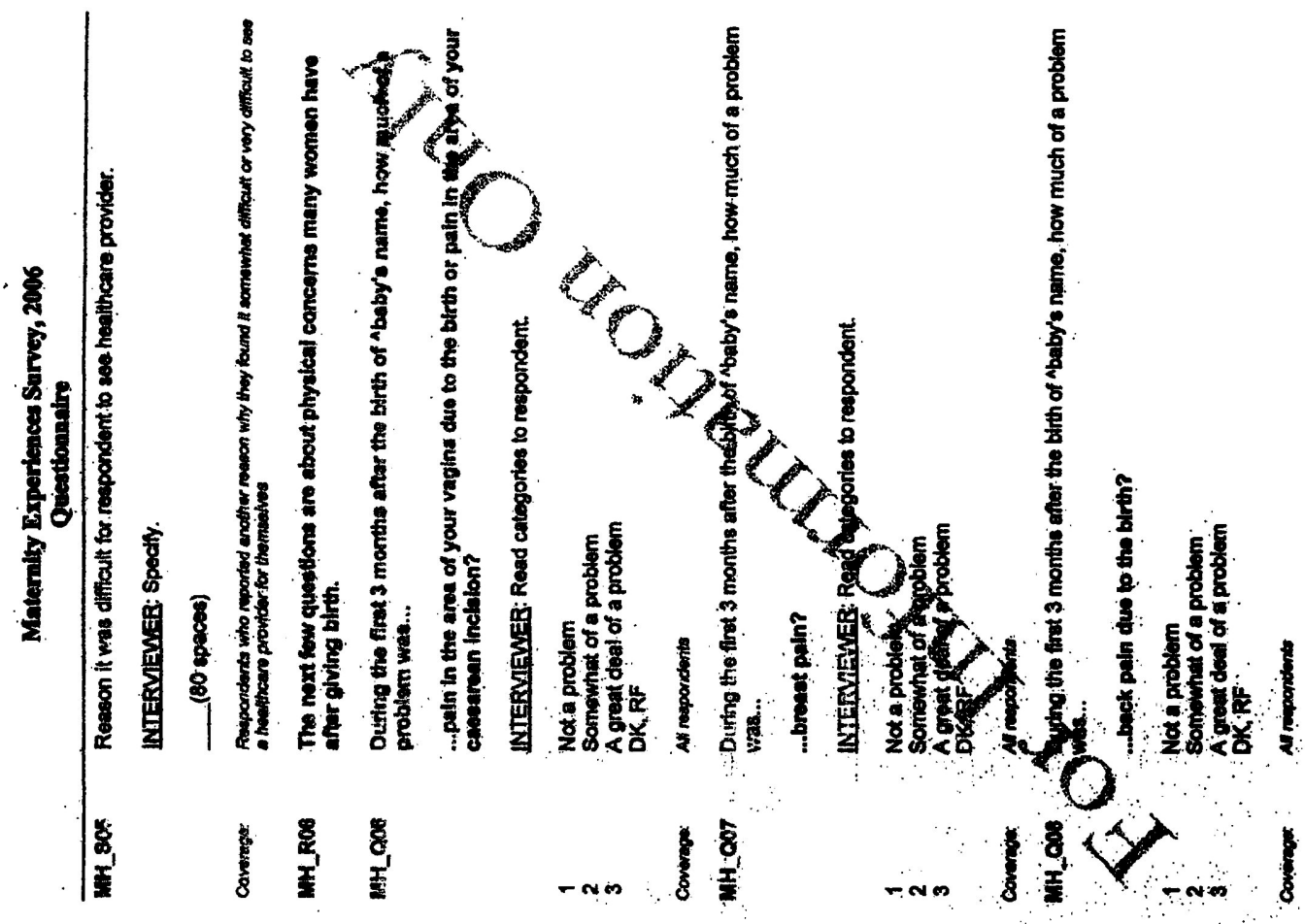




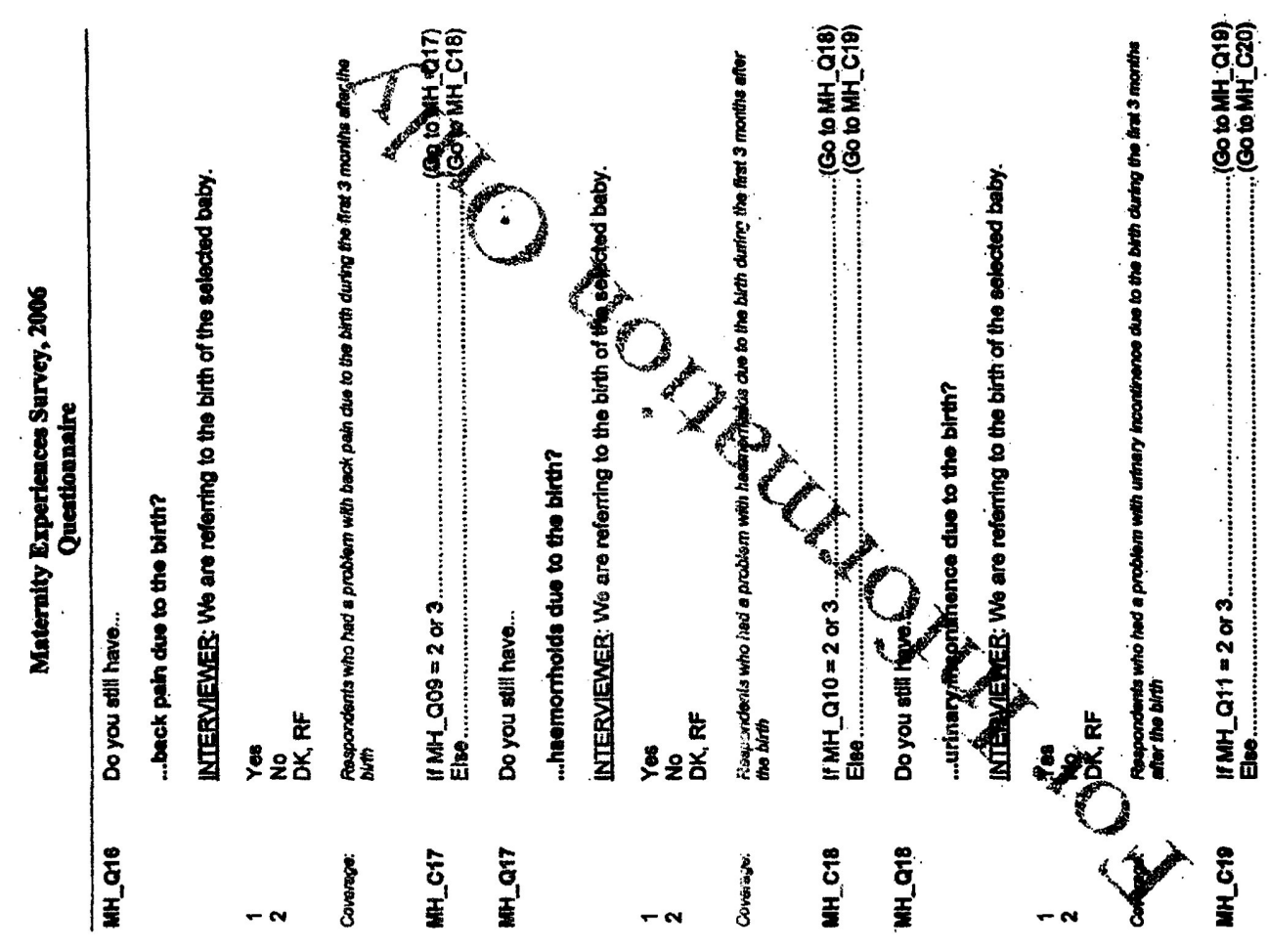

管

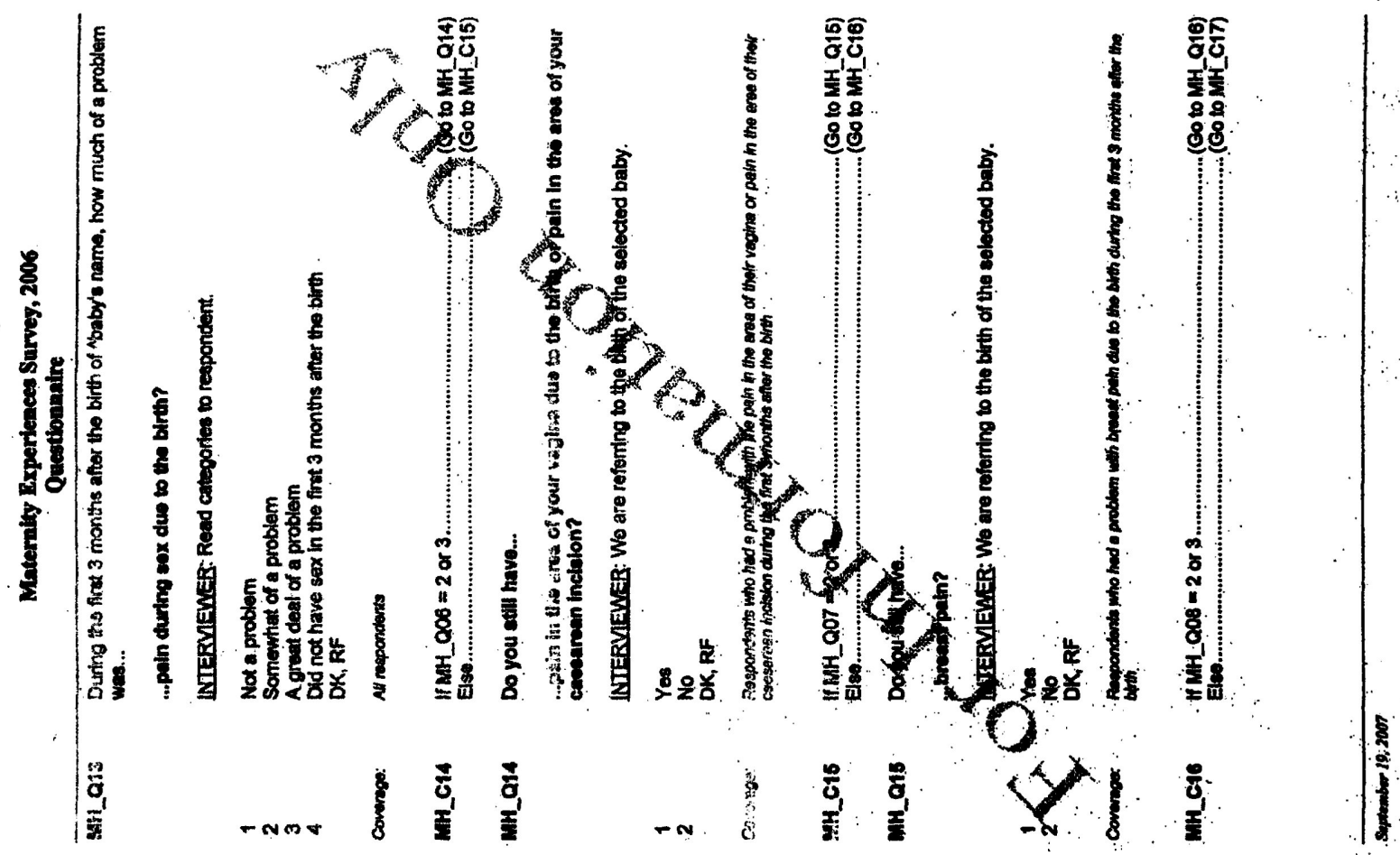



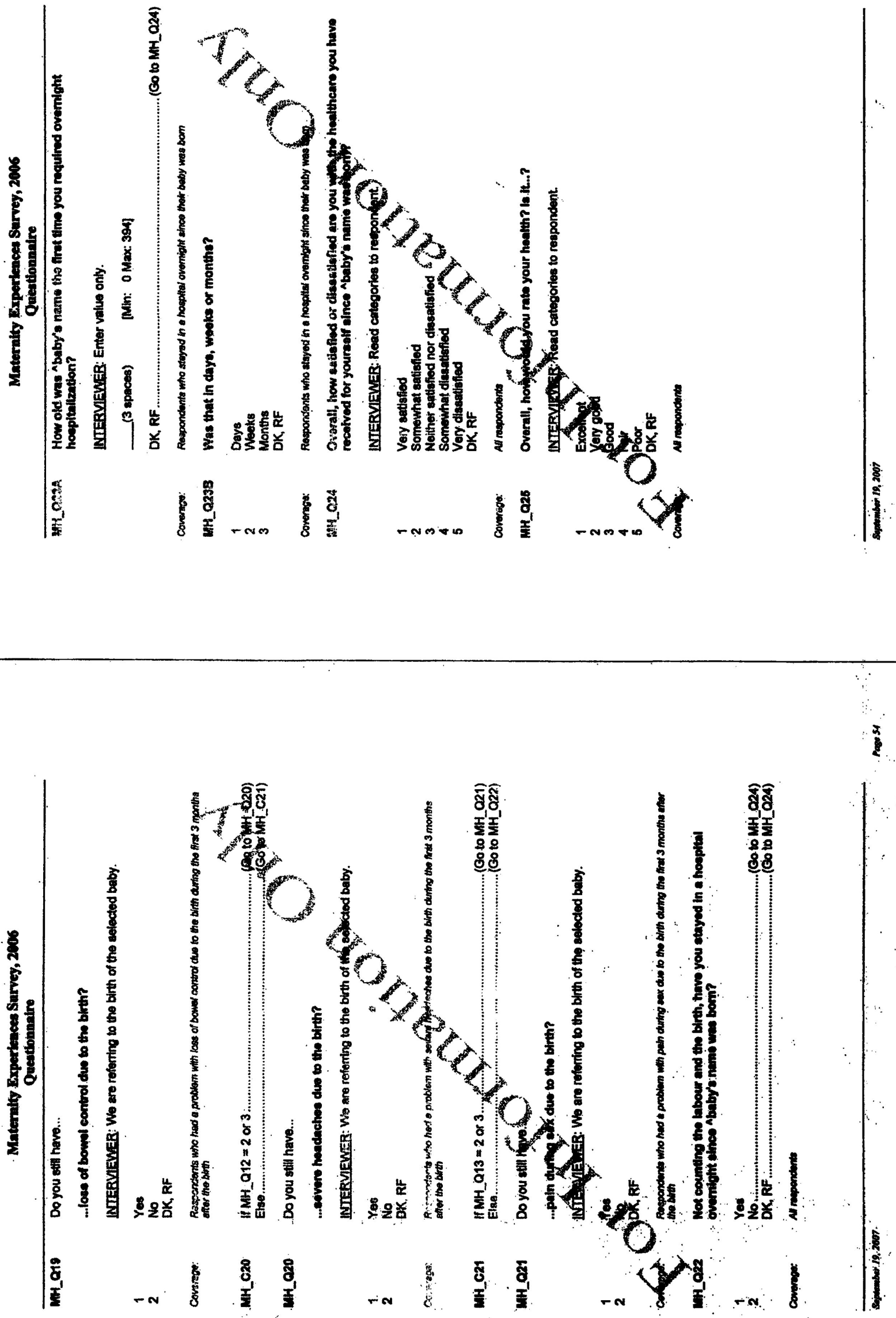

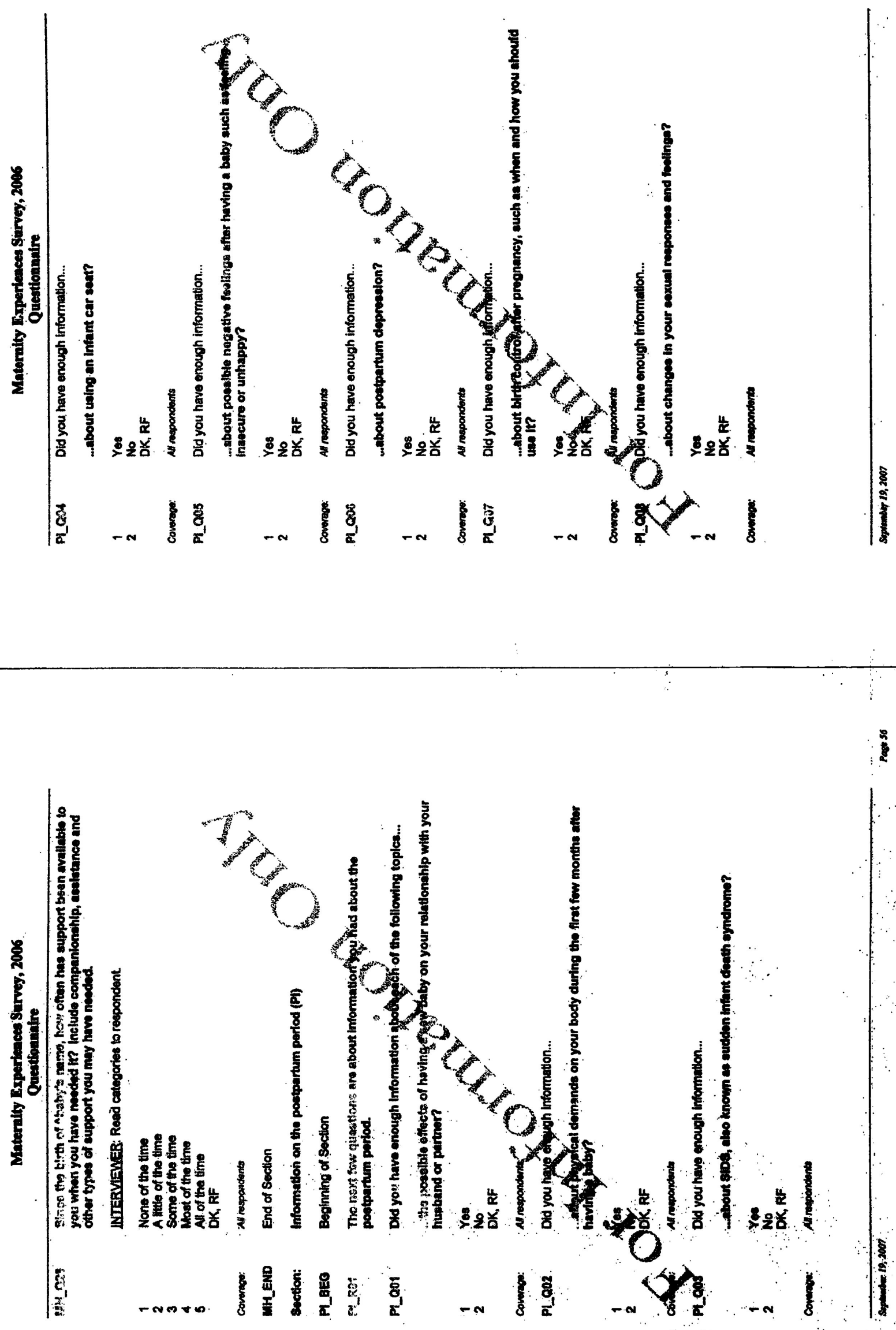

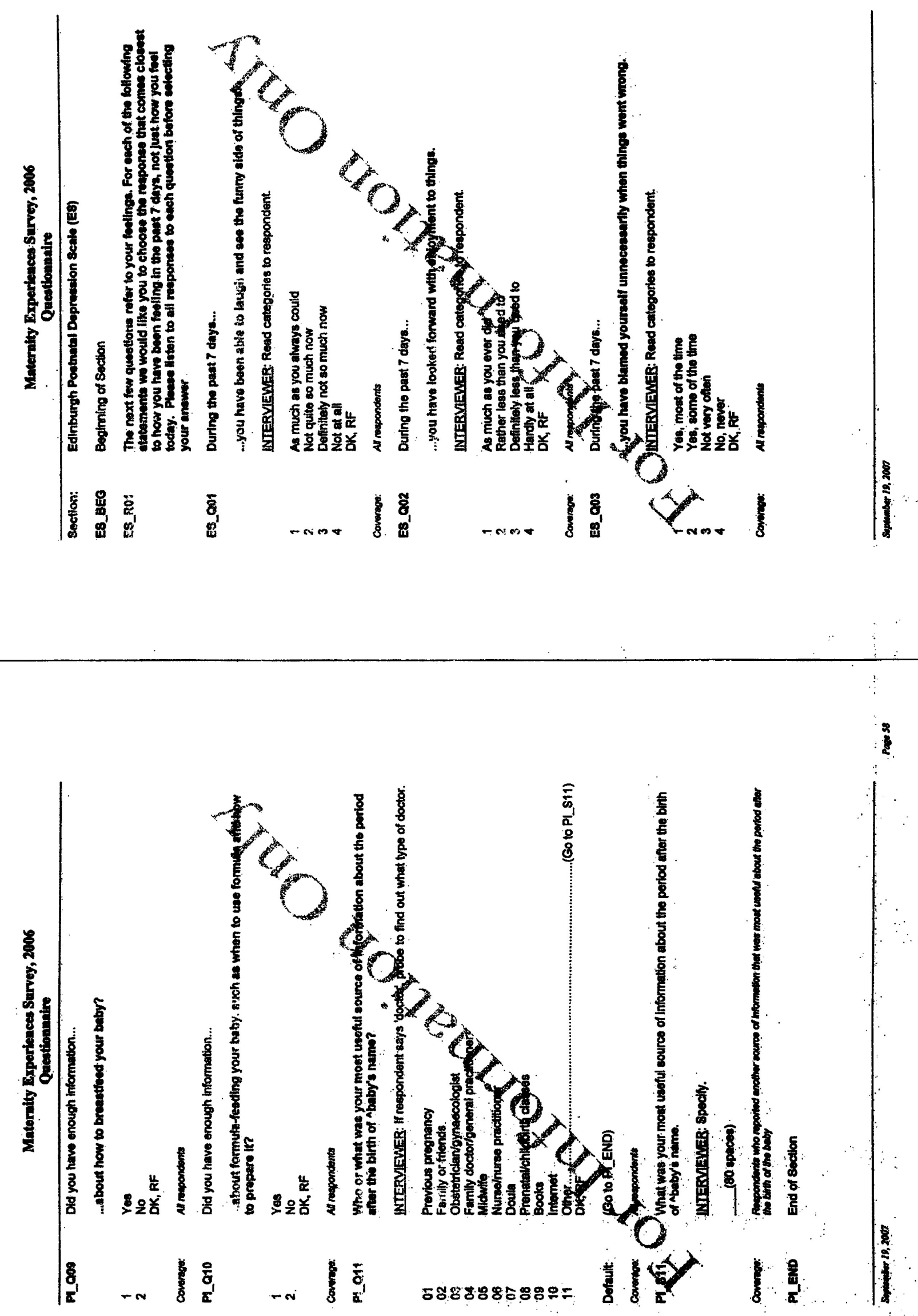

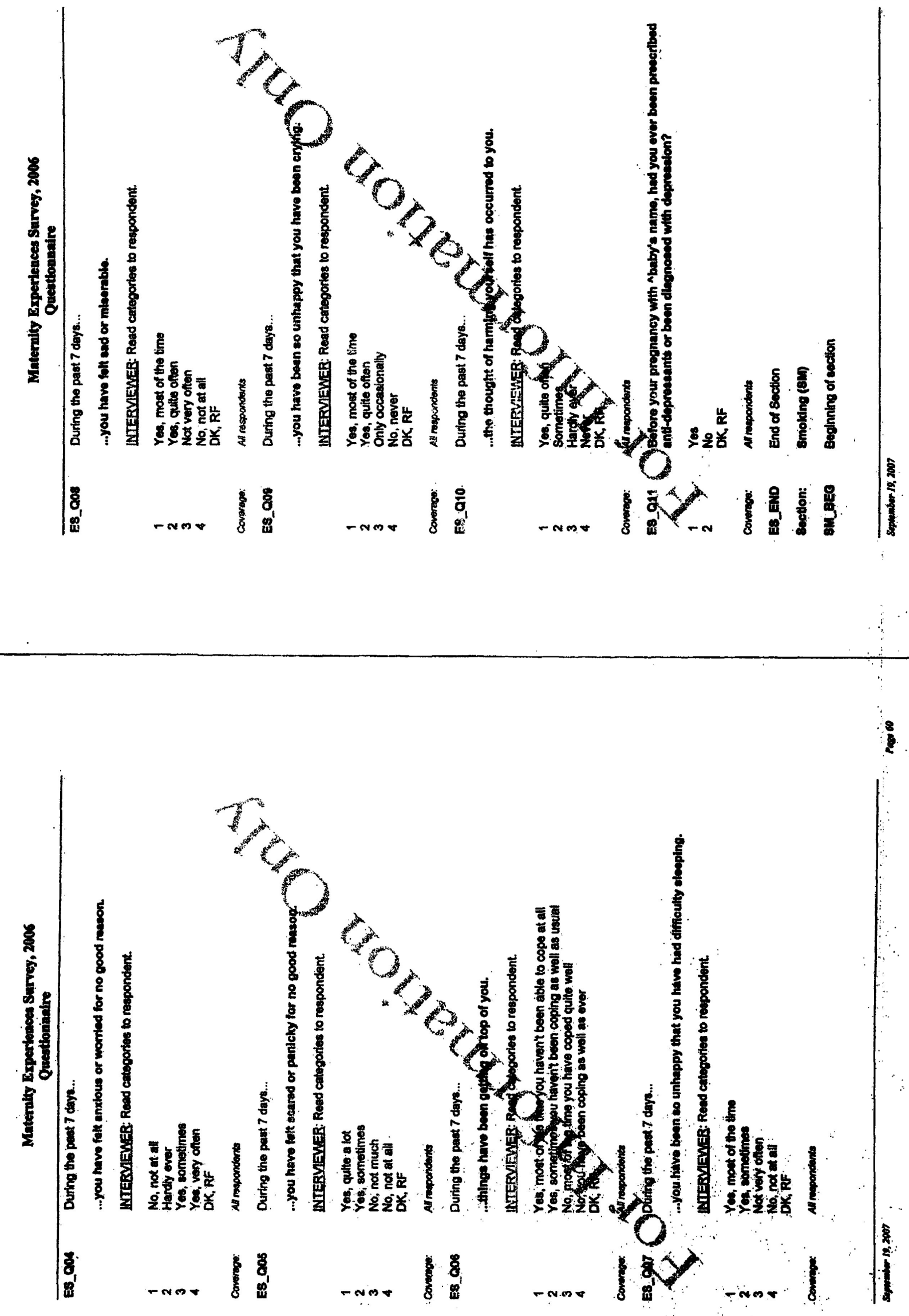

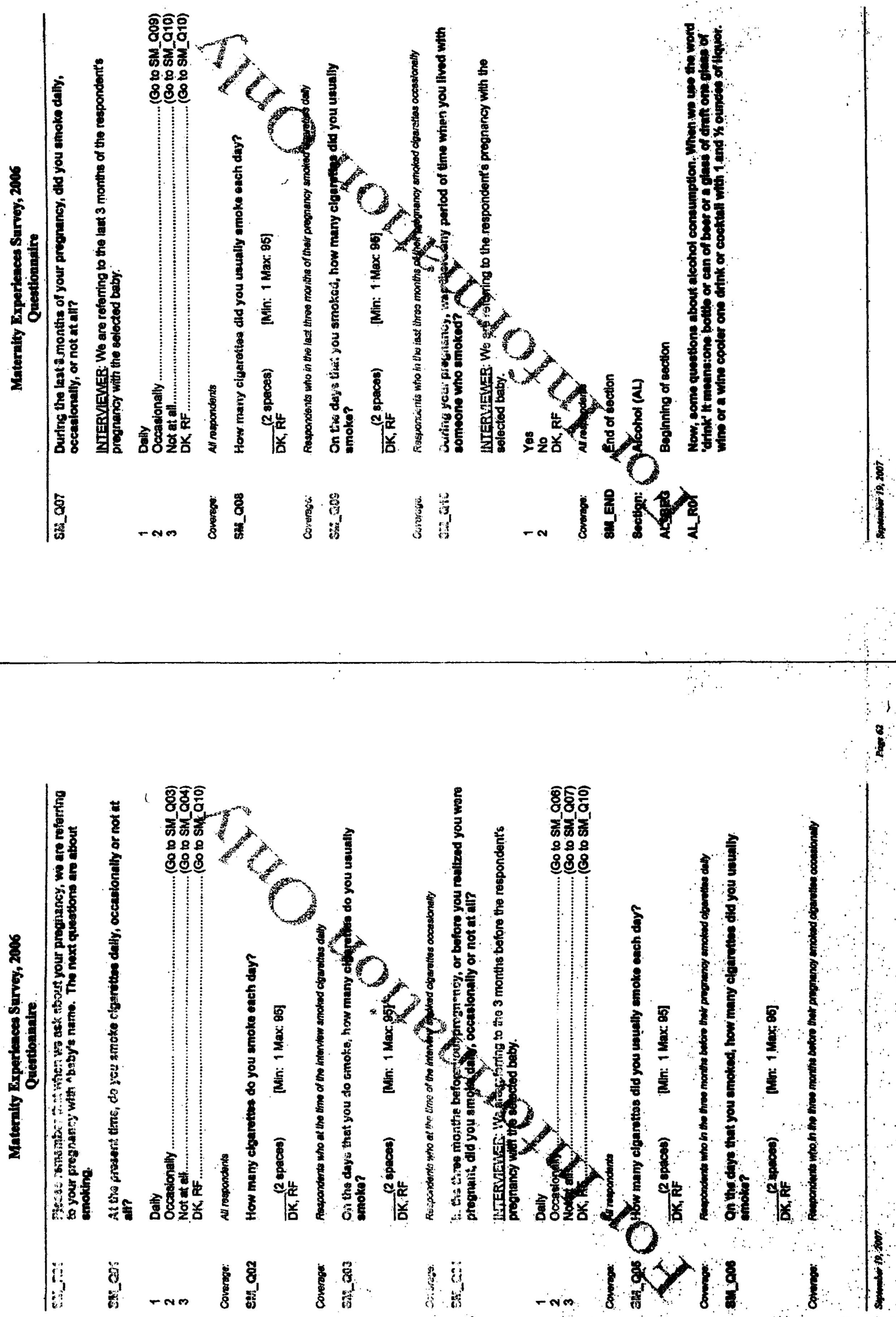

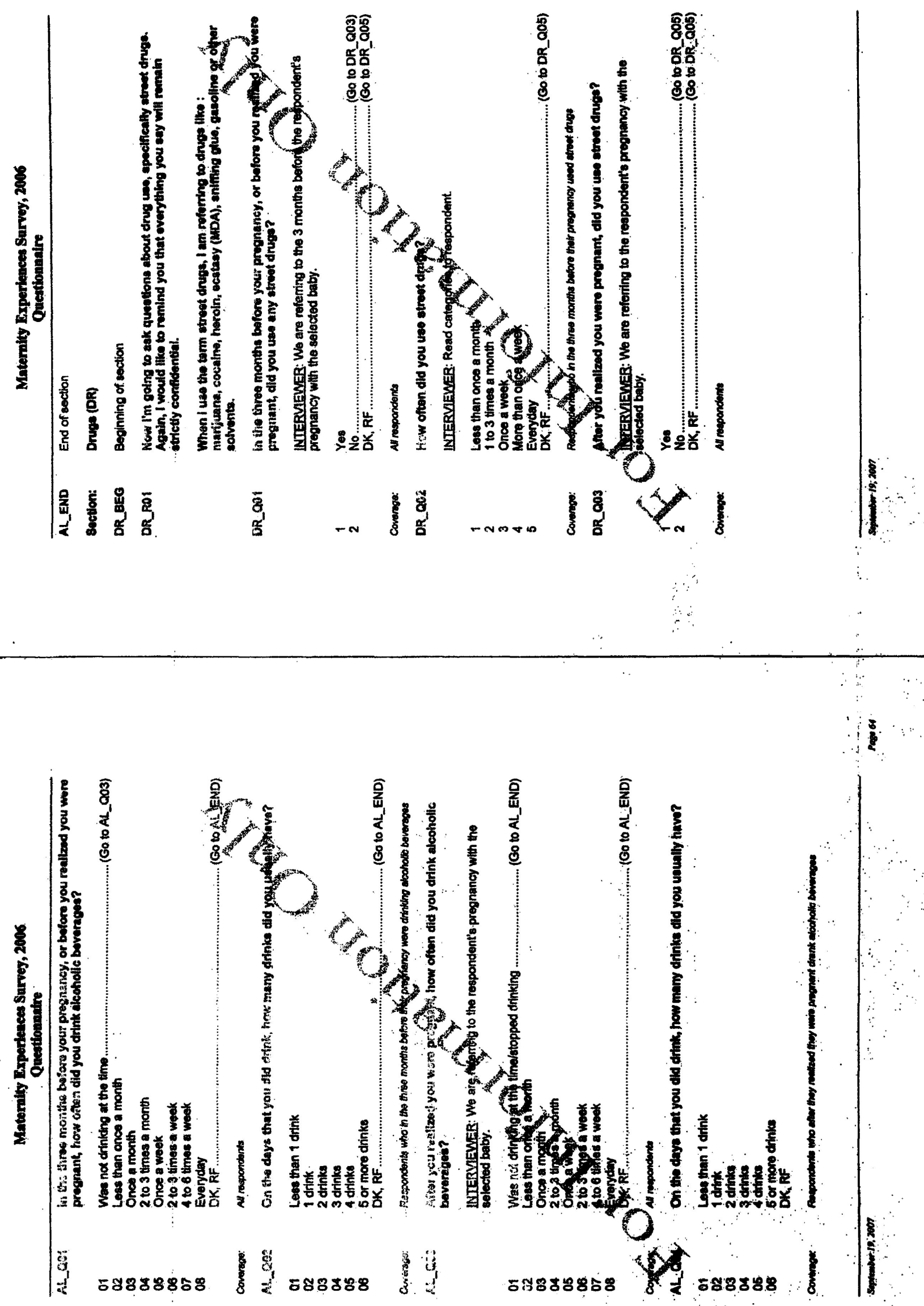

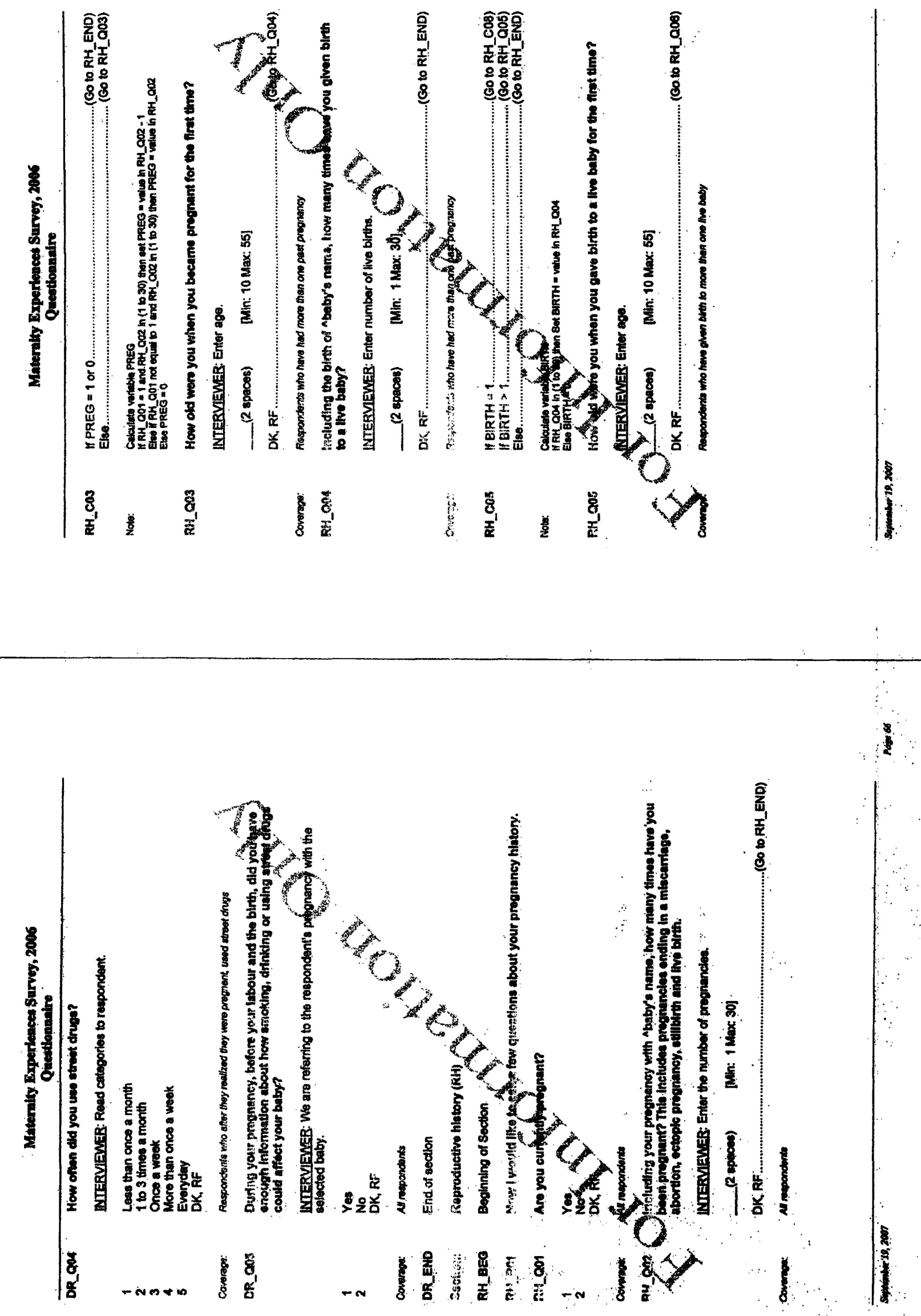


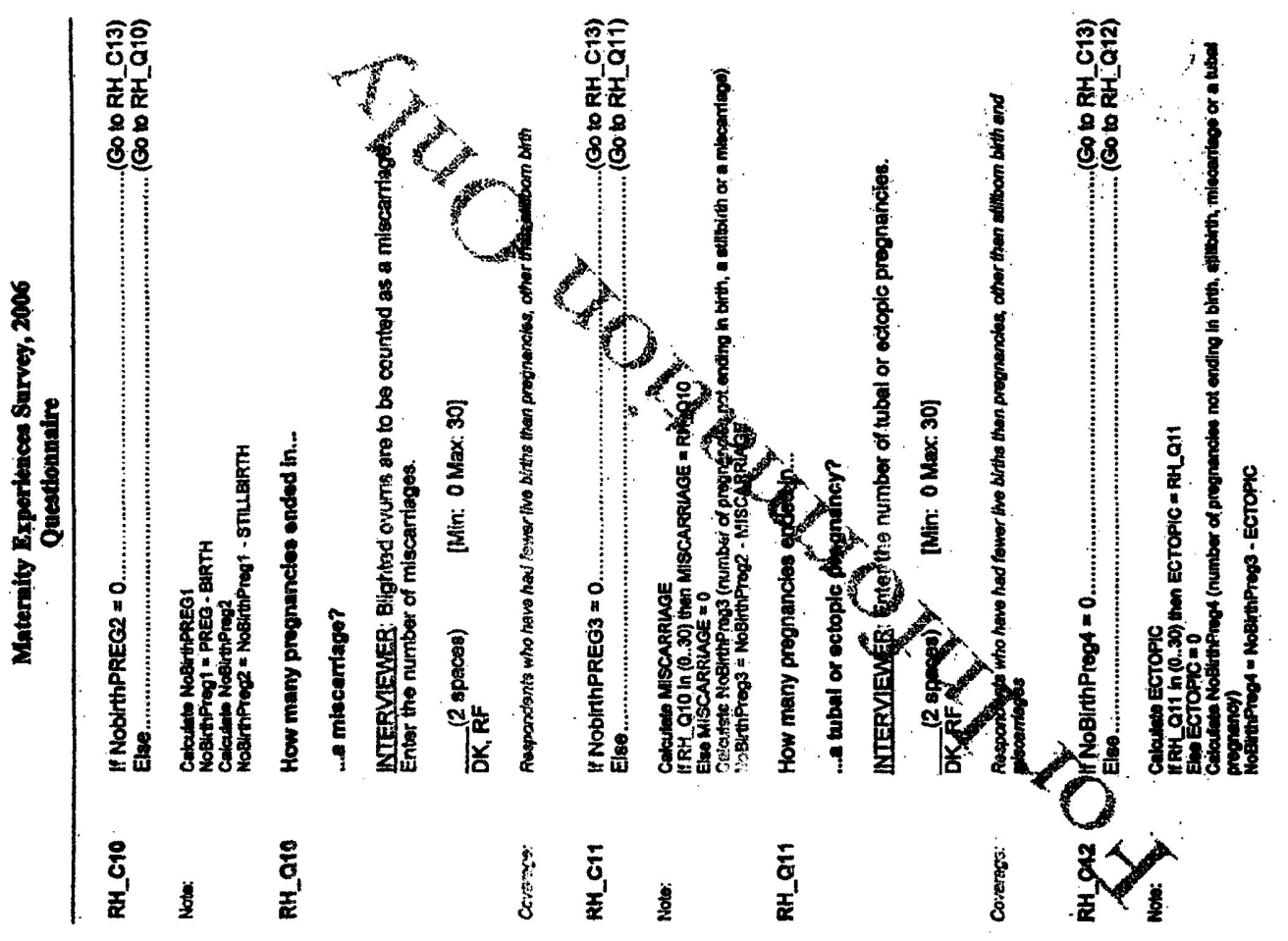

i

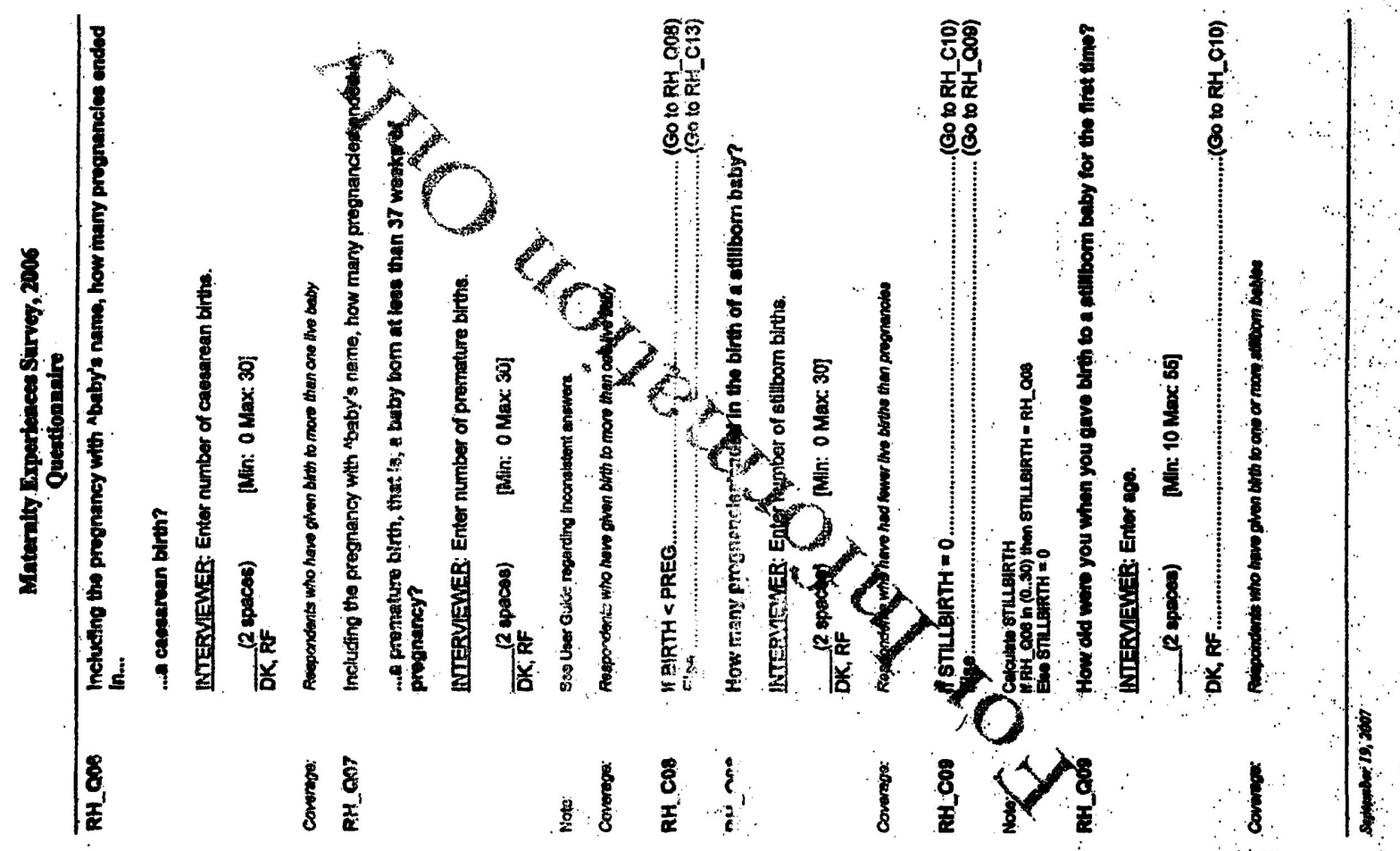



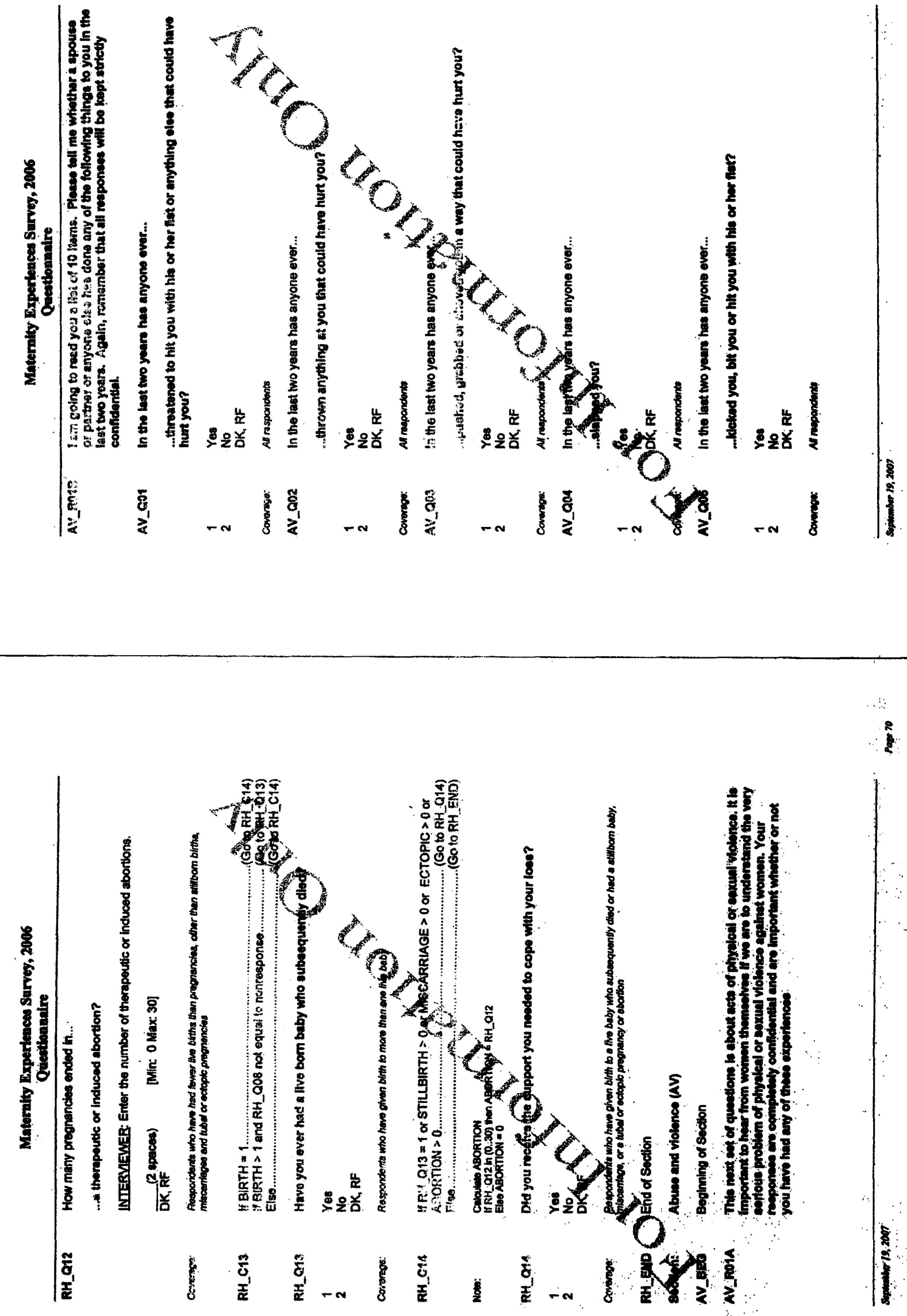

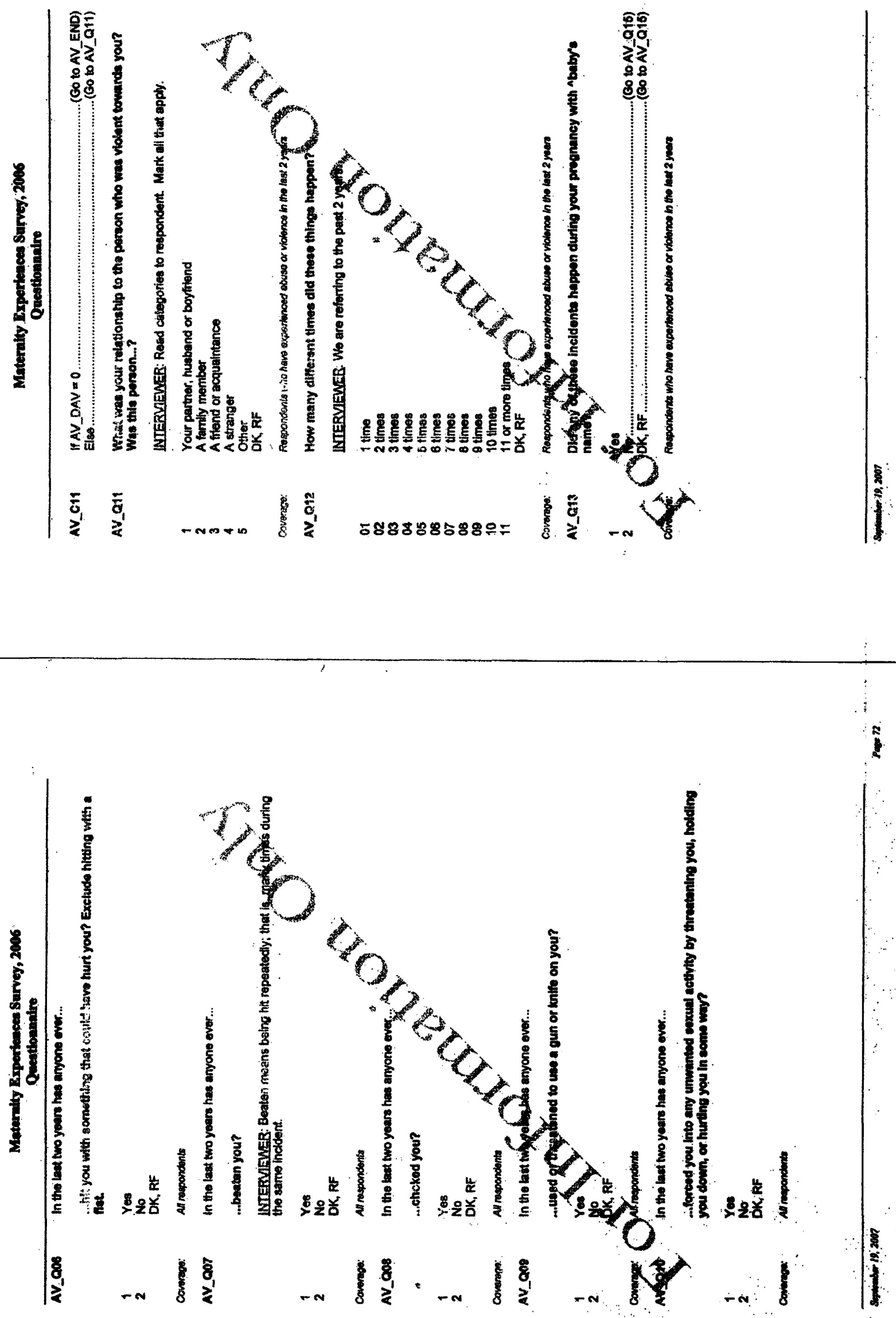


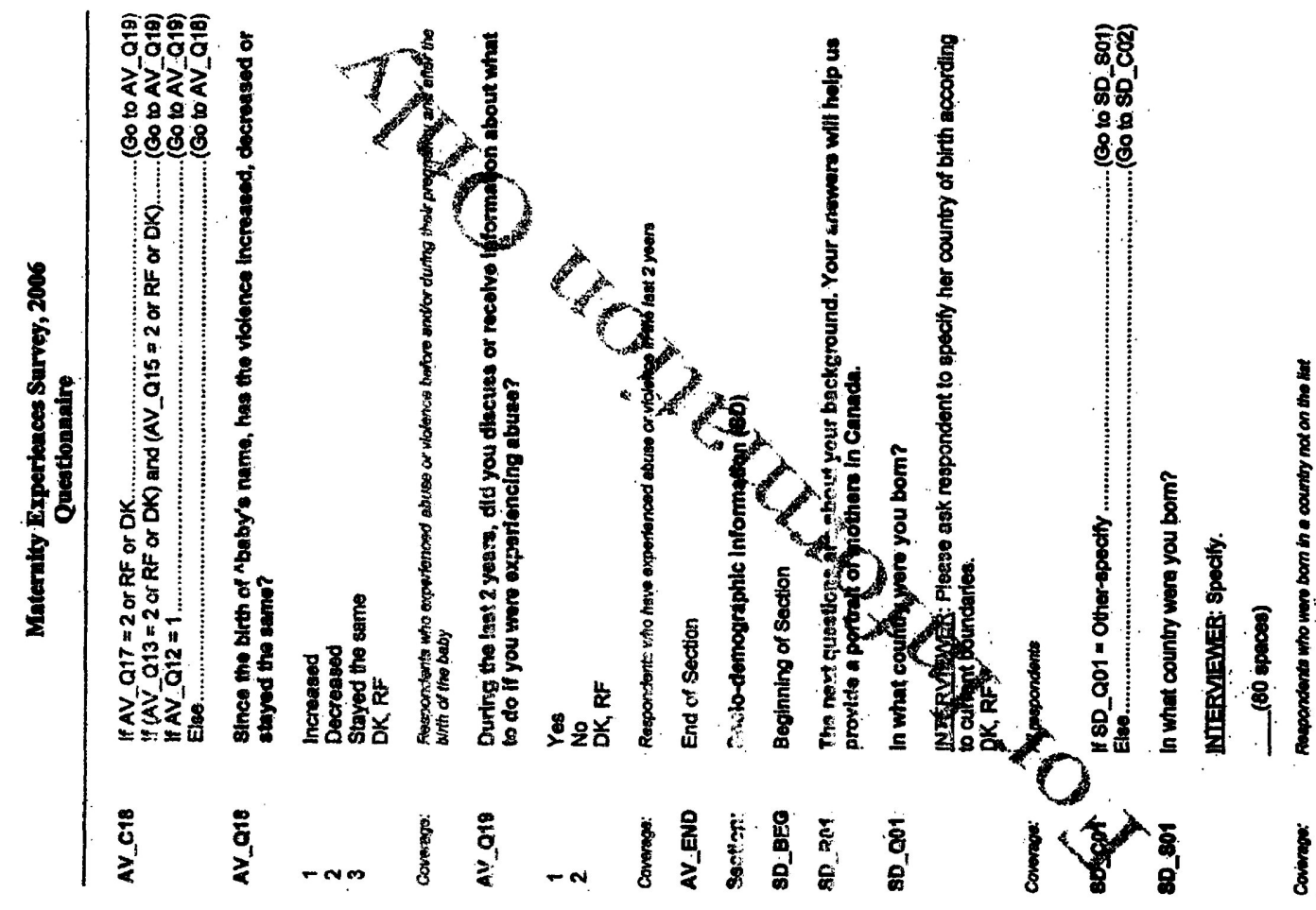

s

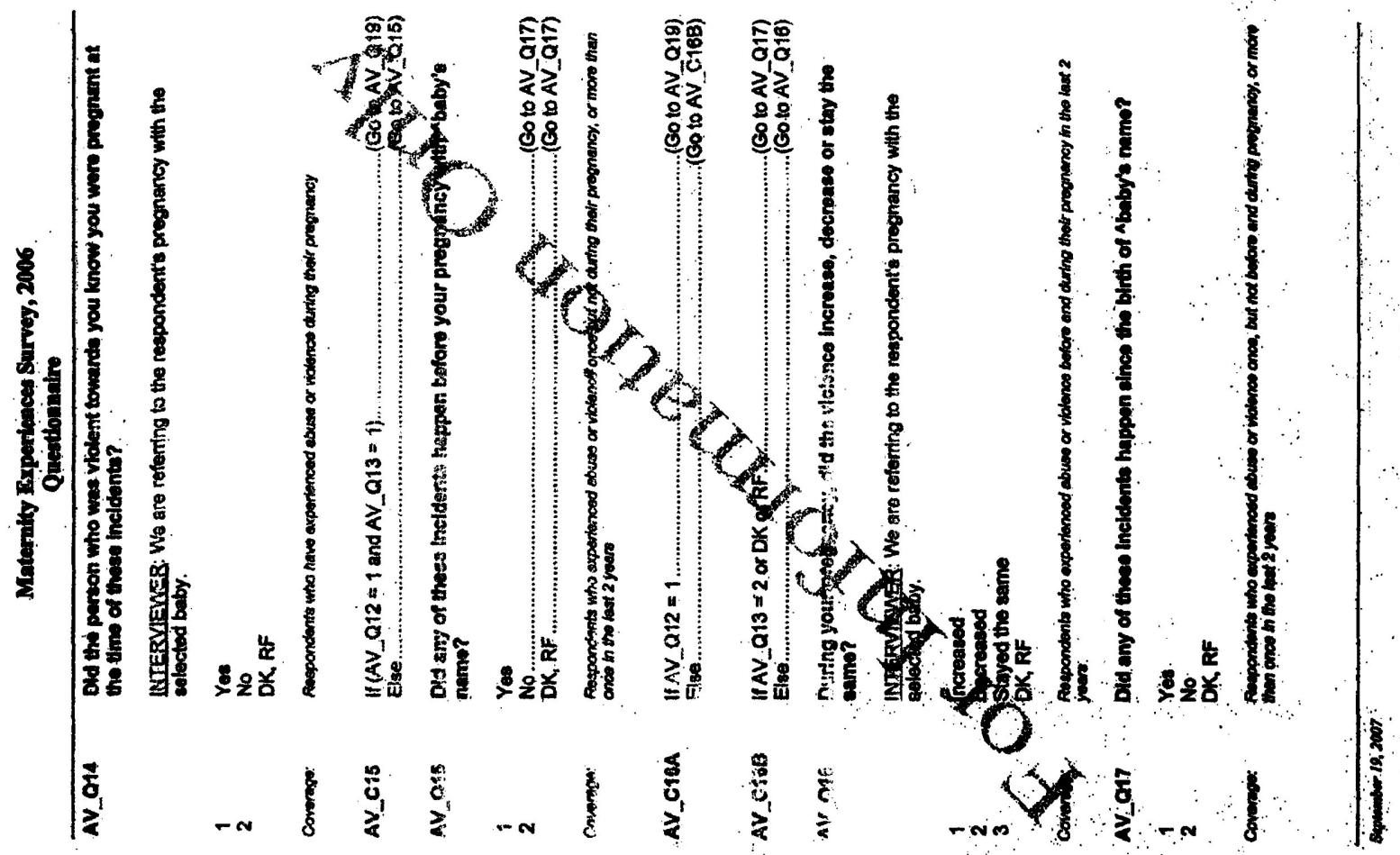



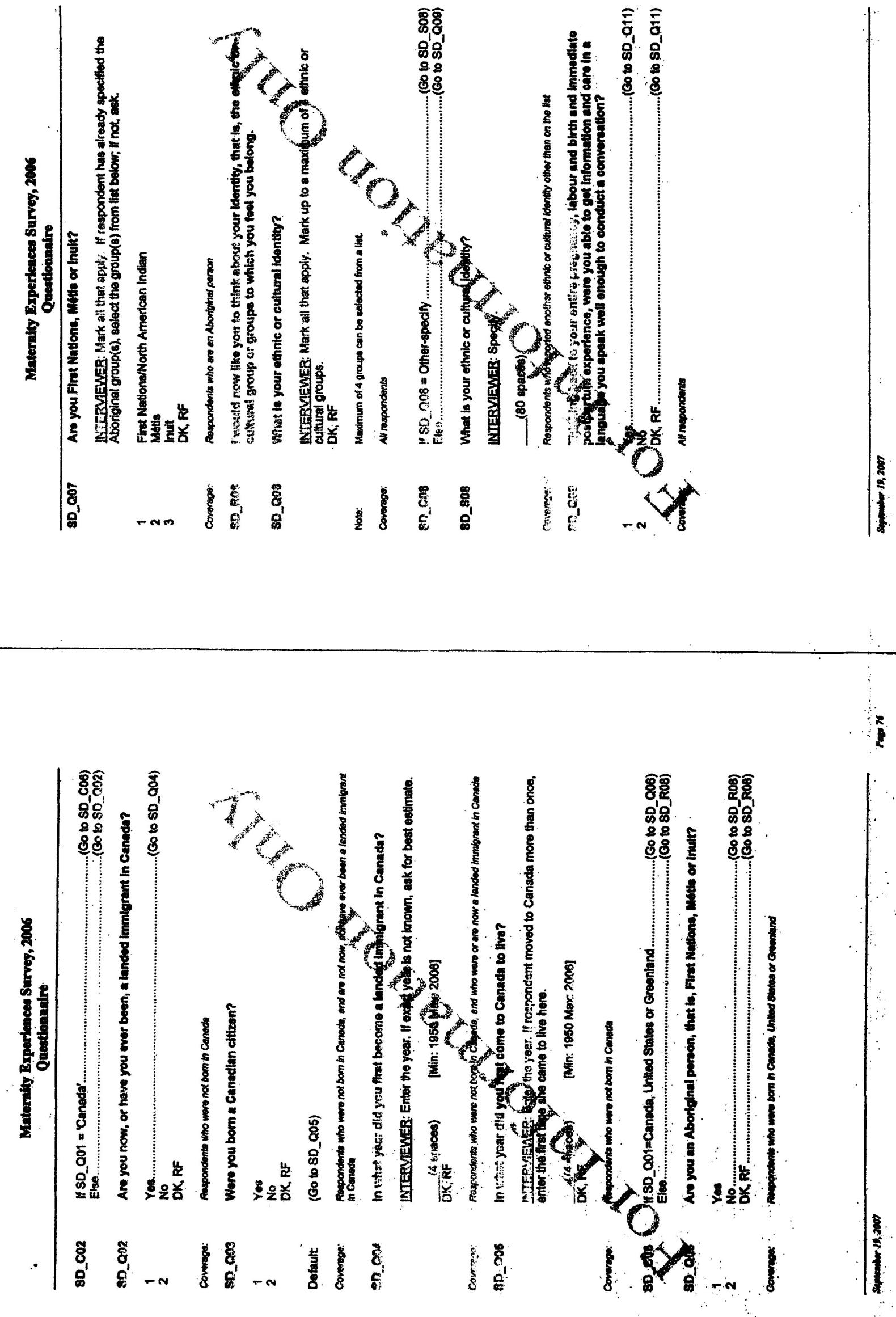

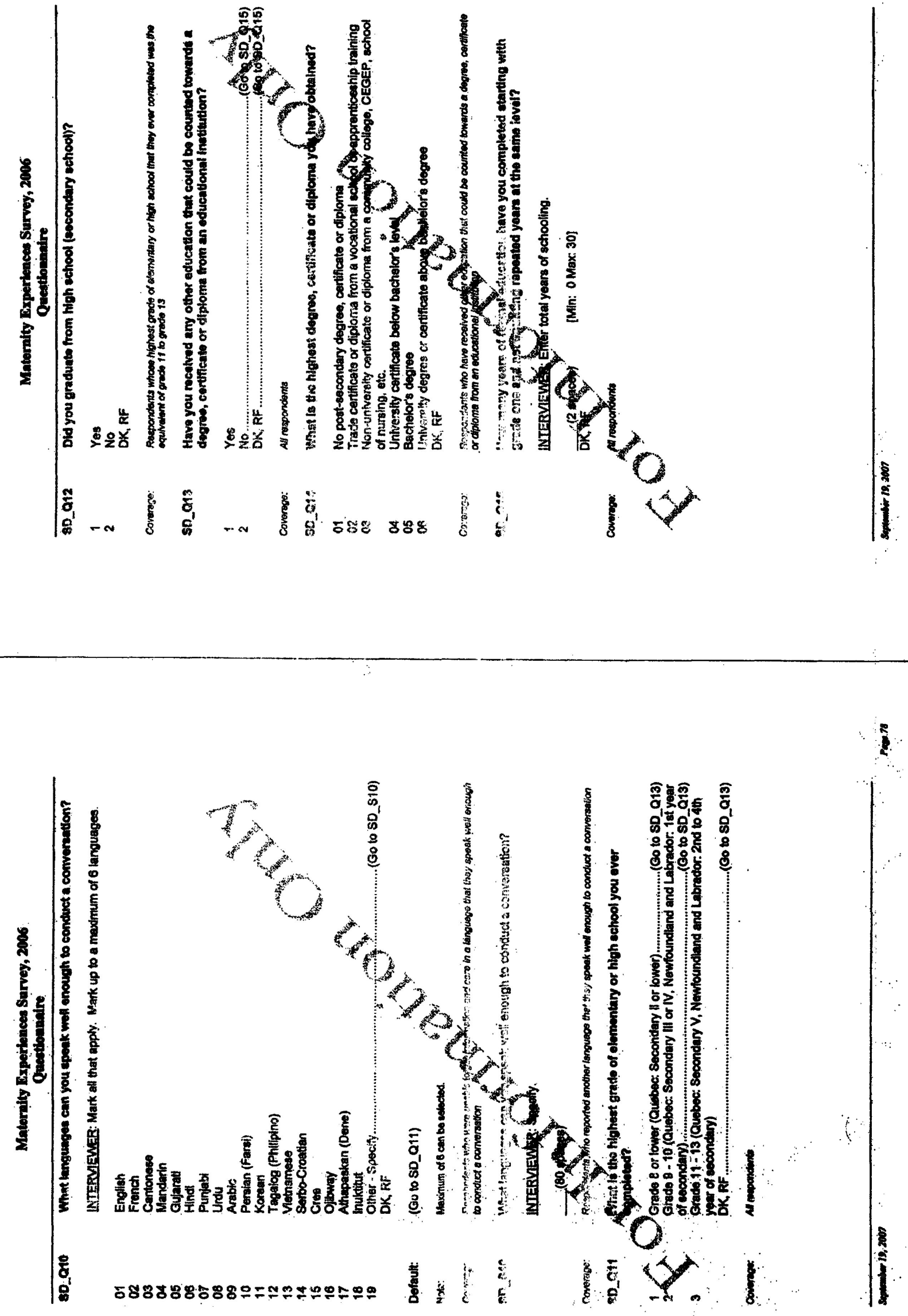

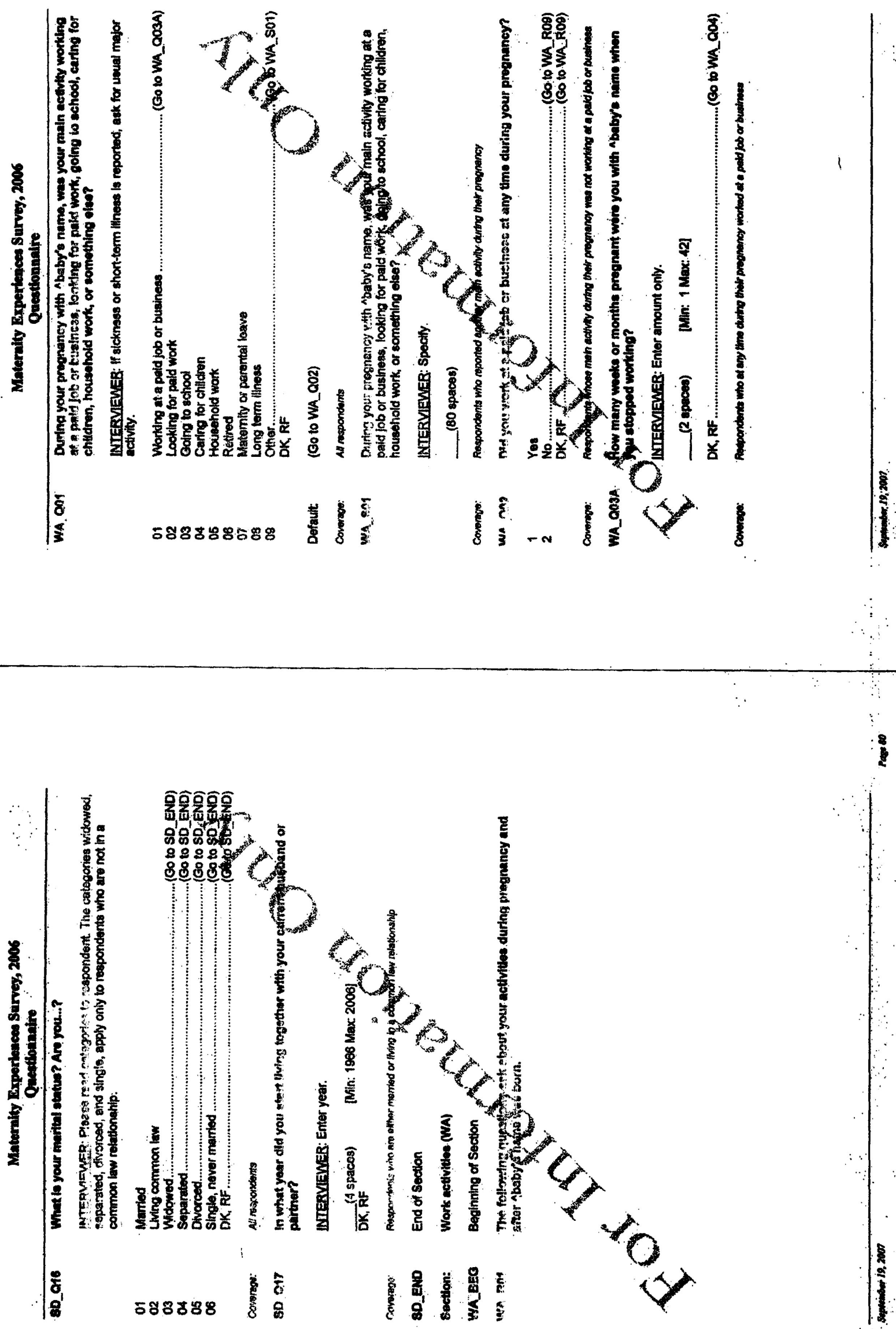

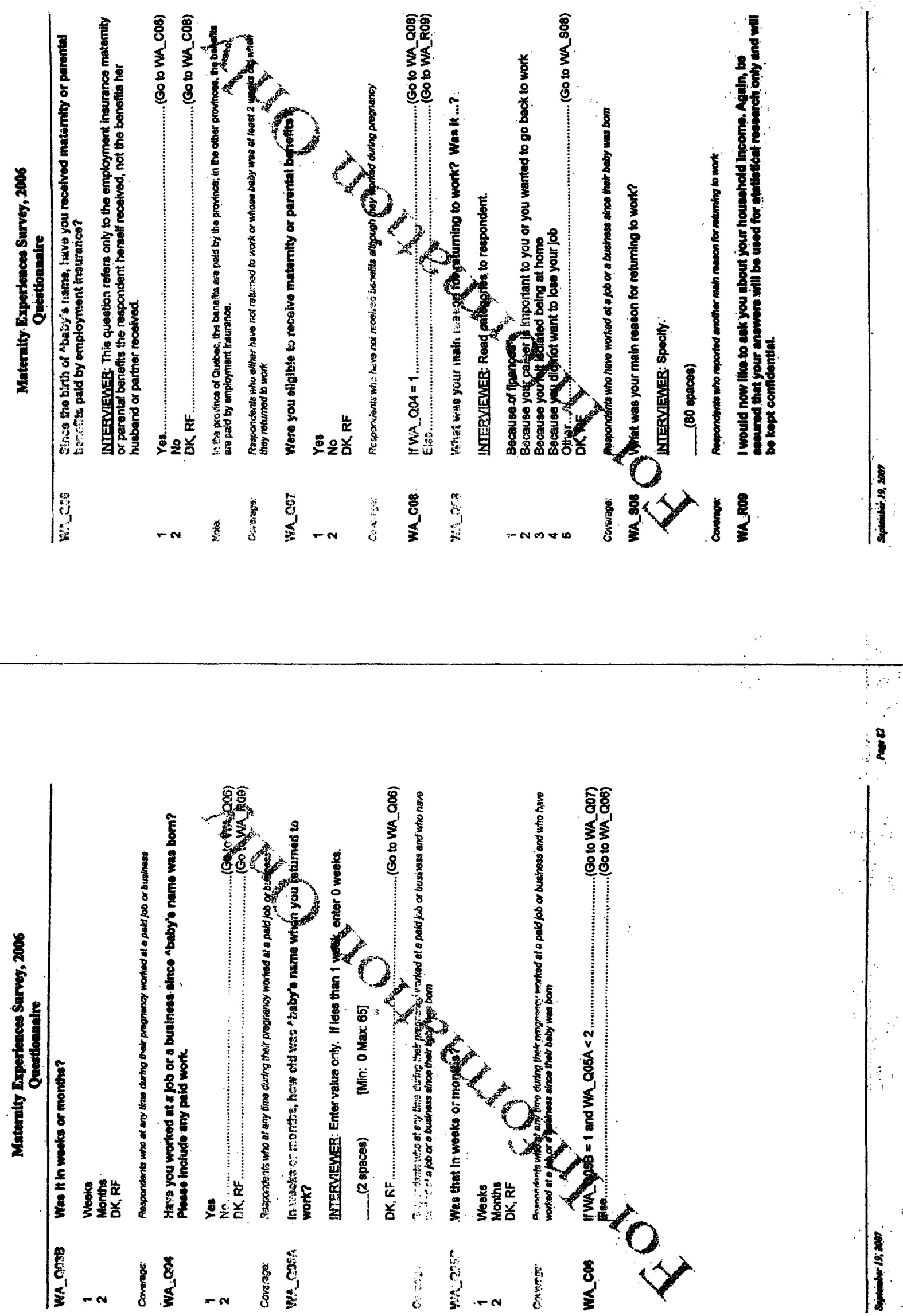

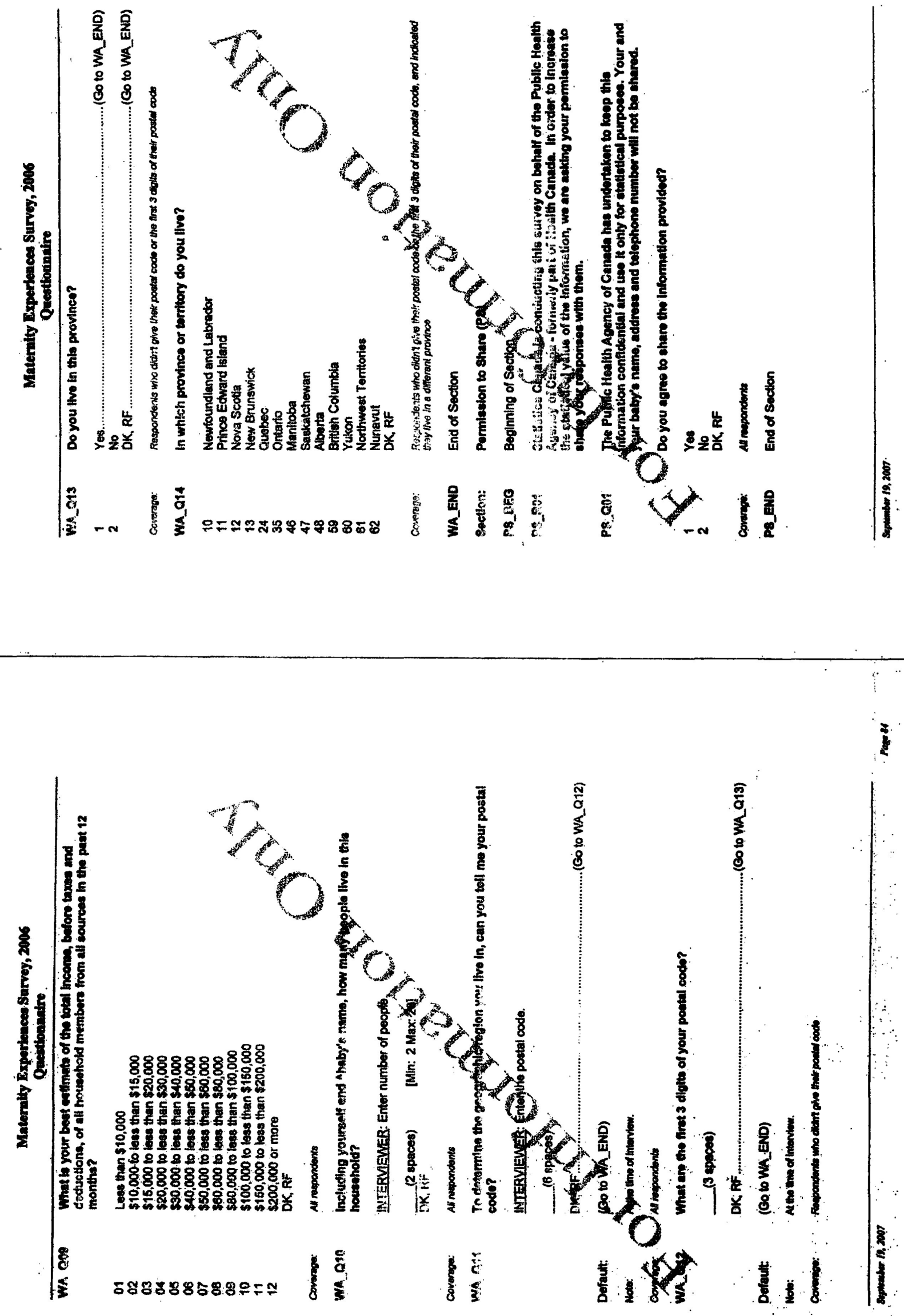
Appendix 2

Variable Recoding of Canadian Maternity Experience Survey 


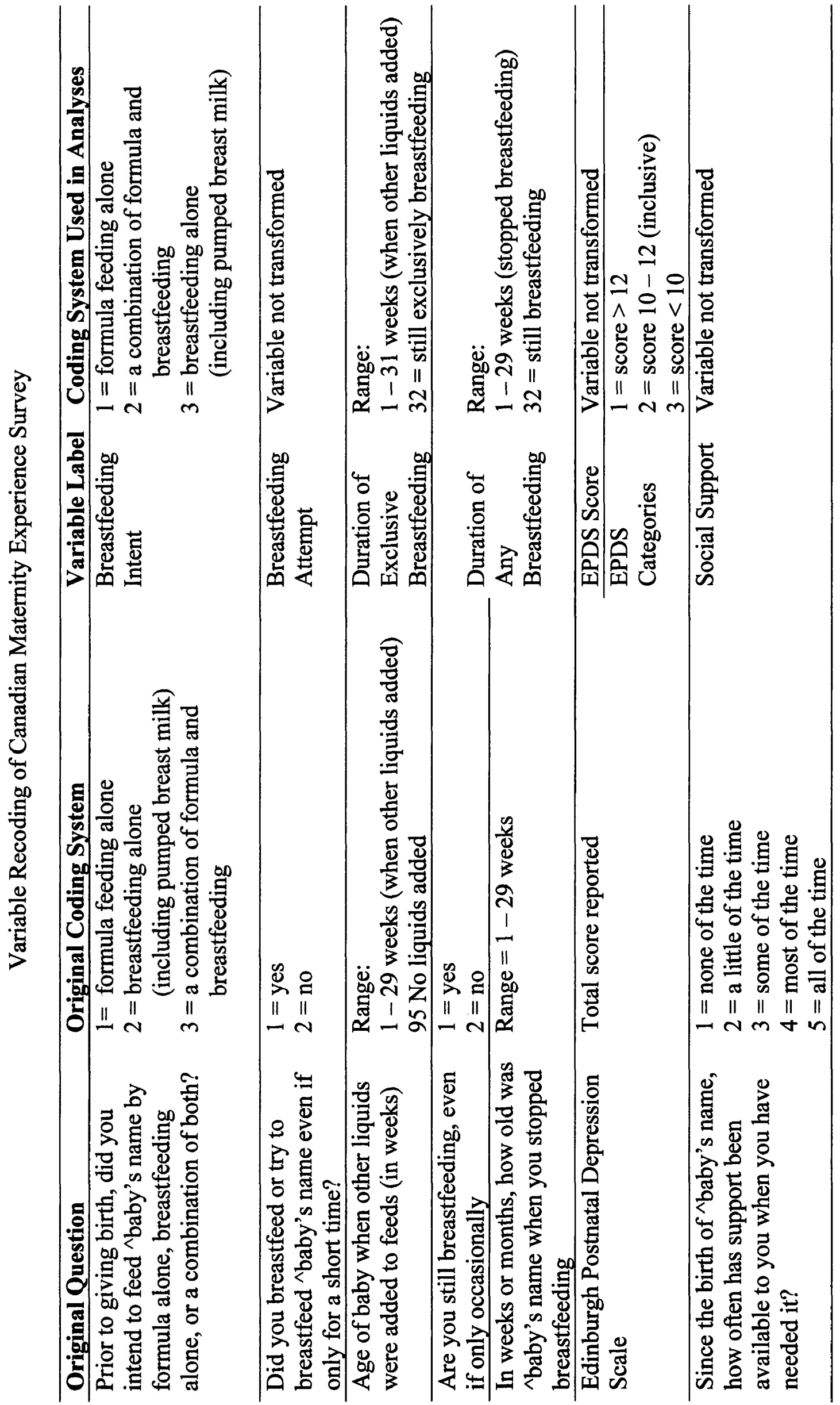




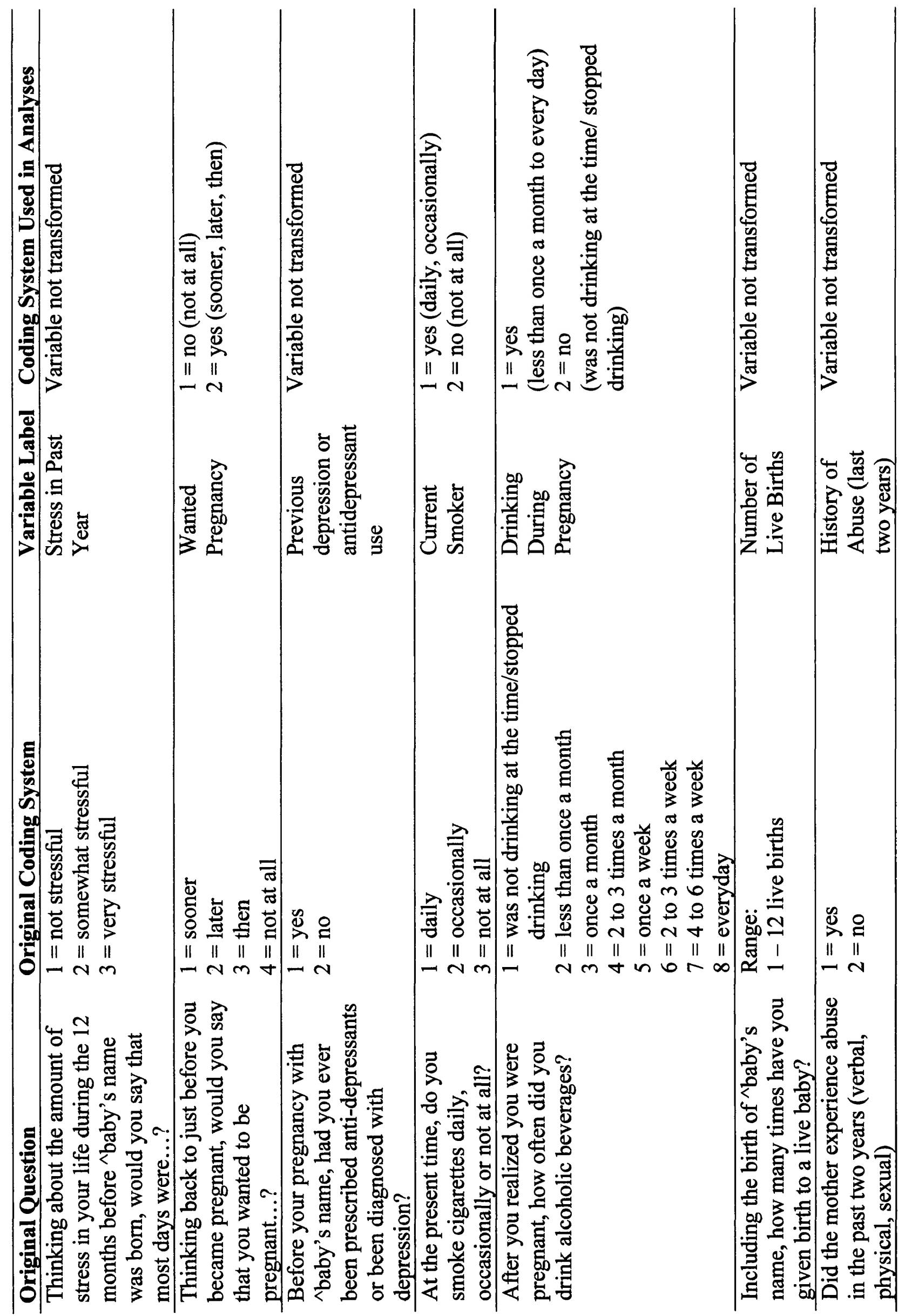




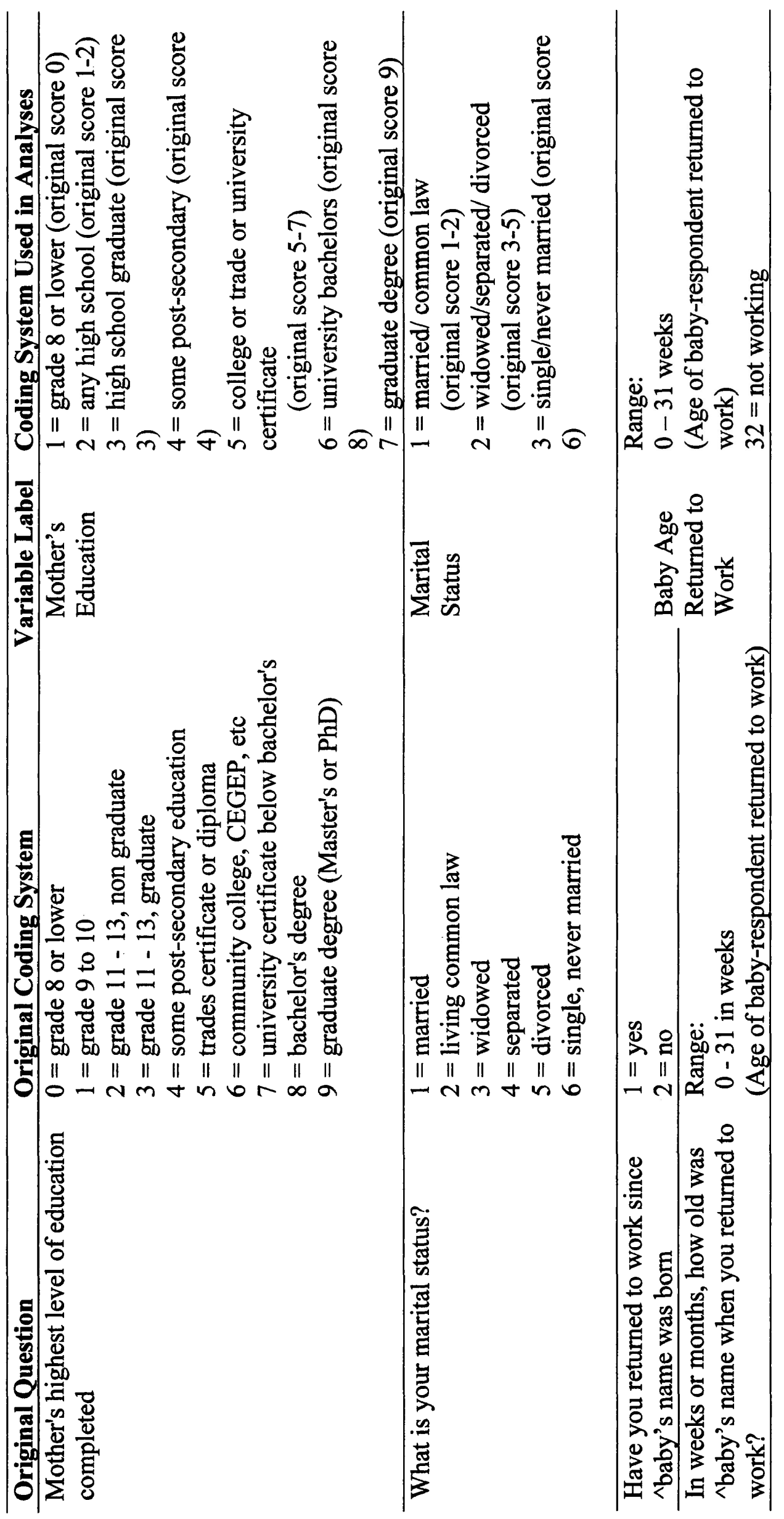




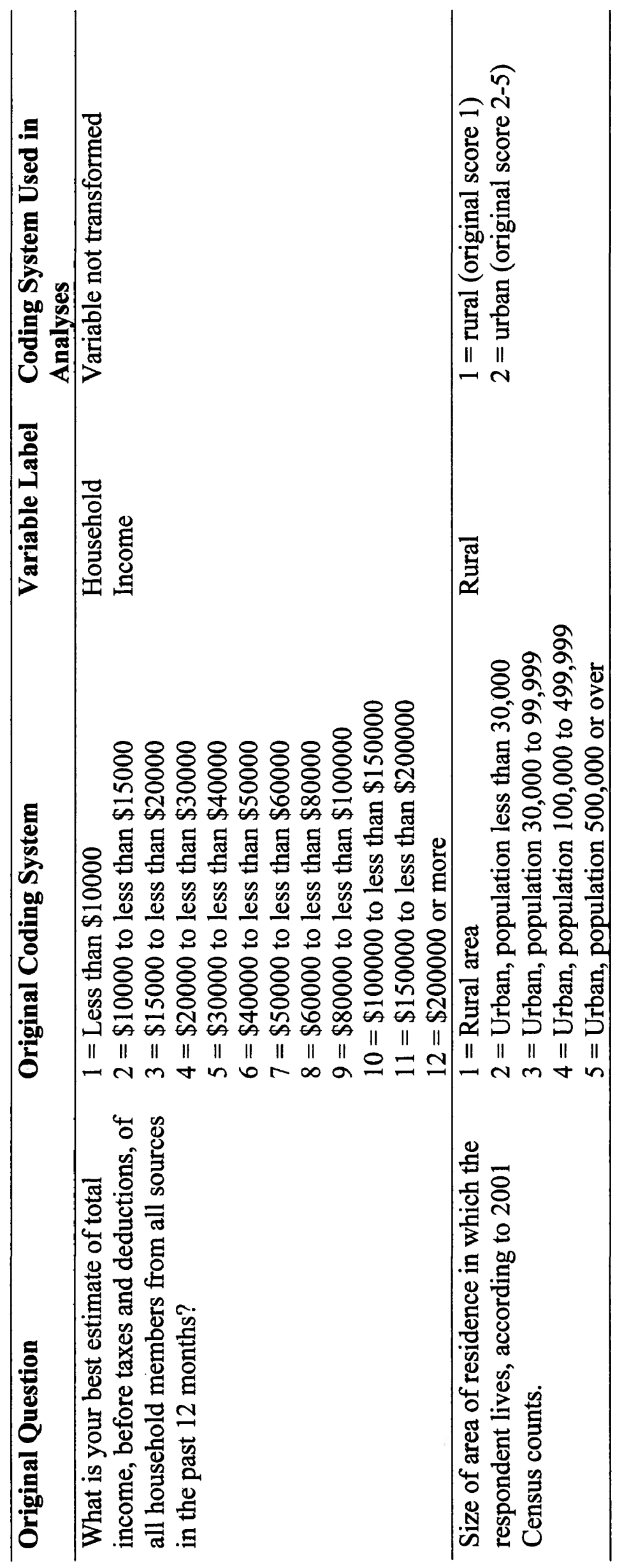

